\title{
Fundamental Studies of the Durability of Materials for Interconnects in Solid Oxide Fuel Cells
}

\author{
Final Report \\ Principal Investigators: \\ Frederick S. Pettit (pettit@engr.pitt.edu) \\ Gerald H. Meier (ghmeier@engr.pitt.edu) \\ Report Date: 30 September, 2006 \\ DOE Award: DE FC26 02NT41578 \\ Submitted by: \\ Department of Materials Science \& Engineering \\ 848 Benedum Hall \\ University of Pittsburgh \\ Pittsburgh, PA 15261 \\ Subcontract Information: \\ Jack L. Beuth \\ Department of Mechanical Engineering \\ Carnegie Mellon University \\ 5000 Forbes Avenue \\ Pittsburgh, PA 15213-3890 \\ Phone: (412) 268-3873; Fax: (412) 268-3348 \\ E-mail: (beuth@andrew.cmu.edu) \\ James R. Rakowski \\ ATI Allegheny Ludlum \\ Technical and Commercial Center \\ Alabama and Pacific Avenues \\ Brackenridge, PA 15014 \\ Phone: (724) 226-6283; Fax:(724) 226-5067; \\ Email: JRakowski@AlleghenyLudlum.com \\ Bruce Kang \\ West Virginia University \\ Mechanical \& Aerospace Engineering \\ P.O. Box 6106 \\ Morgantown, WV 26506-6106 \\ Phone: (304) 293-3111 x2316; Fax: (304) 293-6689 \\ Email: bruce.kang@mail.wvu.edu
}


DISCLAIMER This report was prepared as an account of work sponsored by an agency of the United States Government. Neither the United States Government nor any agency thereof, nor any of their employees, makes any warranty, express or implied, or assumes any legal liability or responsibility for the accuracy, completeness, or usefulness of any information, apparatus, product, or process disclosed, or represents that its use would not infringe privately owned rights. Reference herein to any specific commercial product, process, or service by trade name, trademark, manufacturer, or otherwise does not necessarily constitute or imply its endorsement, recommendation, or favoring by the United States Government or any agency thereof. The views and opinions of authors expressed herein do not necessarily state or reflect those of the United States Government or any agency thereof. 


\section{ABSTRACT}

Ferritic stainless steels are a leading candidate material for use as an SOFC interconnect, but have the problem of forming volatile chromia species that lead to cathode poisoning. This project has focused both on optimization of ferritic alloys for SOFC applications and evaluating the possibility of using alternative materials.

The initial efforts involved studying the oxidation behavior of a variety of chromia-forming ferritic stainless steels in the temperature range $700-900^{\circ} \mathrm{C}$ in atmospheres relevant to solid oxide fuel cell operation. The alloys exhibited a wide variety of oxidation behavior based on composition.

A method for reducing the vaporization is to add alloying elements that lead to the formation of a thermally grown oxide layer over the protective chromia. Several commercial steels form manganese chromate on the surface. This same approach, combined with observations of $\mathrm{TiO}_{2}$ overlayer formation on the chromia forming, Nibased superalloy IN 738, has resulted in the development of a series of Fe-22 Cr-X Ti alloys $(\mathrm{X}=0-4 \mathrm{wt} \%)$. Oxidation testing has indicated that this approach results in significant reduction in chromia evaporation. Unfortunately, the Ti also results in accelerated chromia scale growth.

Fundamental thermo-mechanical aspects of the durability of solid oxide fuel cell (SOFC) interconnect alloys have also been investigated. A key failure mechanism for interconnects is the spallation of the chromia scale that forms on the alloy, as it is exposed to fuel cell environments. Indentation testing methods to measure the critical energy release rate $(\mathrm{Gc})$ associated with the spallation of chromia scale/alloy systems have been evaluated. This approach has been used to evaluate the thermomechanical stability of chromia films as a function of oxidation exposure.

The oxidation of pure nickel in SOFC environments was evaluated using thermogravimetric analysis (TGA) to determine the $\mathrm{NiO}$ scaling kinetics and a four-point probe was used to measure the area-specific resistance (ASR) to estimate the electrical degradation of the interconnect. In addition to the baseline study of pure nickel, steps were taken to decrease the ASR through alloying and surface modifications. Finally, high conductivity composite systems, consisting of nickel and silver, were studied. These systems utilize high conductivity silver pathways through nickel while maintaining the mechanical stability that a nickel matrix provides. 


\section{TABLE OF CONTENTS}

Title Page

$\underline{\text { Page }}$

Disclaimer

Abstract

Table of Contents

2

List of Graphical Materials

4

Introduction

Executive Summary

Project Description

Experimental

12

Results and Discussion

20

References

Appendix A

Appendix B 


\section{LIST OF GRAPHICAL MATERIALS}

Figure 1. Schematic diagram showing the apparatus to cyclically oxidize coupon specimens in gases with defined and controlled amounts of water vapor in air at a total pressure of $1 \mathrm{~atm}$.

Figure 2. Schematic diagram of the TGA apparatus for continuous measurement of mass during exposure.

Figure 3. Schematic diagram of the dual atmosphere apparatus.

Figure 4. Schematic diagram of the ASR apparatus and cartoon showing a close up of the specimen and electrode/lead attachments.

Figure 5. Schematic diagram showing possible ways of using silver as a conducting path through nickel interconnects.

Figure 6. Schematic diagram of dual atmosphere apparatus for exposing tubular specimens.

Figure 7. Effect of titanium on the mechanical properties of a model Fe-22Cr alloy.

Figure 8. Effect of titanium on the linear coefficient of thermal expansion of a model Fe-22Cr alloy.

Figure 9. TGA data for Fe-Cr-Ti alloys, Crofer, and E-Brite at $900^{\circ} \mathrm{C}$ in dry and moist atmospheres.

Figure 10. Cyclic oxidation data for Fe-Cr-Ti alloys and Crofer, at $800^{\circ} \mathrm{C}$ in dry and moist atmospheres.

Figure 11. Cross - sectional and surface SEM micrographs of alloys exposed for 96 hrs at $900^{\circ} \mathrm{C}$ in dry air containing $0.004 \%$ (a\&b), $0.84 \%$ (c\&d), $1.65 \%$ (e\&f), $2.78 \%$ (g\&h), and 3.98\% (i\&j) titanium.

Figure 12. Long-term oxidation test results at $760^{\circ} \mathrm{C}$ in ambient air for $\mathrm{Fe}-22 \mathrm{Cr}$ alloys with added titanium (E-BRITE sample included for a reference).

Figure 13. Long-term oxidation test results at $760^{\circ} \mathrm{C}$ in air containing $7 \%$ water vapor for $\mathrm{Fe}-22 \mathrm{Cr}$ alloys with added titanium (E-BRITE sample included for a reference).

Figure 14. Comparison of weight gains after 3,000 hours at $760^{\circ} \mathrm{C}$ for $\mathrm{Fe}-22 \mathrm{Cr}$ alloys with added titanium - ratio of terminal weight gain in air containing $7 \%$ added water vapor to terminal weight gain in ambient air. 
Figure 15. Long-term oxidation test results for base $\mathrm{Fe}-22 \mathrm{Cr}$ alloy at $760^{\circ} \mathrm{C}$ in air with and without added water vapor.

Figure 16. Long-term oxidation test results for base Fe-22Cr-1.65Ti alloy at $760^{\circ} \mathrm{C}$ in air with and without added water vapor.

Figure 17. Long-term oxidation test results for base Fe-22Cr-4.0Ti alloy at $760^{\circ} \mathrm{C}$ in air with and without added water vapor.

Figure 18. Metallographic cross-sections of different alloys exposed for 500 hours at $816^{\circ} \mathrm{C}$ in ambient air (light optical micrographs).

Figure 19. Surface of La-Sr-ferrite coating after aluminizing.

Figure 20. Surface of ferritic steel substrate after aluminizing.

Figure 21. Surface of La-Sr-ferrite coating after deposition of $\mathrm{La}_{2} \mathrm{O}_{3}$ from a liquid precursor.

Figure 22. Percentage of Debonding vs. Radial Distance for a $26 \mathrm{Cr}$ Ferritic Alloy Exposed in Wet Air (Simulated Cathode Gas) at $900^{\circ} \mathrm{C}$ for $10-200 \mathrm{hrs}$

Figure 23. Effect of $\mathrm{CeO}_{2}$ deposited by pulsed laser deposition on the growth rate of $\mathrm{NiO}$ at $800^{\circ} \mathrm{C}$ in dry air.

Figure 24 ASR as a function of the square root of the oxidation time at $800^{\circ} \mathrm{C}$ for pure $\mathrm{Ni}$ and $\mathrm{CeO}_{2}$-doped $\mathrm{Ni}$.

Figure 25 Cross-sections of Ni 200 tubes exposed for 600 hours at $800^{\circ} \mathrm{C}$. The top specimen was exposed with dry air inside and outside the tube. The bottom specimen was exposed with $\mathrm{Ar}-10 \% \mathrm{H}_{2} \mathrm{O}-4 \% \mathrm{H}_{2}$ inside the tube and dry air on the outside. The micrograph was taken from the side exposed to air.

Figure 26. Silver Via, $800^{\circ} \mathrm{C} 100$ Hours, exposed under dual atmospheric conditions. The upper surface was exposed to dry air while the lower surface was exposed to simulated anode gas of $\mathrm{Ar}-10 \% \mathrm{H}_{2} \mathrm{O}-4 \% \mathrm{H}_{2}$.

Figure 27. Comparison of thickness reductions for various silver samples.

Figure 28. SEM micrograph comparison of sterling and pure silver samples after 3week high-temperature exposure. 
Figure 29. Time-series analysis of sterling silver surface during high-temperature exposure.

Figure 30. Fracture surfaces of sterling silver samples after high-temperature exposure.

Figure 31. Step densities for pure silver and sterling silver samples. 


\section{INTRODUCTION}

Solid oxide fuel cells provide a potential way to generate electricity with high efficiency and low pollution. The operating principles of fuel cells have been known for over 100 years and low-temperature fuel cells provided the electric power on all the Gemini and Apollo spacecraft. However, fuel cells have not achieved widespread commercial use for a number of economic and technical reasons.

One of the most important technical challenges for solid oxide fuel cells, which operate in the temperature range $700^{\circ}-900^{\circ} \mathrm{C}$, is the design of interconnects (current collectors). These components, in addition to electrically connecting individual cells in a stack, must separate the anode compartment of one cell from the cathode compartment of the adjacent cell. This means that one side of an interconnect is exposed to the fuel, typically hydrogen or hydrocarbons in which the oxygen partial pressure is low, and the other side is exposed to the oxidant, which is typically air with some amount of water vapor. Metallic alloys have many attractive features as potential interconnect materials. Oxidation resistant alloys are designed to form one of three protective oxides: alumina, silica, or chromia. Of these, the electrical resistivities of alumina and silica are much too high for interconnect applications. For metallic interconnects, interconnect system resistance can be greatly increased by oxide layer thickening and spallation. For chromia formers, evaporation of the chromia scale can severely degrade cathode performance. Thus chromia scale growth, scale spallation and scale evaporation are the three principal "failure mechanisms" for interconnects forming chromia scales on their surfaces. Because they are coupled, alloy changes to address one failure mechanism can affect one or more of the other failure mechanisms, making alloy design a complex task. 


\section{EXECUTIVE SUMMARY}

This project had four objectives:

- To develop mechanism-based evaluation procedures for the stability of SOFC interconnect materials and to use these procedures to study and modify a group of alloys, which have already been identified as candidate interconnect materials, i.e. ferritic stainless steels.

- To study fundamental aspects underlying the thermomechanical behavior of interconnect materials and develop accelerated testing protocols. (CMU Subcontract)

- To investigate the potential for the use of "new" metals as interconnect materials.

- Development of a durable, conductive ceramic/metal (cermet) material, suitable for long-term use as a contacting material in the cathode chamber of SOFC. (WVU Subcontract)

The program consisted of four major tasks aligned with its four objectives.

\section{Task 1: Mechanism-based Evaluation Procedures}

A variety of chromia-forming interconnect alloys were subjected to thermal cycling in air, in simulated anode gas $\left(\mathrm{Ar}-\mathrm{H}_{2}-\mathrm{H}_{2} \mathrm{O}\right)$ and with simultaneous exposure to air on one side and simulated anode gas on the other. Exposure temperatures range from $700^{\circ} \mathrm{C}$ to $900^{\circ} \mathrm{C}$. Oxidation kinetics were tracked by mass change measurements and corresponding changes in oxide scale resistances were measured. Exposed specimens were examined in cross-section by scanning electron microscopy (SEM) to document changes in structure with exposure.

Methods were studied to slow the growth of chromia scales on $\mathrm{Cr}$ and Ferritic alloys upon exposure to oxidizing gases. The effect of alloying additions (e.g. Mn, Ti) to ferritic steels to reduce harmful $\mathrm{CrO}_{3}$ and $\mathrm{CrO}_{2}(\mathrm{OH})_{2}$ evaporation by forming a sealing outer layer over the chromia scale was evaluated. The ability of chromite coatings to reduce evaporation from chromia-forming interconnect alloys was investigated.

\section{Task 2: Fundamental Aspects of Thermomechanical Behavior (CMU)}

Understanding the resistance of growing chromia scales to spallation requires a fundamental understanding of the mechanics of chromia adhesion. From a fracture mechanics standpoint, the adherence of protective oxide scales to alloy substrates is governed by 1) the stored elastic energy in the scale, which drives delamination and 2) the fracture toughness of the alloy/oxide interface, which quantifies the resistance to fracture.

The stored elastic energy in the scale is increased by increases in the scale thickness and increases in the residual stress in the scale. In this task, X-ray diffraction (XRD) was used to measure stresses in chromia films formed on pure chromium and chromia-forming alloys after the exposures described for Task 1.

An indentation test was also used to measure the fracture toughness of chromia/alloy interfaces for the same exposures. In the test, the chromia scale is penetrated by the indenter and the plastic deformation of the underlying substrate induces compressive radial strains in the substrate. These strains are transferred to the coating and the associated coating stress drives the extension of a roughly axisymmetric interface 
crack. The interfacial toughness can be determined from the results of a mechanics analysis of the indentation problem and a measurement of the delamination radius.

\section{Task 3: Alternative Material Choices}

Metallic materials other than chromia-formers are being considered for use as low temperature SOFC interconnects. Experiments similar to those described for Task 1 were performed on pure $\mathrm{Ni}$. Its only oxide, $\mathrm{NiO}$, has no vapor species with high partial pressures and it has a higher electrical conductivity than chromia. Also, NiO should not even form in the anode gas. The doping of the $\mathrm{NiO}$ scale with $\mathrm{SrO}$ or $\mathrm{CeO}_{2}$ was investigated as a way to slow the growth rate. Finally, the use of Ag conducting paths through Ni interconnects was studied.

\section{Task 4: Development of Durable Contacting Material (WVU)}

At present, candidate cermets have been developed by ball-milling of various oxide powders with silver or silver-oxide powders, followed by dry-pressing and sintering in a high-temperature furnace. The cermets were evaluated by SEM to determine the compatibility of silver with the candidate oxide materials, as well as the dispersion of silver throughout the cermet. The cermets were also tested for hardness/ductility using Vickers hardness testing. Conductivity was evaluated using a simple multimeter test to evaluate the resistance of the cermet. A thermomechanical analyzer was also used to evaluate the CTE of the materials to verify compatibility with other SOFC components. Lastly, cermets were placed in a high-temperature furnace to be exposed to the SOFC operating temperature $\left(\sim 800^{\circ} \mathrm{C}\right)$, while a high-volume air flow was introduced to simulate the cathode environment of the SOFC.

All measurements, conductivity, hardness, and mass were taken before and after exposure to the simulated cathode environment in order to make a determination of the effects on the cermet material.

Major accomplishments of this project include:

- Determined that even very small concentrations of Al or Si in ferritic alloys result in the formation of internal films with high electrical resistivity.

- Discovered that exposure under some fuel cell operating conditions (e.g. water vapor) accelerates sigma phase formation in some ferritic stainless steels. Alloy purity is also important for retarding sigma-phase formation.

- Discovered that it is possible to modify a ferritic steels to form an overlayer of $\mathrm{TiO}_{2}$ which suppresses the evaporation from the underlying chromia scale.

- Determined that the growth rate of chromia on ferritic alloys can be greatly suppressed by surface doping with $\mathrm{CeO}_{2}$.

- Adapted an indentation technique for measuring interfacial fracture toughnesses of oxides formed on interconnects and coatings applied to interconnects.

- Found that the growth rate of $\mathrm{NiO}$ can be slowed significantly by surface doping with $\mathrm{SrO}$ or $\mathrm{CeO}_{2}$.

- Found that, unlike ferrous alloys, the oxidation of $\mathrm{Ni}$ is not altered significantly under dual atmosphere conditions.

- Showed that Ni interconnects containing Ag conduction paths are feasible.

- Completed three M.S. theses and six Senior Projects. 


\section{PROJECT DESCRIPTION}

\section{Objectives}

- To develop mechanism-based evaluation procedures for the stability of SOFC interconnect materials and to use these procedures to study and modify a group of alloys, which have already been identified as candidate interconnect materials, i.e. ferritic stainless steels.

- To study fundamental aspects underlying the thermomechanical behavior of interconnect materials and develop accelerated testing protocols. (CMU Subcontract)

- To investigate the potential for the use of "new" metals as interconnect materials.

- To develop a durable, conductive ceramic/metal (cermet) material, suitable for long-term use as a contacting material in the cathode chamber of SOFC. (WVU Subcontract)

\section{Approach}

The program consists of four major tasks aligned with its four objectives.

\section{Task 1: Mechanism-based Evaluation Procedures}

A variety of commercial chromia-forming interconnect alloys have been subjected to thermal cycling in air, in simulated anode gas $\left(\mathrm{Ar}-\mathrm{H}_{2}-\mathrm{H}_{2} \mathrm{O}\right)$ and with simultaneous exposure to air on one side and simulated anode gas on the other. Combined exposures have been shown at PNNL to often yield different behavior than exposures with the same gas on both sides of the specimen. Exposure temperatures range from $700^{\circ} \mathrm{C}$ to $900^{\circ} \mathrm{C}$. Oxidation kinetics have been tracked by mass change measurements and corresponding changes in oxide scale resistances have been measured. Exposed specimens have been examined in cross-section by scanning electron microscopy (SEM) to document changes in structure with exposure.

Methods have been studied to slow the growth of chromia scales on $\mathrm{Cr}$ and ferritic alloys with exposure, to decrease the contribution of the scale to interconnect resistance. The effect of alloying additions (e.g. Mn, Ti) to ferritic steels to reduce harmful $\mathrm{CrO}_{3}$ and $\mathrm{CrO}_{2}(\mathrm{OH})_{2}$ evaporation by forming a sealing outer layer over the chromia scale has been evaluated. The ability of chromite coatings to reduce evaporation from chromia-forming interconnect alloys has also been investigated.

\section{Task 2: Fundamental Aspects of Thermomechanical Behavior (CMU)}

Understanding the resistance of growing chromia scales to spallation requires a fundamental understanding of the mechanics of chromia adhesion. From a fracture mechanics standpoint, the adherence of protective oxide scales to alloy substrates is governed by 1) the stored elastic energy in the scale, which drives delamination and 2) the fracture toughness of the alloy/oxide interface, which quantifies the resistance to fracture.

The stored elastic energy in the scale is increased by increases in the scale thickness (which can be measured by cross-section SEM) and increases in the residual 
stress in the scale. In this task, x-ray diffraction (XRD) has been used to measure stresses in chromia films formed on pure chromium and chromia-forming alloys after the exposures described for Task 1.

An indentation test has also been used to quantify the fracture toughness of chromia/alloy interfaces for the same exposures. In the test, the chromia scale is penetrated by the indenter and the plastic deformation of the underlying substrate induces compressive radial strains in the substrate. These strains are transferred to the scale and the associated scale stress drives scale spallation. Scales can spall as intact coatings, with an interface crack propagating radially outward, or spallation can occur as the debonding of small flakes, with the density of flaking decreasing with distance from the indent. The interfacial toughness can be estimated from the results of a mechanics analysis of the indentation problem and a measurement of the extent of the delamination failures.

\section{Task 3: Alternative Material Choices}

Metallic materials other than chromia-formers are being considered for use as low temperature SOFC interconnects. Experiments similar to those described for Task 1 have been performed on pure $\mathrm{Ni}$. Its only oxide, $\mathrm{NiO}$, has no vapor species with high partial pressures and it has a higher electrical conductivity than chromia. Also, NiO should not even form in the anode gas. Also, the doping of the $\mathrm{NiO}$ scale with $\mathrm{SrO}$ or $\mathrm{CeO}_{2}$ has been investigated as a way to slow the growth rate. Finally, the use of Ag conducting paths through Ni interconnects has been studied.

\section{Task 4: Development of Durable Contacting Material (WVU)}

At present, candidate cermets have been developed by ball-milling of various oxide powders with silver or silver-oxide powders, followed by dry-pressing and sintering in a high-temperature furnace. The cermets have been evaluated by SEM to determine the compatibility of silver with the candidate oxide materials, as well as the dispersion of silver throughout the cermet. The cermets have also been tested for hardness/ductility using Vickers hardness testing. Conductivity has been evaluated using a simple multimeter test to evaluate the resistance of the cermet. A thermomechanical analyzer has also been used to evaluate the CTE of the materials to verify compatibility with other SOFC components. Lastly, cermets have been placed in a high-temperature furnace to be exposed to the SOFC operating temperature $\left(\sim 800^{\circ} \mathrm{C}\right)$, while a high-volume air flow is introduced to simulate the cathode environment of the SOFC.

All measurements, conductivity, hardness, and mass were taken before and after exposure to the simulated cathode environment in order to make a determination of the effects on the cermet material.

\section{EXPERIMENTAL}

\section{Task 1}

Cyclic Oxidation

The cyclic oxidation of a range of commercial ferritic stainless steels has been evaluated under a range of conditions pertinent to fuel cell operation. The alloys were: (Nominal compositions in $\mathrm{wt} \%$ ) 
- E-BRITE (Fe-26 Cr-1 Mo - $0.2 \mathrm{Si}$ )

- $26 \mathrm{Cr}$ Ferritic (Fe-26Cr-1-Mo-2Mn-4.5Ni-1Si-1 Al)

- AL 453 (Fe-22 Cr-0.6 Al-0.3 Mn + 0.1Ce/La)

- Crofer22 APU (Fe-22Cr-0.5Mn-0.08 Ti-0.016P-0.06 La)

The exposure conditions for the ferritic alloys included:

- $\mathrm{T}=900^{\circ} \mathrm{C}$ and $700^{\circ} \mathrm{C}$ (Limited experiments were performed at $800^{\circ} \mathrm{C}$ )

- One-Hour Cycles (45 min. hot, 15 min.cold)

- Atmospheres

- $\quad$ Dry Air (Simulated Cathode Gas)

- $\quad$ Air +0.1 atm $\mathrm{H}_{2} \mathrm{O}$ (Simulated Moist Cathode Gas)

- $\quad \mathrm{Ar} / \mathrm{H}_{2} / \mathrm{H}_{2} \mathrm{O}$ (Simulated Anode Gas)

$\left(p_{\mathrm{O}_{2}}=10^{-17} \mathrm{~atm}\right.$ at $900^{\circ} \mathrm{C}$ and $10^{-20}$ at $700^{\circ} \mathrm{C}$ )

The exposure apparatus used for these exposures is shown schematically in Figure 1.

An additional group of model alloys was prepared in an attempt to grow a $\mathrm{TiO}_{2}$ outer layer to suppress $\mathrm{Cr}$ volatility. Four heats of novel $\mathrm{Fe}-\mathrm{Cr}$-Ti alloys and one Ti-free control heat were produced in a vacuum induction melting furnace in the form of fiftypound ingots at ATI Allegheny Ludlum. The chemical composition of each ingot was determined at ATI Allegheny Ludlum's Analytical Services laboratory (results reported in weight percent). Extensive manufacturing trials were carried out to evaluate the processing characteristics of the high-Ti stainless steels. The ingots were successfully hot-rolled to $10 \mathrm{~mm}$, surface conditioned, and then cold rolled to 1 and $2 \mathrm{~mm}$ thickness for oxidation testing and mechanical/physical property determination.

Heat Identification Code

\begin{tabular}{cccccc}
\hline Element & RV 2103 & RV 2104 & RV 2095 & RV 2096 & RV 2097 \\
\hline $\mathrm{Cr}$ & 21.8 & 21.8 & 22.1 & 22.2 & 22.2 \\
$\mathrm{Ti}$ & 0.004 & 0.84 & 1.65 & 2.72 & 3.98 \\
$\mathrm{Mn}$ & 0.033 & 0.030 & 0.031 & 0.024 & 0.023 \\
$\mathrm{C}$ & 0.010 & 0.013 & 0.010 & 0.016 & 0.017 \\
$\mathrm{~N}$ & 0.018 & 0.018 & 0.011 & 0.008 & 0.008 \\
$\mathrm{Ce}$ & 0.004 & 0.027 & 0.031 & 0.027 & 0.027 \\
$\mathrm{La}$ & 0.001 & 0.009 & 0.012 & 0.012 & 0.010 \\
$\mathrm{Al}$ & 0.005 & 0.005 & 0.008 & 0.030 & 0.049 \\
$\mathrm{Si}$ & 0.043 & 0.042 & 0.036 & 0.020 & 0.020 \\
\hline
\end{tabular}




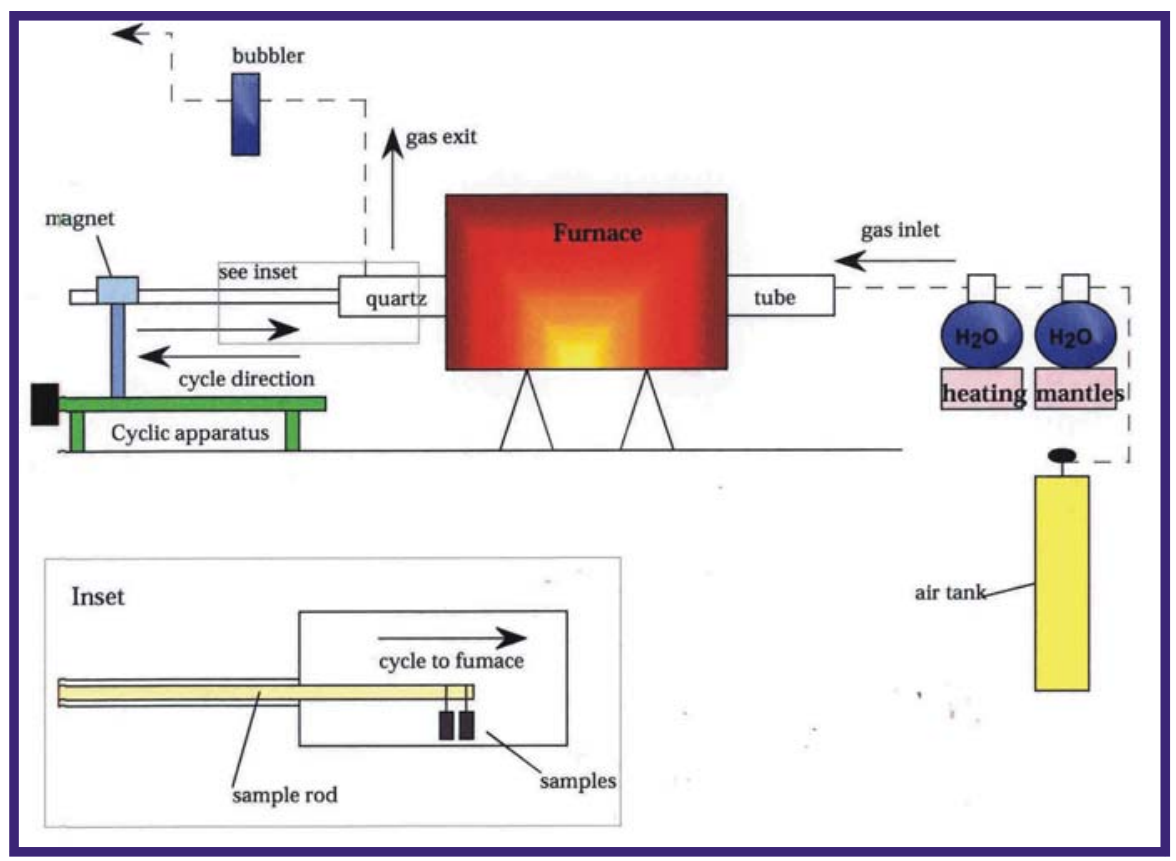

Figure 1. Schematic diagram showing the apparatus to cyclically oxidize coupon specimens in gases with defined and controlled amounts of water vapor in air at a total pressure of $1 \mathrm{~atm}$.

The series of Fe-Cr-Ti alloys were subjected to cyclic tests as described above at $800^{\circ} \mathrm{C}$ in the dry air and moist cathode gas environments. Long term exposures were also performed in these atmospheres at $760^{\circ} \mathrm{C}$. As these are new alloys, thermogravimetric (TGA) measurements were also made. In this test, the sample is held at constant temperature (no cycling) and the mass of the sample is continuously measured via a microbalance (Figure 2). The results are used to determine the parabolic rate constant which is related to the oxide thickness. The different atmospheres were used to exploit the fact that vaporization occurs faster in moist environments. Comparing the results from moist and dry tests will give an idea of the effectiveness of the oxide in preventing vaporization. The test parameters are as follows:

- Alloys - Fe-22Cr-xTi ( $\mathrm{x}=0-4)$, E-Brite, Crofer

- $\mathrm{T}=800^{\circ} \mathrm{C}, 900^{\circ} \mathrm{C}$

- $\quad$ Time $=1$ week $(168 \mathrm{hrs})$

- Atmosphere

o Dry Air

o Air +0.1 atm $\mathrm{H}_{2} \mathrm{O}$ 


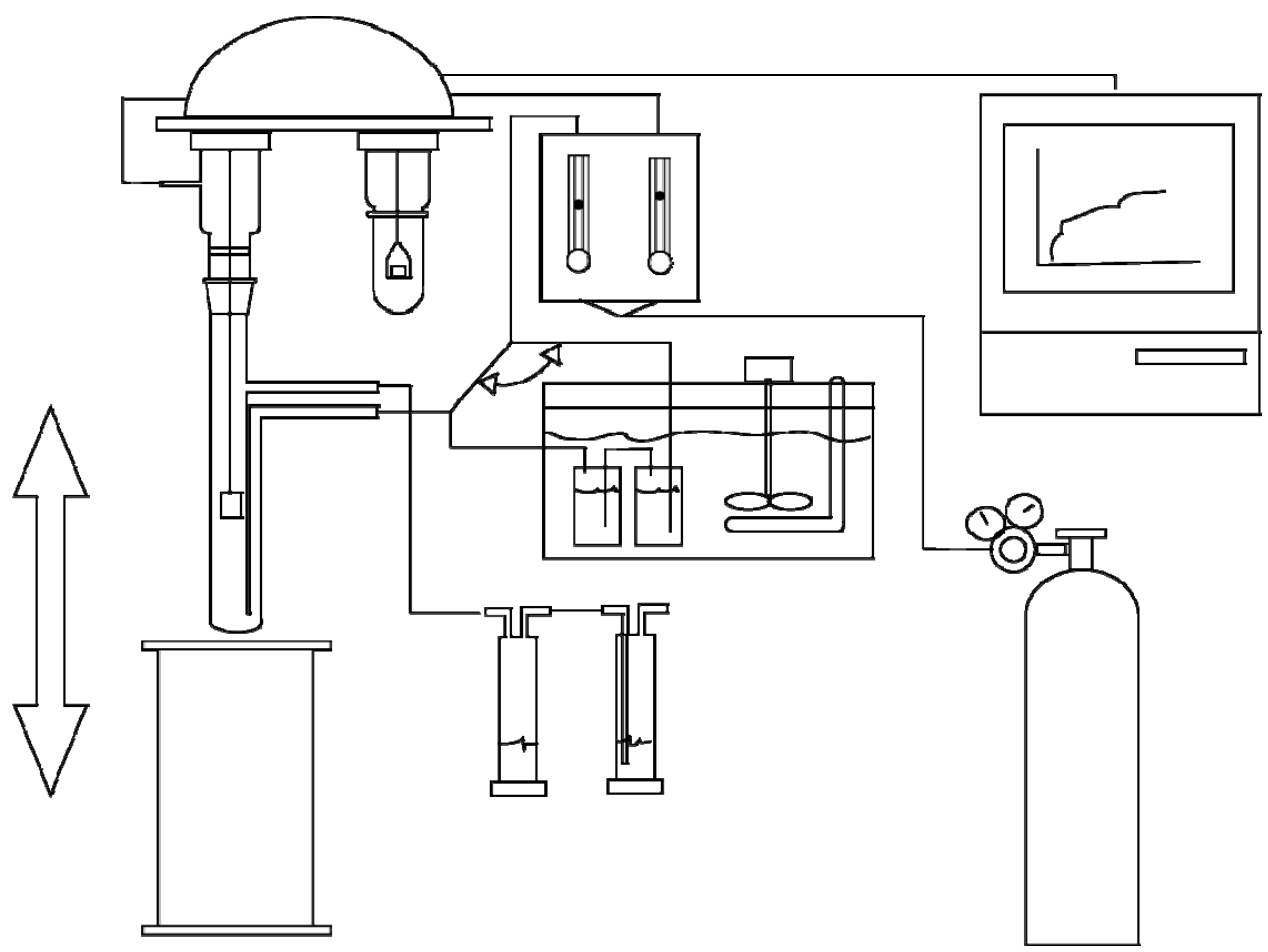

Figure 2. Schematic diagram of the TGA apparatus for continuous measurement of mass during exposure.

\section{Dual Atmosphere Exposures}

A dual atmosphere testing apparatus was also constructed (Figure 3). The system consists of three parts. The first is the specimen holder, which is a superalloy cup with a hole in the bottom, through which the fuel gas is introduced. A mica washer (compressive seal) and the specimen are placed in the cup, covering the hole. The second piece is a stainless steel tube that fits into the top of the cup. It is used to introduce the oxidant gas to the system and is in contact with the specimen to supply further compression as necessary to seal the system. These two pieces are placed in a quartz tube sealed with silicone stoppers, which is in turn in a vertical furnace. Outside the system, opposing jacks at the ends of the cup and tube can be used to apply even further compression.

\section{Specimen Characterization}

Following exposure the oxidation products and alloy microstructure were characterized using x-ray diffraction (XRD), scanning electron microscopy (SEM) and energy dispersive $\mathrm{X}$-ray analysis (EDS). 


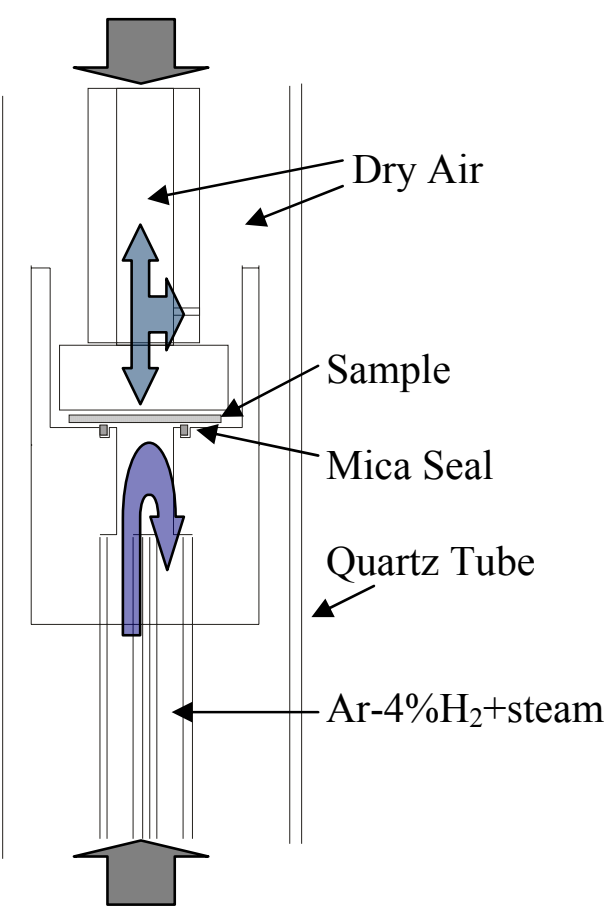

Figure 3. Schematic diagram of the dual atmosphere apparatus.

\section{Coated Specimens}

Specimens coated with a sputtered $\mathrm{LaCrO}_{3}$ (some were also $\mathrm{Sr}$ doped) layer have been studied as these coatings may suppress oxide evaporation. The substrates are as follows:

- E-Brite (same as above)

- AL 453 (same as above)

- $29-4 \mathrm{C}(29 \mathrm{Cr}, 4 \mathrm{Mo}, 0.5 \mathrm{Mn}, 0.3 \mathrm{Ni}, 0.35 \mathrm{Si})$

- Type 446 stainless steel (similar to E-Brite)

- Inconel 600 (Ni based, 14-17 Cr, 6-1 Fe, $\max 1 \mathrm{Mn}$ )

X-ray diffraction showed that the coatings were amorphous in the as coated condition. E-Brite and T-446 specimens were exposed in a dry air (simulated cathode gas) atmosphere at $900^{\circ} \mathrm{C}$ for 100 hours to crystallize the coating and to form a chromia layer. It was observed during SEM analysis that the coatings had become porous during the exposure. The porosity was considered to be detrimental to the effectiveness of the coating to prevent vaporization. As a result, the subsequent experiments on the coated specimens involve annealing to crystallize the coatings. However, the volume change during crystallization resulted in cracking of the coatings. A limited number of experiments were performed to attempt to seal the cracks. The techniques used were:

- Aluminizing in a commercial CVD reactor.

- Application of a liquid precursor to form La-oxides. 


\section{Area Specific Resistance Measurements}

The electrical conductivity of the oxidized specimens was measured using a 4 point probe technique. Figure 4 is a schematic diagram of the apparatus that was constructed. Electrical contact was made with the coupons, following oxidation using platinum paste (SPI Lot No.1090120). The paste was painted in 6x6 mm squares on both sides of the specimen. Following application of the platinum paste, the specimens were exposed at $600^{\circ} \mathrm{C}$ for one hour in dry air to drive off the binder in the paste, and to sinter the platinum particles. Platinum paste was then reapplied to the specimen, which was followed by another annealing step at $600^{\circ} \mathrm{C}$ for one hour. The surfaces of the specimens were then examined using an optical microscope or a scanning electron microscope to insure that the paste covered the desired area. The specimen is then placed between two Pt foils that previously had lead wires spot welded in place. This sandwich is placed in the slot in the specimen holder and the screws are tightened to ensure physical contact is maintained throughout the test. The specimen holder is placed on another holder that is attached to the reaction tube end cap. This entire set up is then put into the furnace and heated. The lead wires are attached to the current source/voltmeter. Current was applied using a Jandel Model RM2 current source, at a fixed amperage between 1000-10,000 $\mu$ A. The voltage drop across the specimen was also measured by the Keithley 2001 multimeter. A resistance is calculated via Ohm's law, V=I*R. The ASR is then calculated by multiplying the resistance by the known area of the Pt paint.
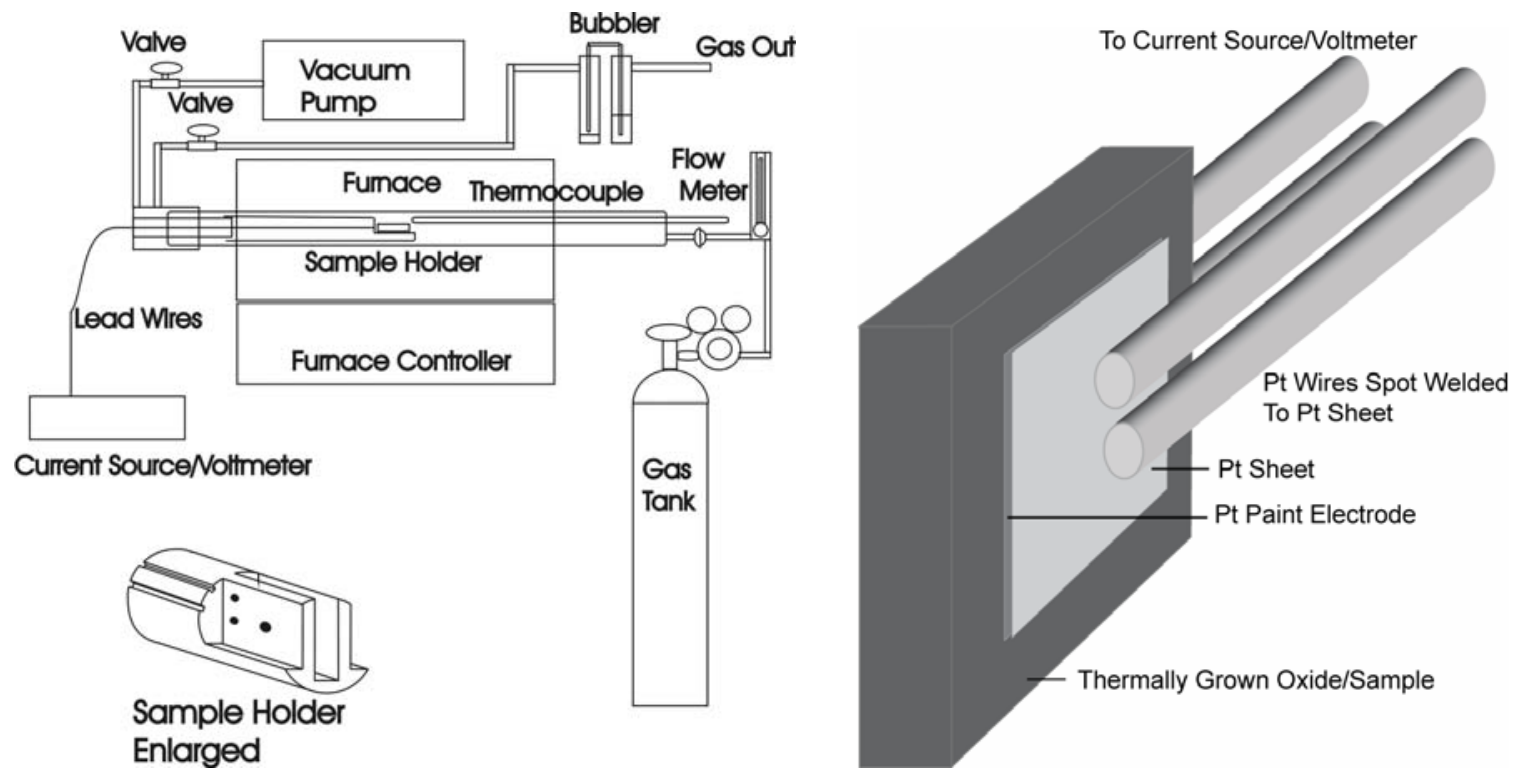

Figure 4. Schematic diagram of the ASR apparatus and cartoon showing a close up of the specimen and electrode/lead attachments. 


\section{Task 2}

Indentation Testing

The use of indentation as a means for inducing chromia scale spallation from interconnect alloys builds upon previous research by the PIs involving indentation of thermal barrier coating (TBC) systems $[1,2]$. Testing goals in TBC and interconnect alloy systems are similar, where an understanding of mechanisms leading to coating spallation is needed, as are methods for accelerating cyclic thermal testing to evaluate new coating/substrate systems.

The test for SOFC interconnects currently involves indenting the specimen using a Rockwell hardness tester and a conically-shaped brale indenter. The chromia scale is penetrated by the indenter and the interconnect alloy substrate is plastically deformed. This plastic deformation induces compressive radial strains in the substrate, which are transferred to the chromia scale (there is a match of in-plane strains across the interface). This causes an axisymmetric region of spallation, either in the form of intermittent flaking of the scale or as an intact peeling of the scale from the substrate. The radial extent of the debonding or its density as a function of radial distance can be related (through fracture modeling) to the fracture toughness or distribution of fracture toughness of the chromia/alloy interface. Micrographs of debonds resulting from indentation are given in the section on Indentation Testing of Interface Adhesion.

This type of test can be applied to other brittle coating systems deposited or grown on comparatively ductile substrates. As part of this program, chromite-coated interconnect alloys are being tested, where indentation can induce spallation of the chromite coating and a chromia layer growing beneath it. Similarly, this type of test may be applicable to the testing of other SOFC interfaces, such as those between sealant glasses and interconnect materials and those between electrolyte and anode layers in anode-supported cell structures.

Indentation testing has been performed for the following alloy systems and exposure conditions, which parallel cyclic oxidation experiments described above:

- $\quad$ E-BRITE in Air $+0.1 \mathrm{~atm} \mathrm{H}_{2} \mathrm{O}: 100 \mathrm{Hrs}$. and $200 \mathrm{Hrs}$ @ $900^{\circ} \mathrm{C}$

- $\quad$ E-BRITE in $\mathrm{Ar} / \mathrm{H}_{2} / \mathrm{H}_{2} \mathrm{O}$ (SAG): $264 \mathrm{Hrs}, 364 \mathrm{Hrs}$. and 464 Hrs. @ $900^{\circ} \mathrm{C}$

- $\quad \mathrm{La}_{0.8} \mathrm{Sr}_{0.2} \mathrm{CrO}_{3}$ on E-BRITE, AL 453 and AL 29-4C (from PNNL): As Processed

- $\quad \mathrm{LaCrO}_{3}$ on Inconel and SS 446 (from Drexel/NETL): As Processed

- $\mathrm{La}_{0.8} \mathrm{Sr}_{0.2} \mathrm{CrO}_{3}$ on E-BRITE and $\mathrm{LaCrO}_{3}$ on SS 446: $100 \mathrm{Hrs}$. $900^{\circ} \mathrm{C}$

- Indentation tests on interconnect specimens exposed at $700^{\circ} \mathrm{C}$ is currently underway.

A full description of these tests and their relation to cyclic oxidation testing is provided in the sections on Indentation Testing of Interface Adhesion and Accelerated Testing

\section{Task 3}

Experiments are being carried out on pure $\mathrm{Ni}$ as a possible alternative interconnect material since the oxygen partial pressure in the anode gas is too low to 
oxidize Ni. Efforts to decrease the electrical resistance of the interconnect oxide are twofold. First, surface dopants are being used to reduce the scale thickness. Pulsed laser deposition (PLD) is used to deposit thin films of $\mathrm{SrO}$ and $\mathrm{CeO}_{2}$ onto the surface of nickel. Second, the resistance introduced by the thermally grown oxide is being by-passed by the use of high conductivity pathways. Silver is not considered as a possible interconnect material due to the high permeability of hydrogen and oxygen in silver, which causes water nucleation and mechanical instability. However, silver may be able to provide a high conductivity pathway through another material. Systems in which silver wires are passed through nickel and silver powder is melted into holes drilled in nickel have been examined. Figure 5 presents a schematic diagram of these composite specimens.

\section{Exposure Conditions}

The exposure conditions for the Ni-base materials are the same as those described for Task 1. In addition, since some Ni alloys are available as tubes, a second dual atmosphere apparatus has been constructed, Figure 6 .

\section{Specimen Characterization}

The specimen characterization techniques are the same as those described for Task 1.
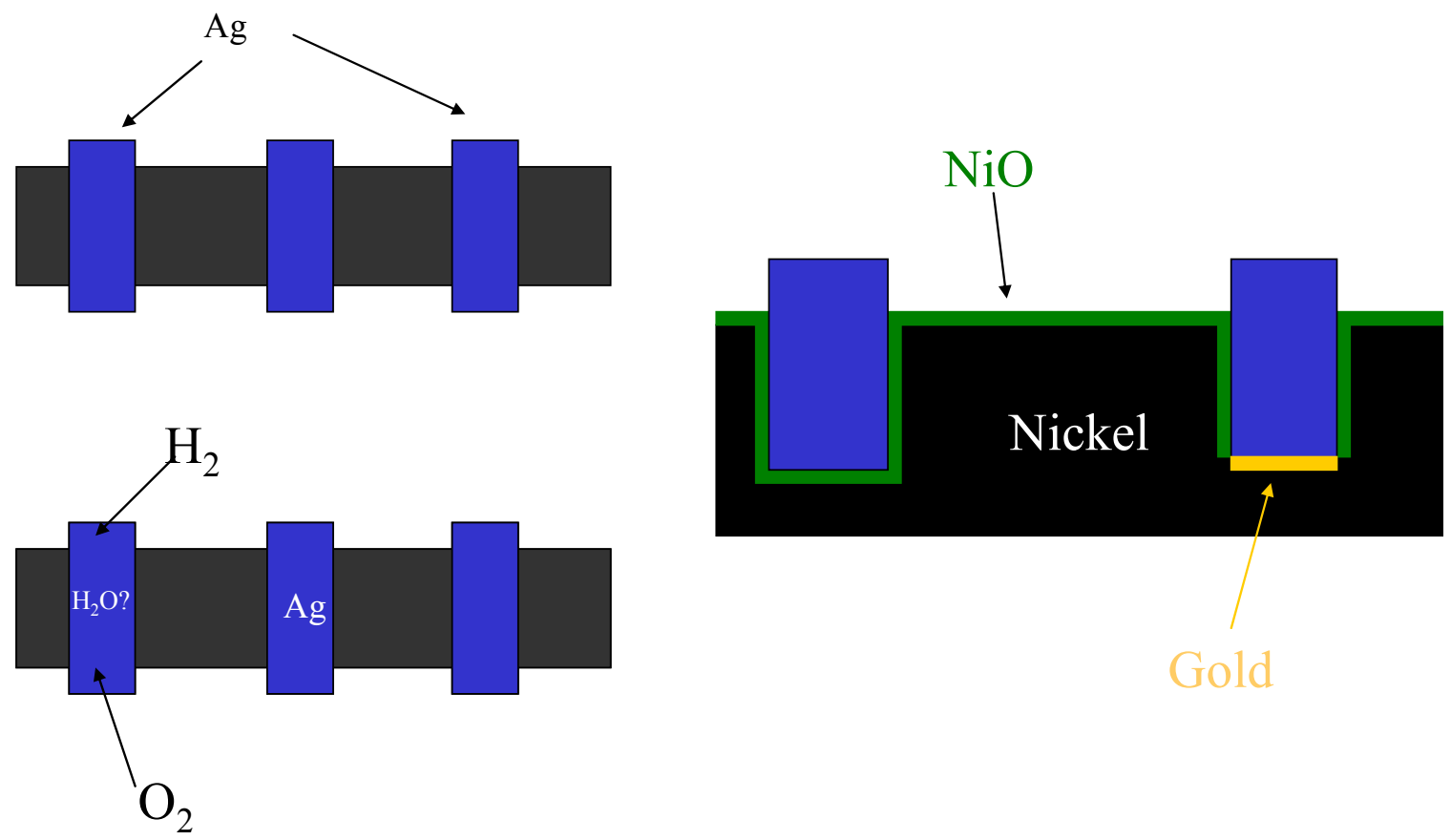

Figure 5. Schematic diagram showing possible ways of using silver as a conducting path through nickel interconnects. 


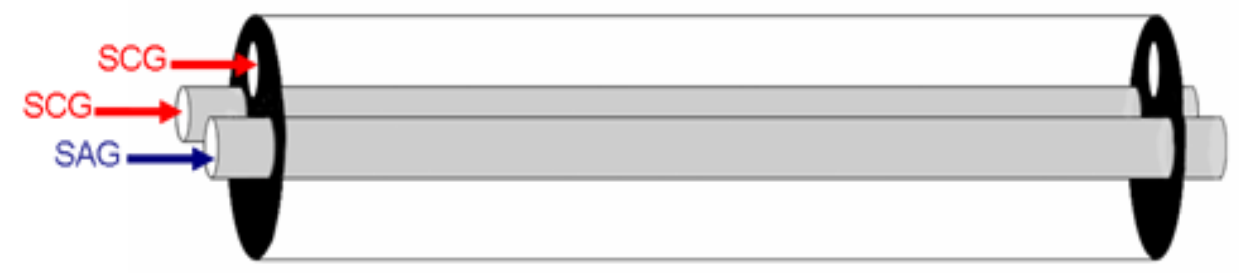

Figure 6. Schematic diagram of dual atmosphere apparatus for exposing tubular specimens.

\section{Task 4: Development of Durable Contacting Material (WVU)}

Samples have been fabricated using various compositions of silver and differing oxides such as LSM and copper-oxide. The samples were fabricated by dry pressing followed by sintering at high-temperature for various periods of time. It was determined that this method did not result in samples that were robust enough for use in the hightemperature evaporation experiments. In order to fabricate samples that were durable enough for testing, it was decided that the method of fabrication be modified. Instead of the ball-milling/pressing/sintering method previously used, it was decided that the oxidation of specific alloys would be a simpler method to produce reliable samples. Sterling silver has been identified as a candidate for use as a contacting material due to its favorable composition and low-cost. Upon oxidation, the copper in the sample becomes copper-oxide which is meant to act as a barrier against evaporation of the silver in the sample, extending the usable life of the cermet. Sterling silver has been tested in hightemperature exposure alongside pure silver for a period of 27 weeks to gain an understanding of the performance of copper-oxide in protecting against silver evaporation.

\section{RESULTS AND DISCUSSION}

\section{Task 1: Mechanism-based Evaluation Procedures}

The oxidation results for the ferritic stainless steels under fuel cell conditions have been reported previously [3]. These results have also been described in a manuscript accepted for publication in Oxidation of Metals. This manuscript is attached as Appendix A.

In attempts to reduce the growth rate of chromia, and, therefore, the electrical resistance, E-Brite samples have been doped with $\mathrm{CeO}_{2}$ using pulsed laser deposition (PLD). Oxidation experiments for 100 hours at $800^{\circ} \mathrm{C}$ in air show that the doping drastically reduced the thickness of the chromia scale.

Sigma phase was observed to form at $700^{\circ} \mathrm{C}$ in the alloys with higher chromium concentrations, e.g. $26 \mathrm{Cr}$ Ferritic and E-BRITE. Sigma phase is promoted in these alloys by the presence of Mo. (additions of W would have a similar effect.) It was also found 
that impurity elements, such as $\mathrm{Si}$, accelerated the formation of the sigma phase, e.g. 26 $\mathrm{Cr}$ Ferritic developed this phase more rapidly than did E-BRITE. A previously unknown result was that sigma phase formation was dramatically accelerated in atmospheres containing water vapor. Sigma- phase must be avoided since it is very brittle and tends to crack.

It was found that even small amounts of $\mathrm{Al}$ or $\mathrm{Si}$ (less than $0.5 \mathrm{wt} \%$ ) in ferritic steels result in the formation of continuous alumina or silica films which greatly increases the ASR. Therefore, future alloy development should hold these elements to the minimum values possible.

A major problem with chromia-forming alloys is oxide volatility as $\mathrm{CrO}_{3}$, particularly in the cathode gas, since the $\mathrm{CrO}_{3}$ partial pressure increases with oxygen partial pressure. The volatile species are reduced at electrochemically active sites on the cathode during $\mathrm{SOFC}$ operation, which inhibits the required oxygen reduction. Analysis of the $\mathrm{Cr}$ vapor species indicates water contents above about $0.1 \%$ in air result in partial pressures of $\mathrm{CrO}_{2}(\mathrm{OH})_{2}$ which exceed the partial pressure of $\mathrm{CrO}_{3}$ and result in cathode poisoning. There are three potential solutions to this problem:

1. Develop cathode materials that are not affected by $\mathrm{Cr}$ contamination.

2. Suppress the evaporation of $\mathrm{Cr}$-species from ferritic alloys.

3. Develop $\mathrm{Cr}$-free materials with suitable interconnect properties.

The latter two approaches have been pursued in this research. Approach 3 is described in Task 3 below.

An ideal approach to suppressing Cr volatility would be to develop an alloy which forms a $\mathrm{Cr}$-free oxide overlayer. Experiments on Ni-base superalloys indicated that $\mathrm{Ti}$ additions might provide such a layer. Four heats of novel Fe-Cr-Ti alloys with $\mathrm{Ti}$ contents varying between 1 and $4 \mathrm{wt} \%$ and one Ti-free control heat were produced by ATI Allegheny Ludlum. Ingots were melted in a vacuum induction furnace with a fifty pound crucible. These were hot and cold-worked to flat sheets approximately $0.5 \mathrm{~mm}$ thick by $150 \mathrm{~mm}$ wide without incident.

Initial characterization of these $\mathrm{Fe}-\mathrm{Cr}-\mathrm{Ti}$ alloys was carried out to determine the effect of titanium on mechanical properties and on coefficient of thermal expansion. Figure 7 presents the results of duplicate tensile tests. Titanium was found to increase both yield and ultimate tensile strength and to decrease plastic elongation compared to the base $\mathrm{Fe}-22 \mathrm{Cr}$ alloy. The changes were significant for the two highest titanium alloys, where the ductility was particularly low and may be unacceptable for forming applications.

Adding titanium was found to have a negligible effect on the linear coefficient of thermal expansion (CTE) compared to the base $\mathrm{Fe}-22 \mathrm{Cr}$ alloy at the lowest level of addition ( $0.84 \mathrm{wt} . \%)$. For the higher levels, titanium was observed to systematically increase the CTE (Figure 8). For additions ranging from 1.7 to $4.0 \mathrm{wt} . \%$, the percentage change in CTE relative to the base $\mathrm{Fe}-22 \mathrm{Cr}$ alloy was found to obey the following relationship over the temperature range $600-900^{\circ} \mathrm{C}$.

$$
\Delta \alpha(\%)=4.8 \times(w t . \% T i)-3.5
$$




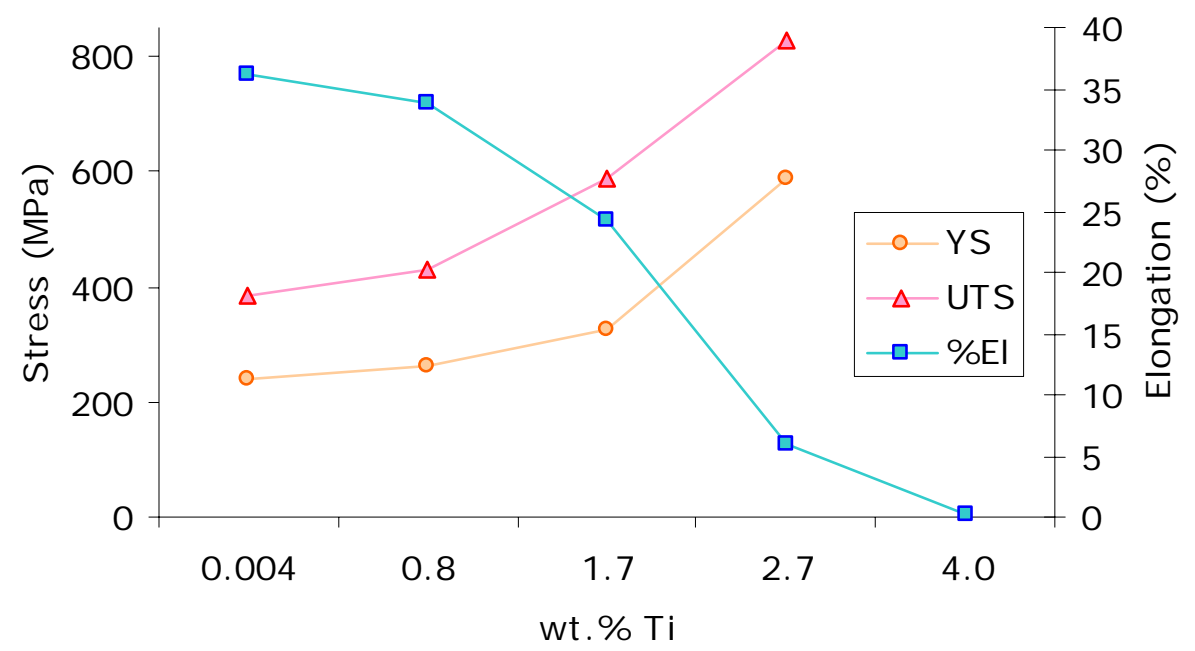

Figure 7. Effect of titanium on the mechanical properties of a model $\mathrm{Fe}-22 \mathrm{Cr}$ alloy.

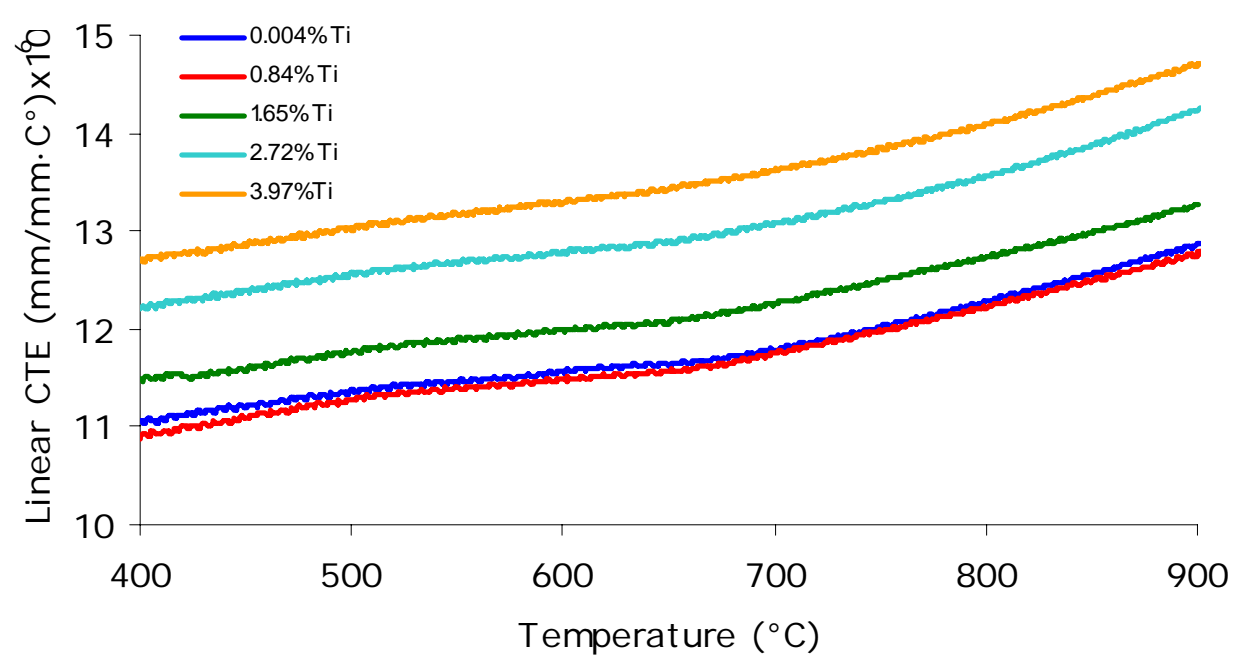

Figure 8. Effect of titanium on the linear coefficient of thermal expansion of a model Fe-22Cr alloy.

Isothermal oxidation (Figures 9) experiments indicate that the Ti additions, at least to $3 \mathrm{wt} \%$, accelerate the oxide growth rate at $900^{\circ} \mathrm{C}$ relative to the $\mathrm{Fe}-\mathrm{Cr}$ baseline alloy and CroFer. The same trend is evident in the cyclic oxidation kinetics at $800^{\circ} \mathrm{C}$ (Figure 10). Figure 11 indicates that indeed these alloys can form a continuous $\mathrm{TiO}_{2}$ overlayer, particularly for the higher Ti concentrations. The cross-sections also indicate that there is significant internal oxidation of the Ti below the chromia scale. 


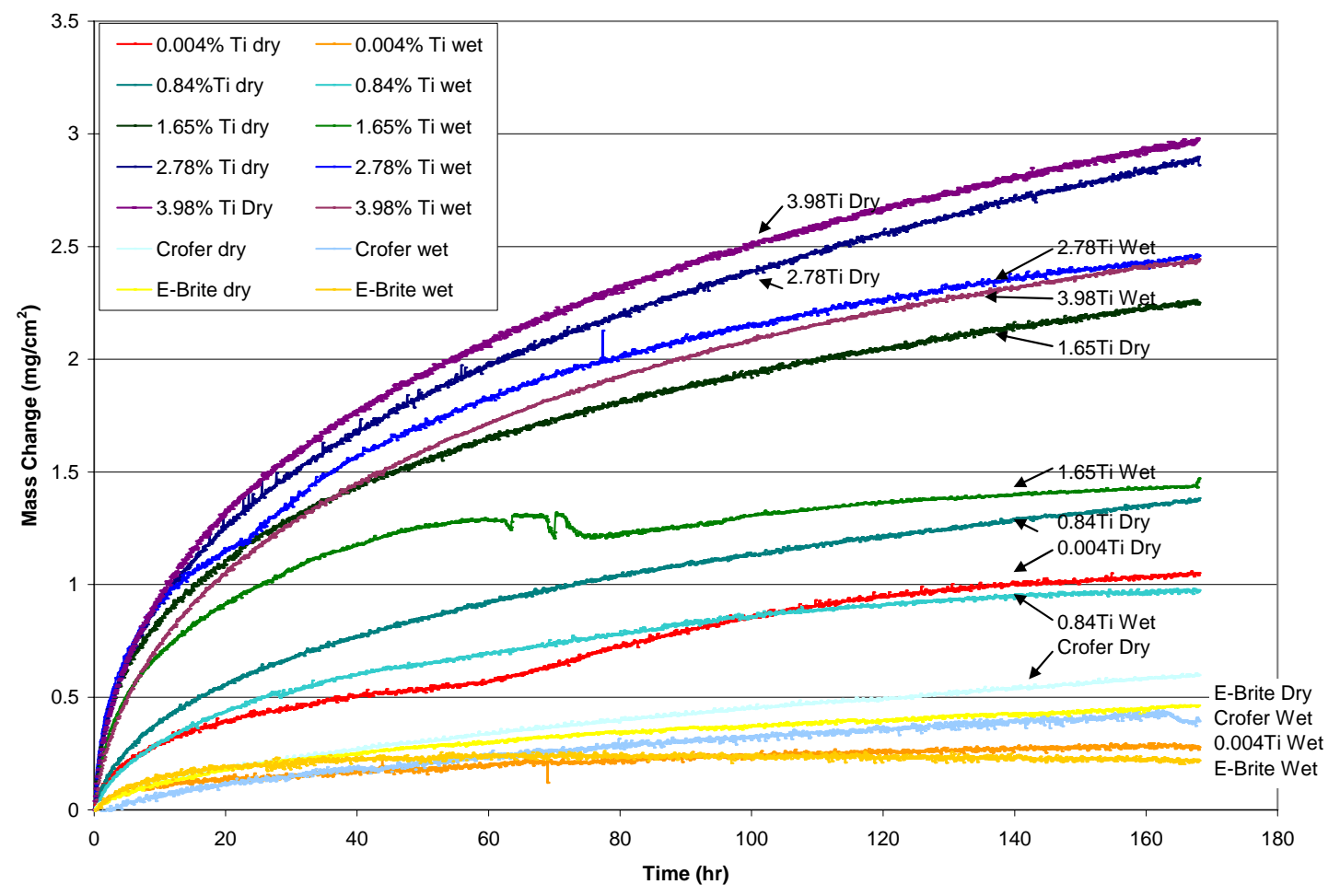

Figure 9. TGA data for Fe-Cr-Ti alloys, Crofer, and E-Brite at $900^{\circ} \mathrm{C}$ in dry and moist atmospheres. 


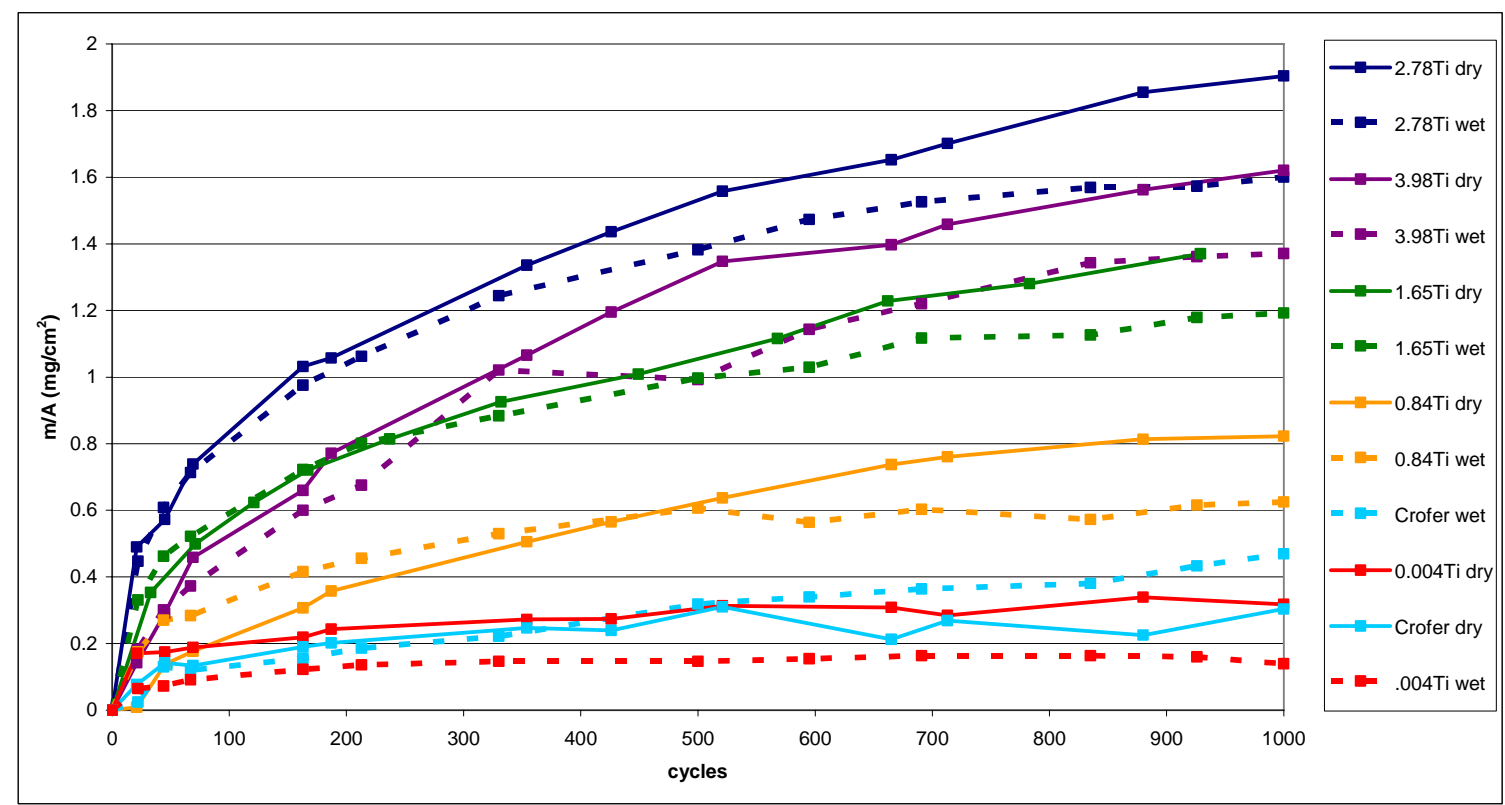

Figure 10. Cyclic oxidation data for Fe-Cr-Ti alloys and Crofer, at $800^{\circ} \mathrm{C}$ in dry and moist atmospheres.

Long-term exposures of the Fe-Cr-Ti alloys were carried out in both ambient and humidified air at $760^{\circ} \mathrm{C}$. Samples of E-BRITE alloy, which has been well-characterized in such tests, was included for comparison purposes. All of the samples were tested simultaneously. The humidified air environment was maintained by using a tube furnace of similar construction to Figure 1. Samples were cycled to room temperature once per week for weighing and inspection throughout the nominal 3,000 hour exposure period.

In ambient air, the addition of titanium resulted in a consistent increase in weight gain up to a level of $2.7 \mathrm{wt} . \%$, at which point the incremental weight gain appears to have reached a plateau (Figure 12). In air containing added water vapor, adding titanium has a notable effect on the rate of chromium oxide evaporation (Figure 13). The E-BRITE and Fe-22Cr model alloy samples both exhibit a tendency towards weight loss, with the cumulative weight gain after 3,000 hours approaching zero. Adding titanium to the base $\mathrm{Fe}-22 \mathrm{Cr}$ appears to reduce the rate of evaporation, with the effect proportional to the amount of added titanium. Figure 14 compares the two data sets by taking the ratio of weight gain after 3,000 hours in humidified air to that in ambient air. If evaporation is completely suppressed, this ratio should equal one. The nominal reduction in the effect of evaporation increases the ratio from about 0.3 for the base $\mathrm{Fe}-22 \mathrm{Cr}$ alloy to approximately 0.8 for the Fe-22Cr-2.7Ti alloy. There is no apparent effect caused by further increasing the titanium content to $4.0 \mathrm{wt}$. \%. 

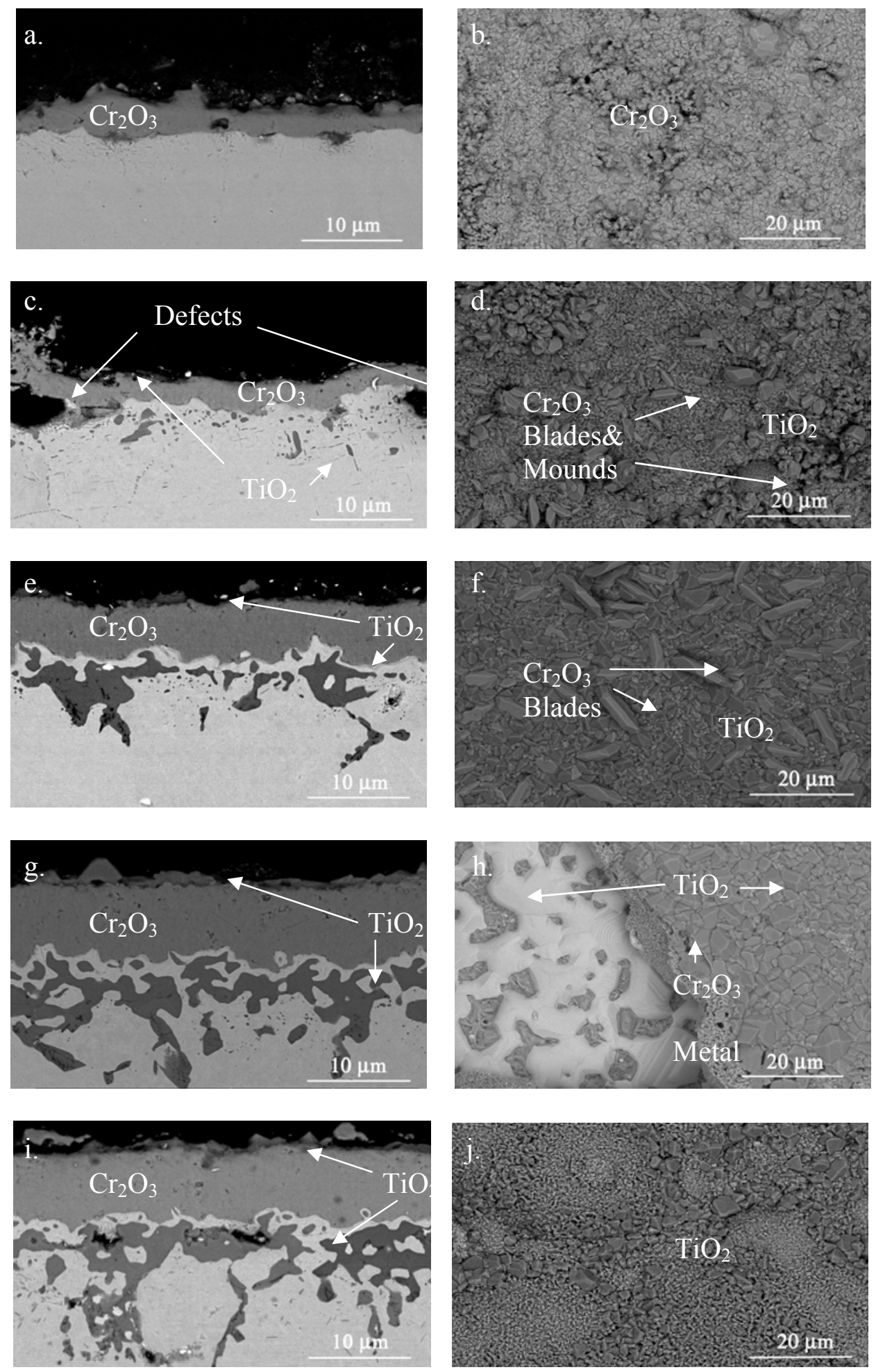

Figure 11. Cross - sectional and surface SEM micrographs of alloys exposed for 96 hrs at $900^{\circ} \mathrm{C}$ in dry air containing $0.004 \%(\mathrm{a} \& \mathrm{~b}), 0.84 \%(\mathrm{c} \& \mathrm{~d}), 1.65 \%$ (e\&f), $2.78 \%(\mathrm{~g} \& \mathrm{~h})$, and $3.98 \%$ (i\&j) titanium. 


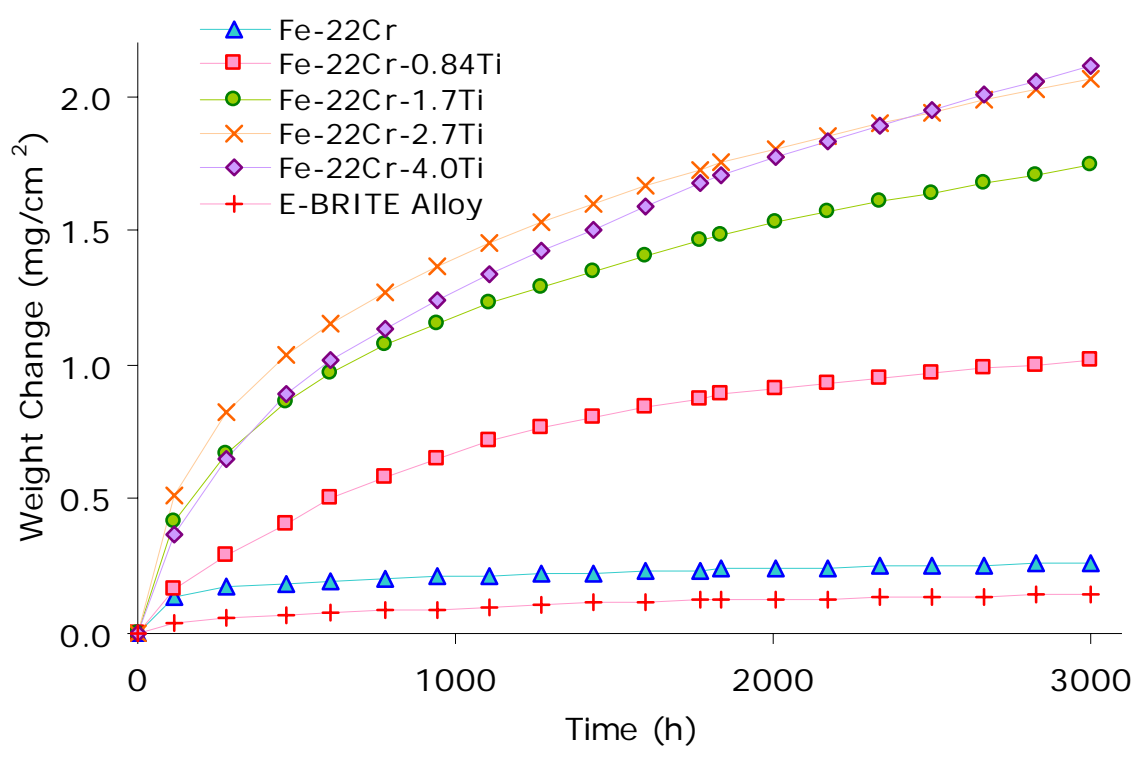

Figure 12. Long-term oxidation test results at $760^{\circ} \mathrm{C}$ in ambient air for $\mathrm{Fe}-22 \mathrm{Cr}$ alloys with added titanium (E-BRITE sample included for a reference).

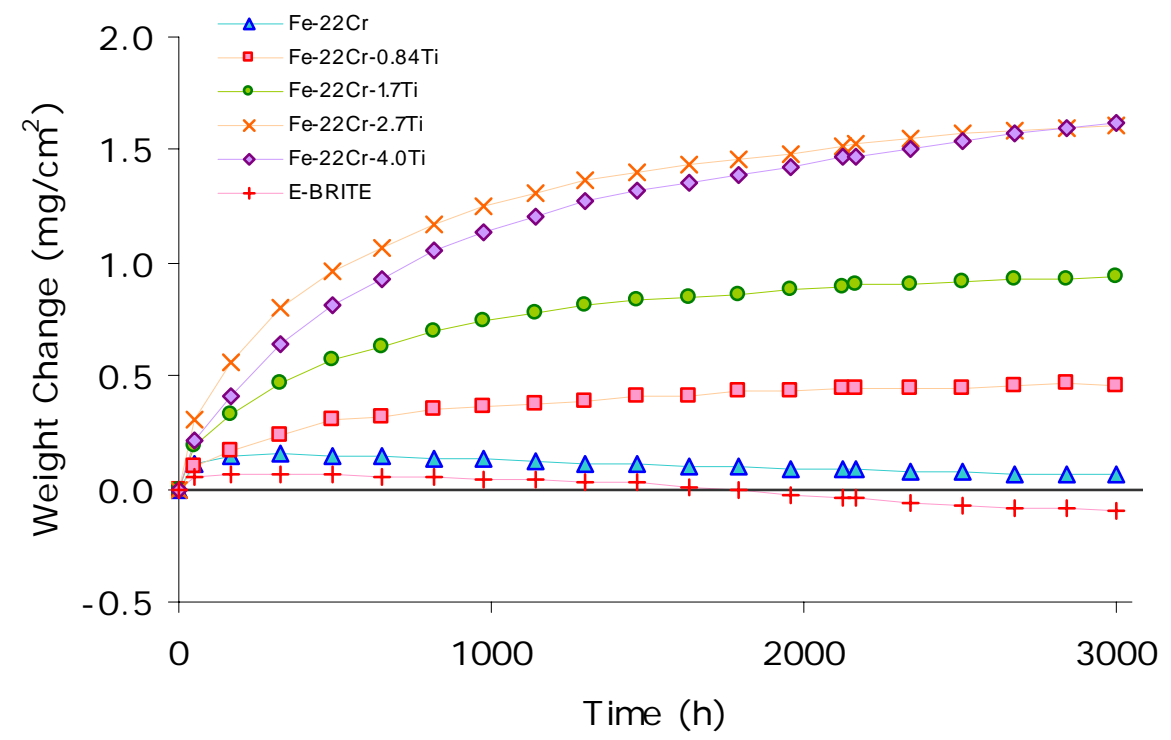

Figure 13. Long-term oxidation test results at $760^{\circ} \mathrm{C}$ in air containing $7 \%$ water vapor for $\mathrm{Fe}-22 \mathrm{Cr}$ alloys with added titanium (E-BRITE sample included for a reference). 


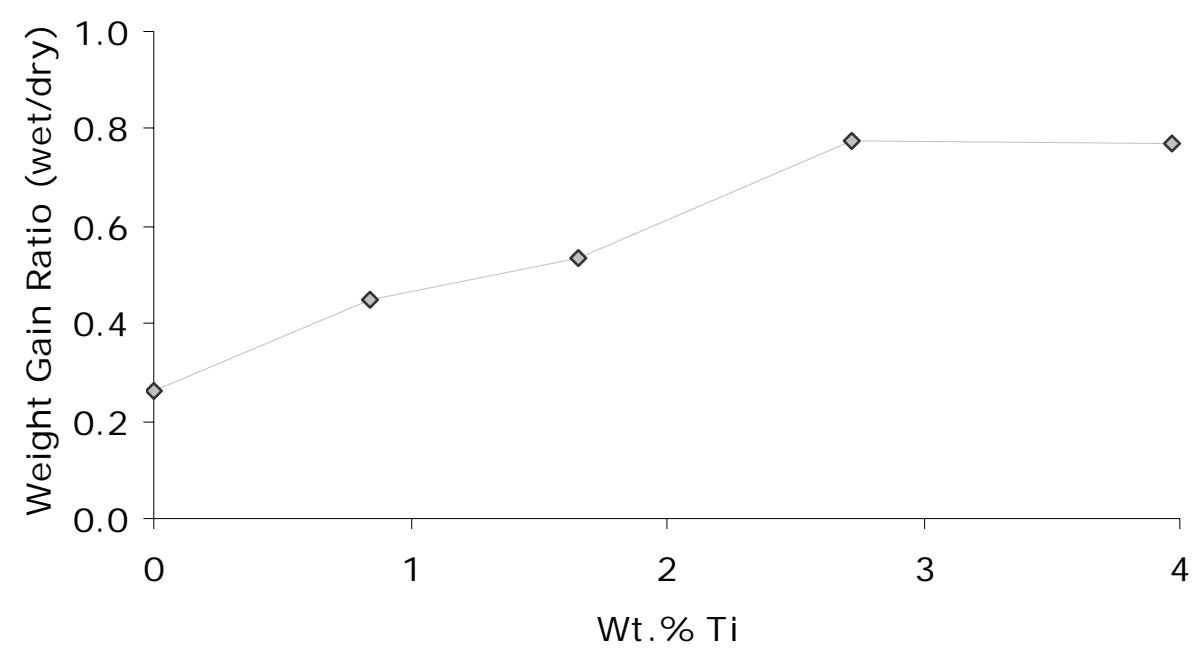

Figure 14. Comparison of weight gains after 3,000 hours at $760^{\circ} \mathrm{C}$ for $\mathrm{Fe}-22 \mathrm{Cr}$ alloys with added titanium - ratio of terminal weight gain in air containing $7 \%$ added water vapor to terminal weight gain in ambient air.

The effect is shown in direct comparisons in Figures 15-17 for the Fe-22Cr base alloy, $\mathrm{Fe}-22 \mathrm{Cr}-1.7 \mathrm{Ti}$, and $\mathrm{Fe}-22 \mathrm{Cr}-4.0 \mathrm{Ti}$. It is apparent that increasing the titanium content reduces or eliminates the tendency for the overall weight gain curve to transition from net positive to negative, as observed for Fe-22Cr. There remains, however, a significant difference between the terminal weight gain results between the samples exposed in ambient and humidified air, with the humidified air testing always resulting in lower weight gains. It is difficult to deconvolute the observed oxidation kinetics for the Fe-Cr-Ti alloys, as the weight gain is made up of three factors - weight gain due to internal oxidation of titanium, weight gain due to external oxide formation (split between titanium oxide and chromium oxide layers), and weight loss due to oxide scale evaporation. There is uncertainty regarding the rates of these processes and there may be complex interactions between them. Therefore, it is difficult to absolutely quantify the efficacy of adding titanium to $\mathrm{Fe}-\mathrm{Cr}$ alloys for reducing the tendency for chromium oxide evaporation in humidified air.

Post-exposure structures similar to those presented for the short-term samples were noted in the long-term oxidation samples. Figure 18 is a collection of micrographs taken after a 500 hour exposure at $816^{\circ} \mathrm{C}$ in ambient air, which resulted in welldeveloped oxide scale microstructures. The titanium-free samples exhibited chromium oxide scales, with the oxide on the E-BRITE alloy being very thin and smooth, while the oxide scale on the Fe-22Cr alloy was thicker and more convoluted. The alloys containing titanium formed thick oxides which were rich in titanium on the surface. The oxides were highly variable in thickness from location to location, with maximum thickness increasing steadily with titanium content. All of the alloys had similar minimum thickness values, which may explain continued volatility at higher titanium levels due to potential thin spots in the titanium oxide outer layer. Beneath the oxide were zones of internal oxidation and internal nitridation. The depth and severity of the internal oxidation increased with titanium content. The number and size of the internal titanium 
nitrides increased with titanium content, but the depth of the internally nitrided zone appeared to be fairly consistent for the titanium-bearing alloys. The presence of the internal nitridation layer is not typical for chromia-forming stainless steels in oxidizing environments and suggests that the titanium addition is permitting nitrogen transport through the oxide scale, either by physical access to the metal through cracks/voids, or by increased permeability through the condensed oxide.

\begin{tabular}{|r|c|c|c|c|c|c|}
\cline { 3 - 7 } \multicolumn{1}{c|}{} & E-BRITE & \multicolumn{5}{c|}{ Fe-22Cr alloys } \\
\cline { 3 - 7 } \multicolumn{1}{c|}{} & alloy & $0.004 \% \mathrm{Ti}$ & $0.84 \% \mathrm{Ti}$ & $1.7 \% \mathrm{Ti}$ & $2.7 \% \mathrm{Ti}$ & $4.0 \% \mathrm{Ti}$ \\
\hline $\begin{array}{r}\text { oxide thickness } \\
\text { (microns) }\end{array}$ & 1.1 & $1.7-2.6$ & $2.1-4.0$ & $2.6-6.7$ & $2.9-8.7$ & $1.9-10.7$ \\
\hline $\begin{array}{r}\text { internal oxide } \\
\text { depth (microns) }\end{array}$ & - & - & 5 & 9 & 21 & 23 \\
\hline $\begin{array}{r}\text { internal nitridation } \\
\text { depth (microns) }\end{array}$ & - & - & 23 & 21 & 21 & 23 \\
\hline
\end{tabular}

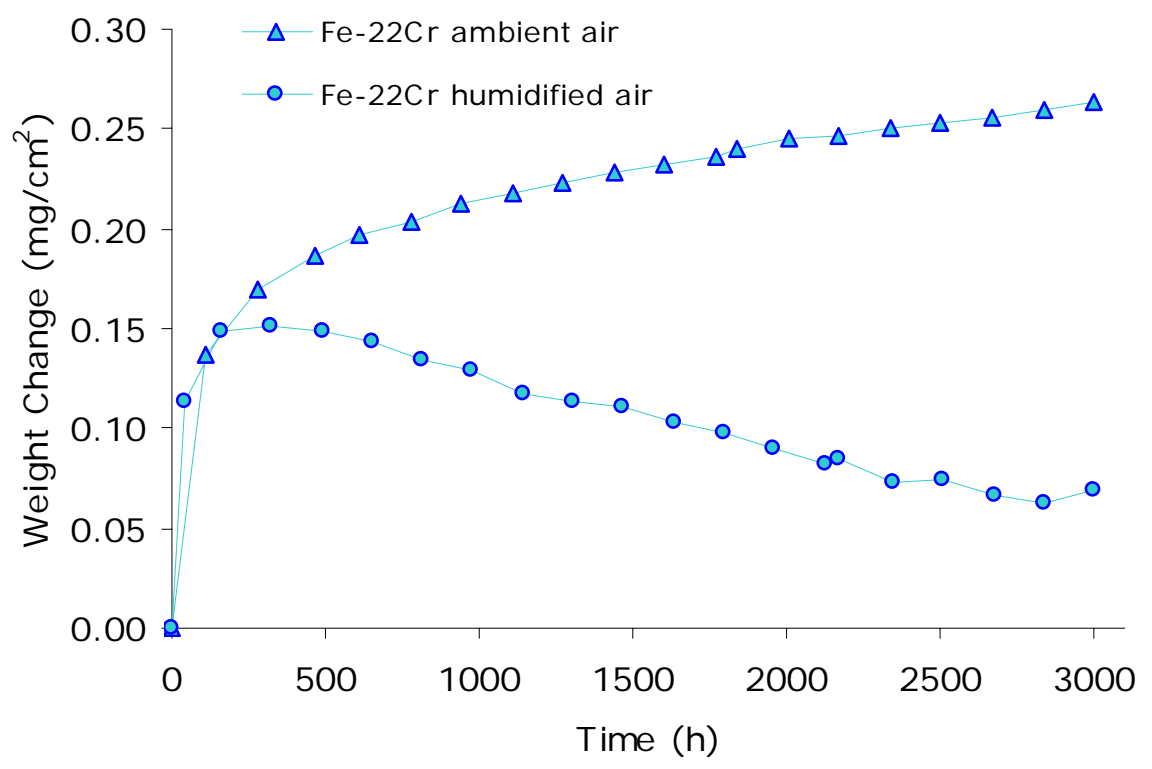

Figure 15. Long-term oxidation test results for base $\mathrm{Fe}-22 \mathrm{Cr}$ alloy at $760^{\circ} \mathrm{C}$ in air with and without added water vapor. 


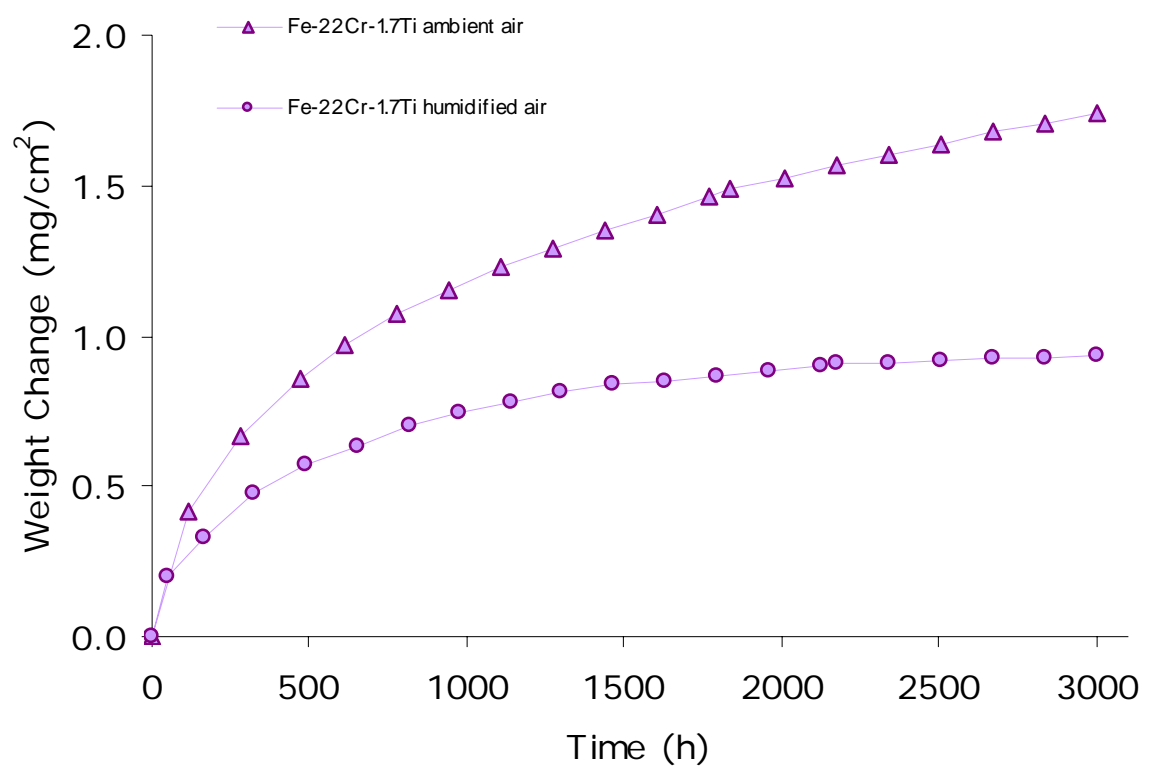

Figure 16. Long-term oxidation test results for base $\mathrm{Fe}-22 \mathrm{Cr}-1.65 \mathrm{Ti}$ alloy at $760^{\circ} \mathrm{C}$ in air with and without added water vapor.

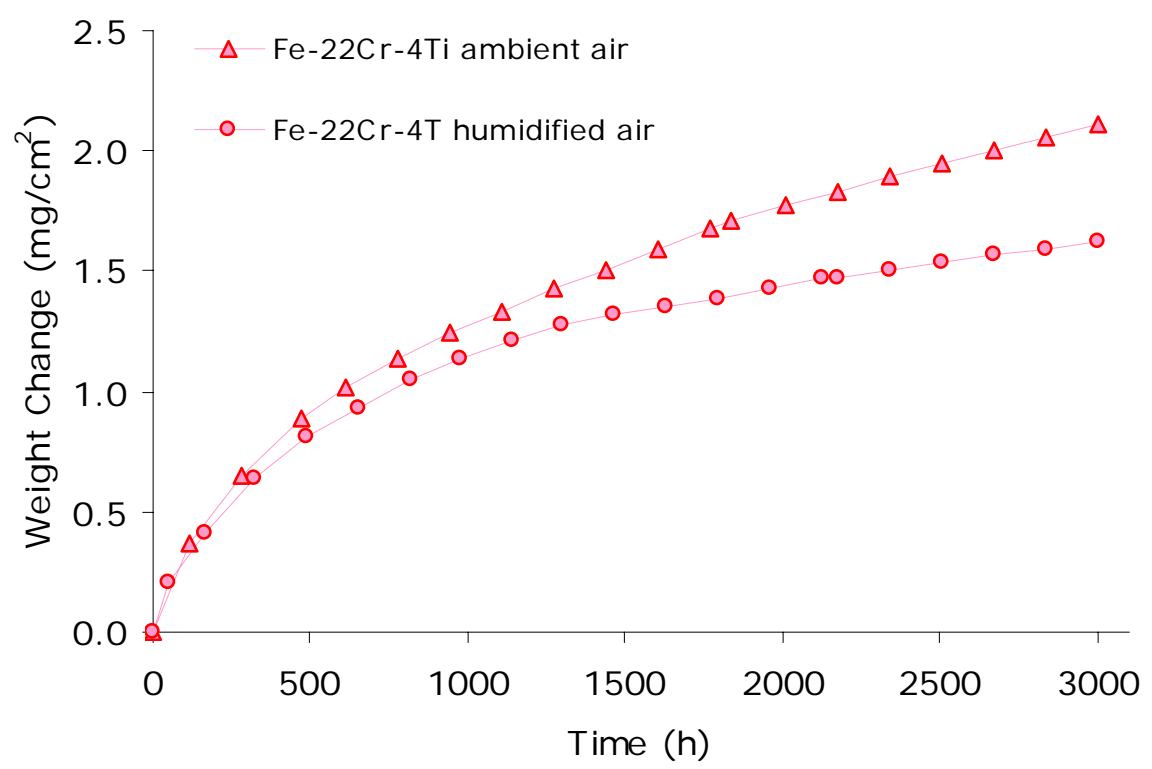

Figure 17. Long-term oxidation test results for base Fe-22Cr-4.0Ti alloy at $760^{\circ} \mathrm{C}$ in air with and without added water vapor. 


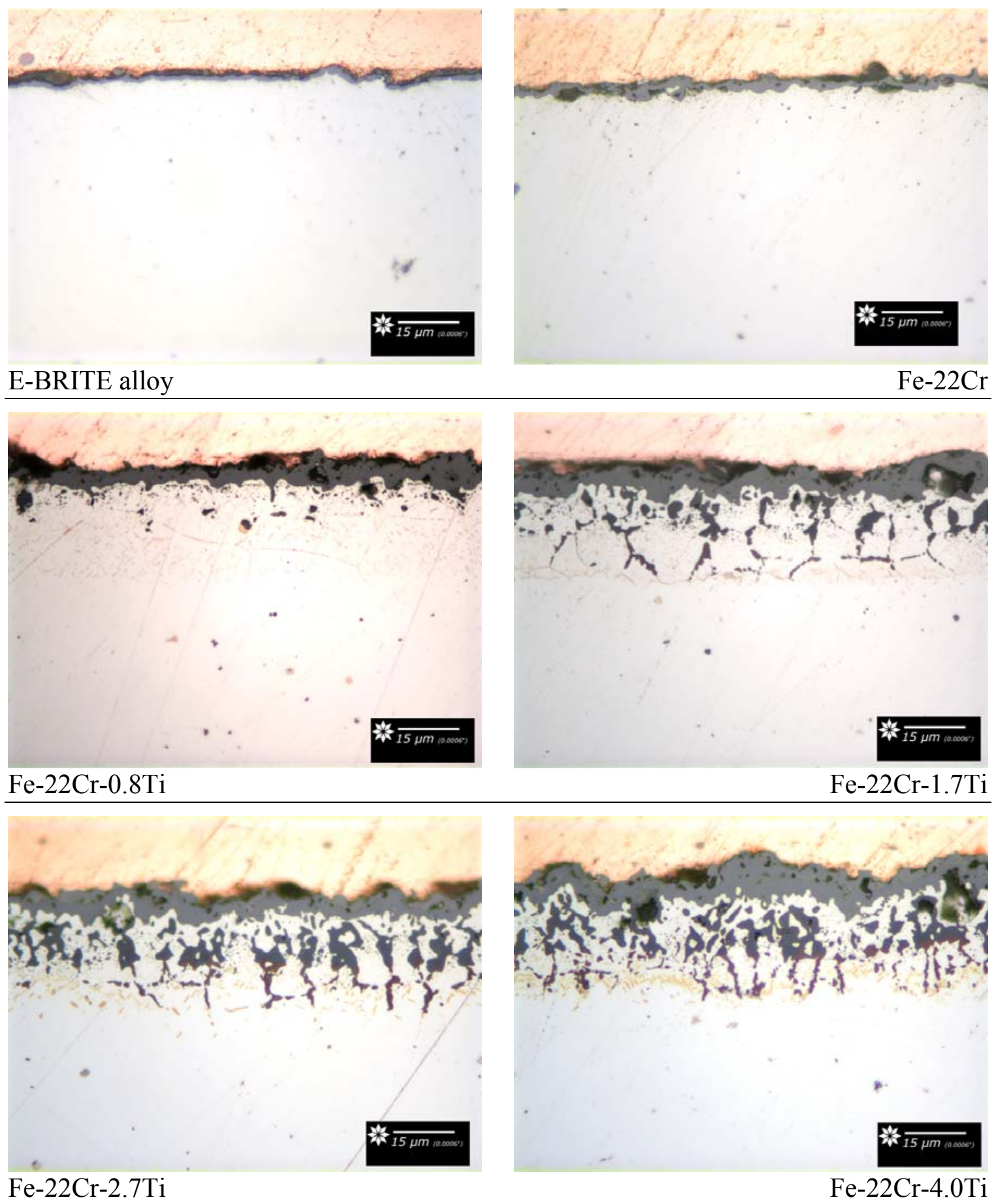

Figure 18. Metallographic cross-sections of different alloys exposed for 500 hours at $816^{\circ} \mathrm{C}$ in ambient air (light optical micrographs). 
A limited number of experiments were conducted in an attempt to seal cracks in $\mathrm{La}_{0.8} \mathrm{Sr}_{0.2} \mathrm{FeO}_{3}$ coatings on a ferritic steel substrate. Two sputter coated E-Brite specimens were annealed at $800^{\circ} \mathrm{C}$ in argon to create cracks as the coatings crystallized. One specimen was then vapor-phase aluminized at Howmet Corporation using a standard procedure used for coating superalloys. It was hoped that the aluminum would only deposit in the cracks so that subsequent heating in air would result in alumina in the cracks to suppress $\mathrm{Cr}$ evaporation. The surface of this specimen after aluminizing is presented in Figure 19. Examination of this surface using EDS indicated the aluminum had deposited on the $\mathrm{La}_{0.8} \mathrm{Sr}_{0.2} \mathrm{FeO}_{3}$ coating as well as in the cracks. Therefore, subsequent oxidation would produce a continuous alumina layer, which would make an unacceptably large contribution to the ASR of the specimen. Figure 20 shows the opposite side of the same specimen where the aluminum was deposited directly on to the E-Brite. The aluminide coating cracked on cooling from the coating temperature presumably because the low CTE of E-Brite resulted in tensile stresses in the brittle coating.

The second specimen was coated with $\mathrm{La}_{2} \mathrm{O}_{3}$ from a liquid precursor. The surface of the coating is presented in Figure 21. There has been some deposition in the cracks. The $\mathrm{La}_{2} \mathrm{O}_{3}$ would tend to react with any volatile $\mathrm{Cr}$-oxides to form the stable compound $\mathrm{LaCrO}_{3}$ which has been used as an interconnect coating. Therefore, there may be value in attempting to optimize the technique for crack sealing using liquid precursors.

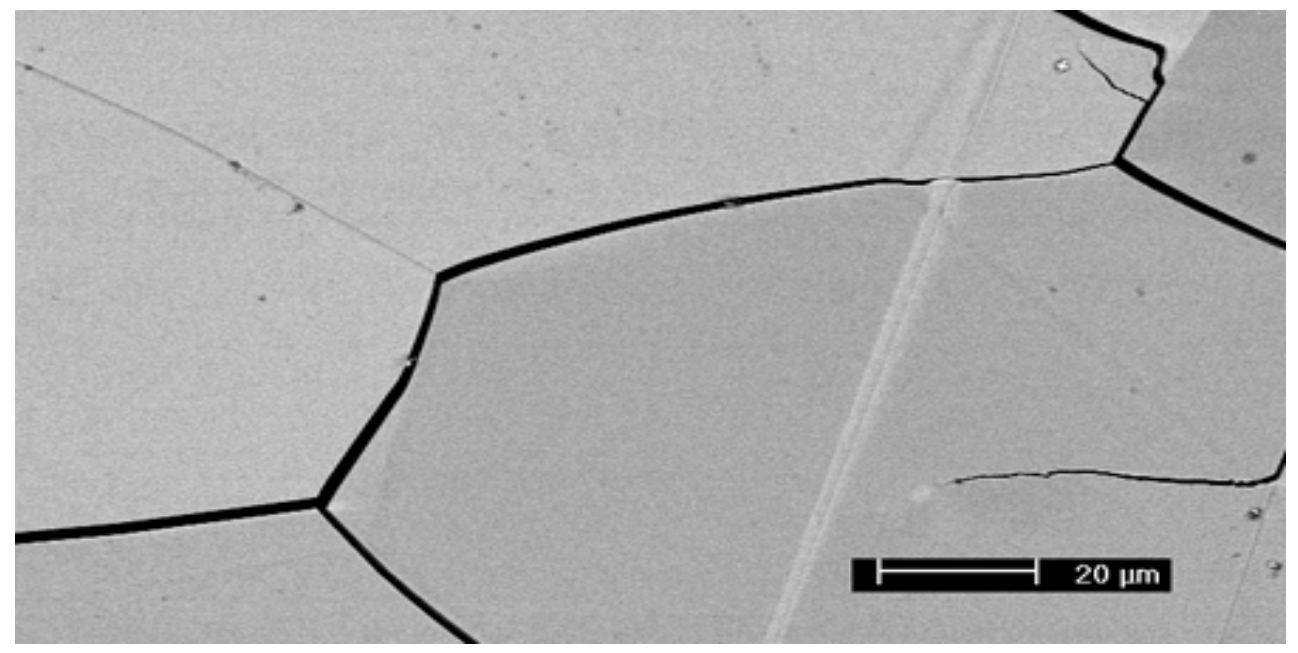

Figure 19. Surface of La-Sr-ferrite coating after aluminizing. 


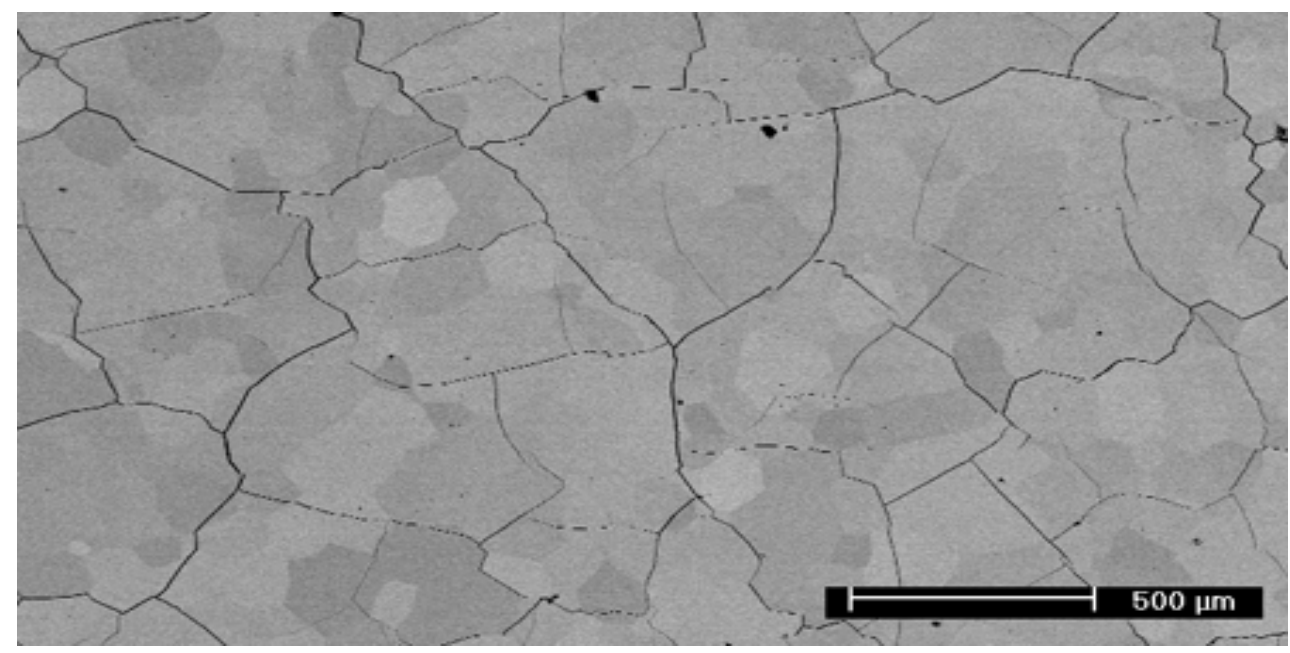

Figure 20. Surface of ferritic steel substrate after aluminizing.

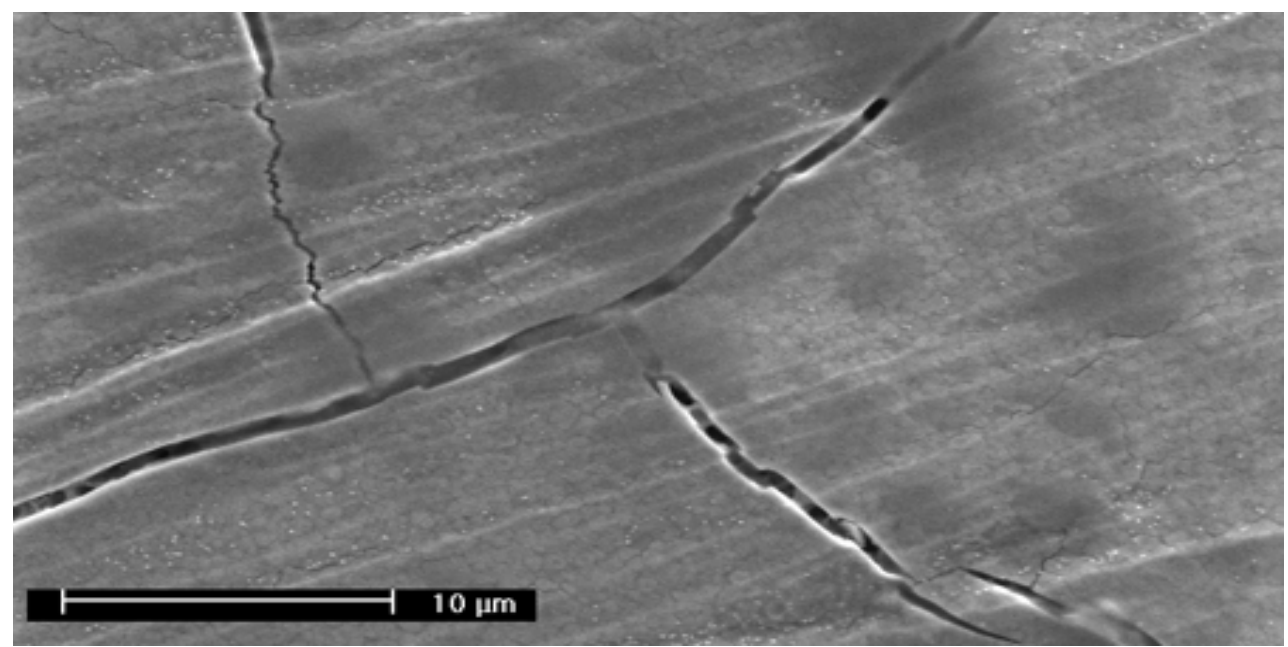

Figure 21. Surface of La-Sr-ferrite coating after deposition of $\mathrm{La}_{2} \mathrm{O}_{3}$ from a liquid precursor.

\section{Task 2: Fundamental Aspects of Thermomechanical Behavior (CMU)}

Previous reports have described the indentation fracture testing of ferritic stainless steel alloys exposed to simulated anode gas (SAG) $\mathrm{Ar} / \mathrm{H}_{2} / \mathrm{H}_{2} \mathrm{O}$ environments. Indented chromia scales formed in SAG debond as an intact coating, and the radial extent of the debonding observed in short-term exposures has been used to estimte the long-term exposure time when spallation can occur. Previous reports also presented indentation results for ferritic stainless steels exposed in air with 0.1 atm $\mathrm{H}_{2} \mathrm{O}$, representing a moist simulated cathode gas (SCG) environment. When indented, those specimens exhibited a 
flaking type of debonding with a decreasing density of flaking with radial distance from the indent. Results for both types of tests are summarized in the paper by Dhanaraj et al. [4] which is attached as Appendix B.

In this past year, an image analysis technique has been developed to analyze the failures seen in SCG-exposed interconnects. In these specimens, bonded areas are black or dark grey, which is the shade of the chromia scale. Areas of spallation appear white or very light grey due to the exposed metal substrate. The imaging technique involves quantifying the distribution of white/grey/black pixels in a single image in regions far from the indentation. The distributions of greys in 5-7 rings around the indentation are also determined. The percentage of debonding in a ring is determined by subtracting the distributions of grey from that ring from the far-field image distribution. The result from the analysis of multiple rings is a plot of the percentage of debonding scale vs. radial distance from the debond. Results from images taken after different exposures allow the tracking of debonding vs. radius as a function of exposure.

Figure 22 gives an example of results from this type of analysis. In the figure, images from indentation of a $26 \mathrm{Cr}$ ferritic alloy exposed in SCG from 10 to 200 hours have been analyzed. Images at 10 and 200 hours are included in the figure, as is a plot of the percentage of debonding vs. $\mathrm{R} / \mathrm{a}$ for different exposures. $\mathrm{R}$ is the radial distance from the indentation and $\mathrm{a}$ is the radius of the indentation. The images taken in these tests show a fairly consistent decrease in debonding density with radius and an increase in debonding density with exposure. Plots of debond percentage vs. R/a from the image analyses are consistent with these qualitative observations. As exposures are increased, the curves of percentage debonding rise, but the increases in debonding stop at 100-200 hours of exposure. At this point, some amount of debonding is observed even at radial distances where the strains due to indentation are almost zero.

The conclusion from these results is that after 100-200 hours of exposure in SCG at $900^{\circ} \mathrm{C}$, spontaneous spallation (spallation that can occur without the use of indentation) has begun to occur. At this point, spontaneous spalls (and perhaps some scale evaporation) act to keep the average thickness of the chromia scale more or less constant, so that plots of debond percentage vs. R/a reach a steady-state. This is consistent with weight gain measurements performed as part of Task 1 of this project. Weight gains in these specimens stop after $100 \mathrm{hrs}$ of exposure and specimen weight remains constant from that point on. 

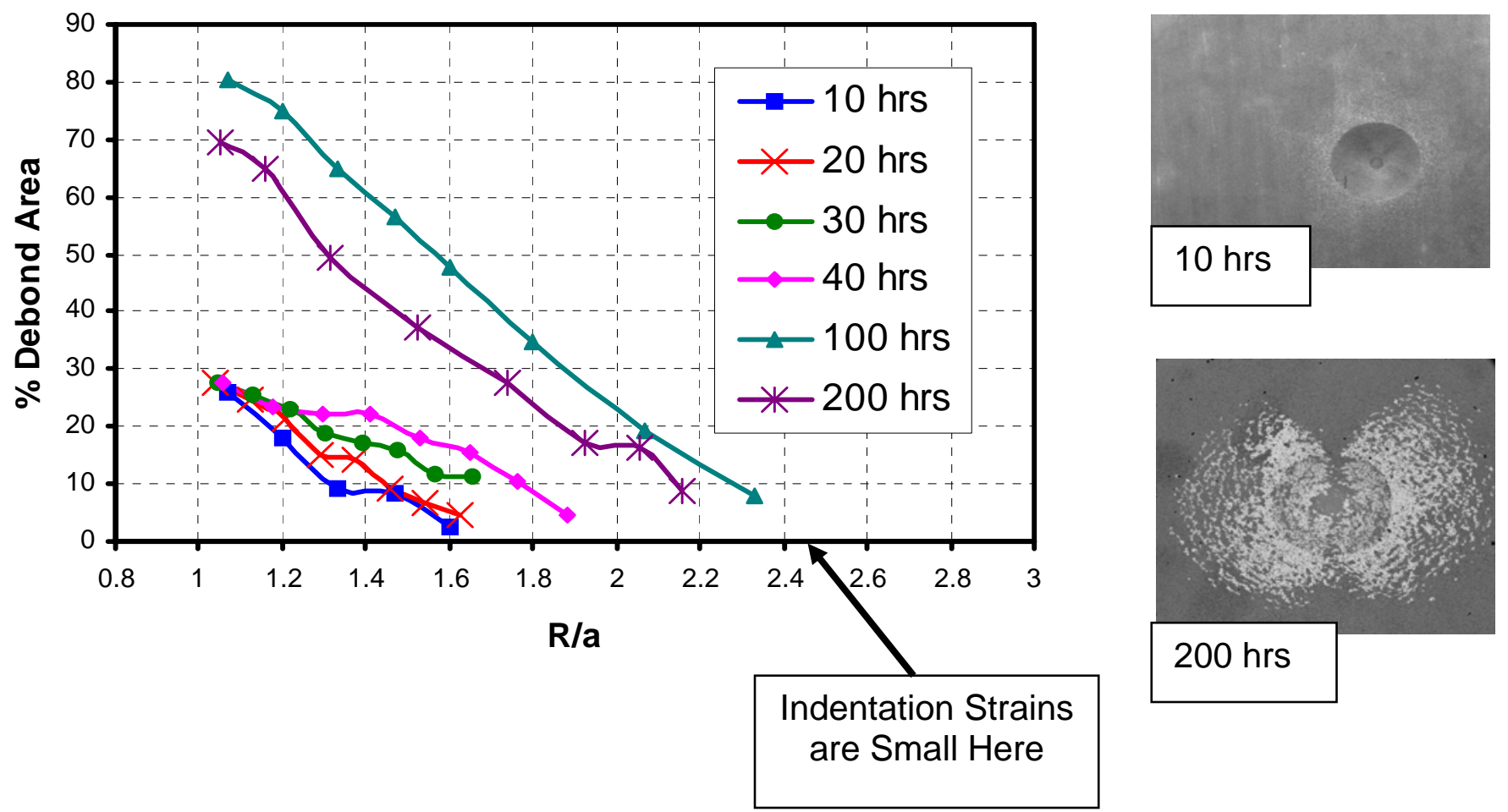

Figure 22. Percentage of Debonding vs. Radial Distance for a $26 \mathrm{Cr}$ Ferritic Alloy Exposed in Wet Air (Simulated Cathode Gas) at $900^{\circ} \mathrm{C}$ for $10-200 \mathrm{hrs}$ 


\section{Task 3 Alternative Materials}

Experiments are being carried out on pure $\mathrm{Ni}$ as a possible alternative interconnect material since the oxygen partial pressure in the anode gas is too low to oxidize Ni. The primary challenge in making Ni perform satisfactorily as an interconnect, is to reduce the electrical resistance of the thermally grown oxide, that forms on the cathode side during fuel cell operation.

Efforts to decrease the electrical resistance of the interconnect oxide are twofold. First, we have tried to reduce the scale thickness by the use of surface dopants. Pulsed laser deposition (PLD) is used to deposit thin films of $\mathrm{SrO}$ and $\mathrm{CeO}_{2}$ onto the surface of nickel. These experiments have shown that $\mathrm{CeO}_{2}$ decreases the thickness of $\mathrm{NiO}$ by a factor of 4 (Figure 23) and $\mathrm{SrO}$ doping decreases it by a factor of 2. ASR is proportional to scale thickness and the resistance decreases accordingly (Figure 24). These dopants can be deposited by inexpensive techniques once the optimum dopants are identified.

Tubes of Ni 200 have been exposed under dual atmosphere conditions in the apparatus presented in Figure 6. Cross-sections of tubes for air-air and air-SAG exposures are presented in Figure 25 and indicate no effect of the dual-atmosphere.

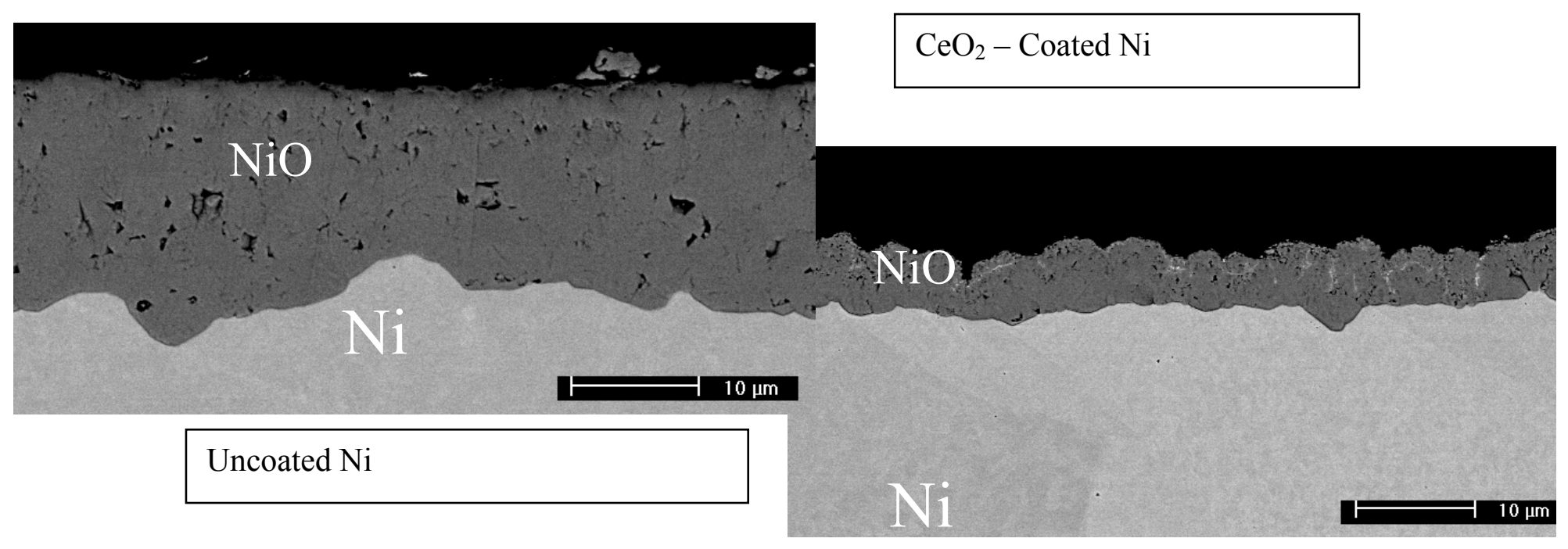

Figure 23. Effect of $\mathrm{CeO} 2$ deposited by pulsed laser deposition on the growth rate of $\mathrm{NiO}$ for 100 hours at $800^{\circ} \mathrm{C}$ in dry air.

Finally, the resistance introduced by the thermally grown oxide has been bypassed by the use of high conductivity pathways. Silver is not considered as a possible interconnect material due to the high permeability of hydrogen and oxygen in silver, which causes water nucleation and mechanical instability. However, silver may be able to provide a high conductivity pathway through another material. Systems in which silver wires are passed through nickel and silver powder is melted into holes drilled in nickel have been examined. Figure 26 shows the cross-section of a Ni specimen where $\mathrm{Ag}$ has been melted in a hole drilled in the Ni. After exposure there is some porosity in 
the silver and it appears the grain boundaries are delineated with pores far into the silver. Importantly, despite the porosity, the specimen had resistance values typical of a metal when measured at room temperature following exposure. In this configuration the $\mathrm{Ni}$ provides the physical integrity of the interconnect and the silver only provides the conduction path through the scale.

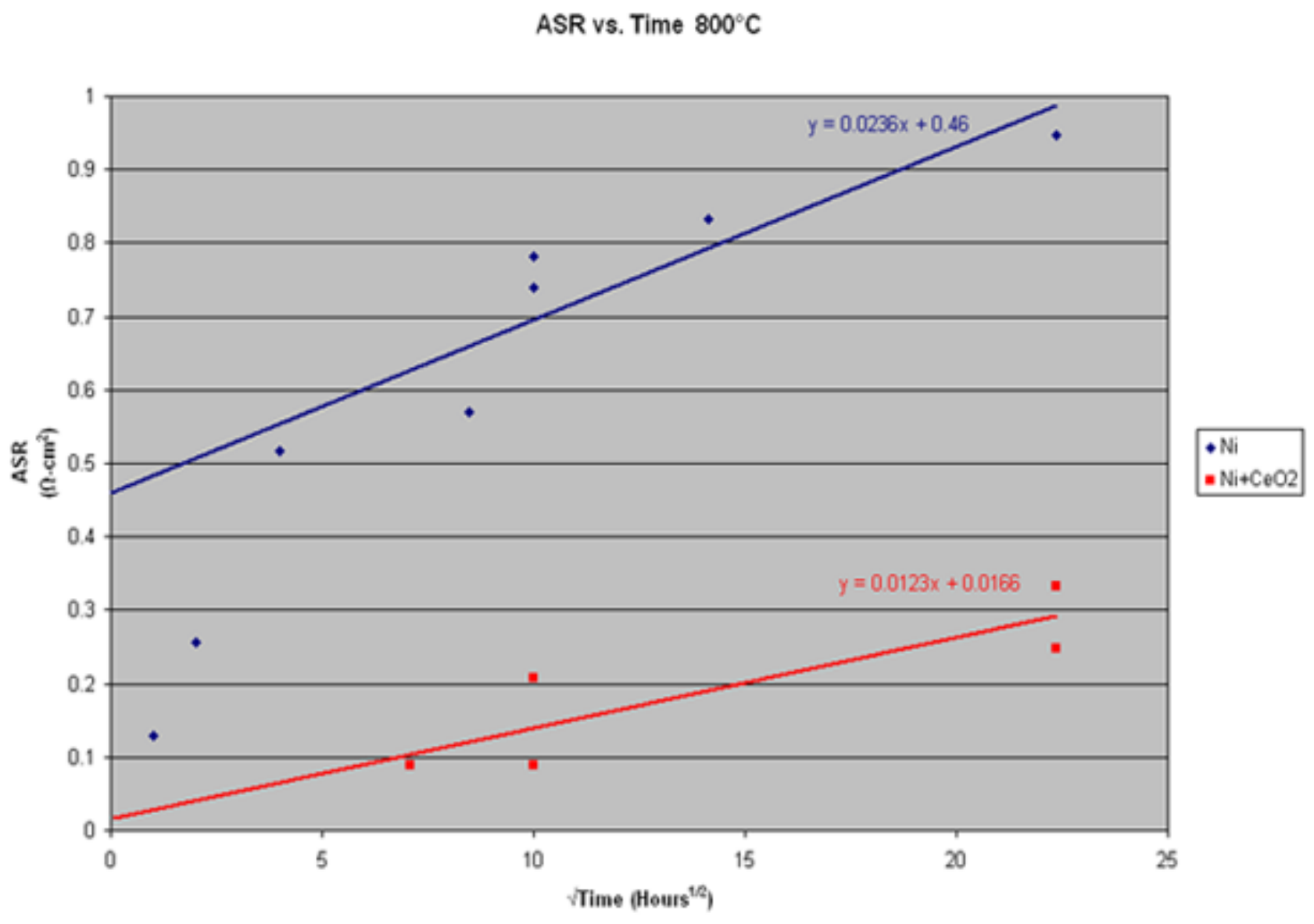

Figure 24. ASR as a function of the square root of the oxidation time at $800^{\circ} \mathrm{C}$ for pure $\mathrm{Ni}$ and $\mathrm{CeO}_{2}$-doped $\mathrm{Ni}$. 

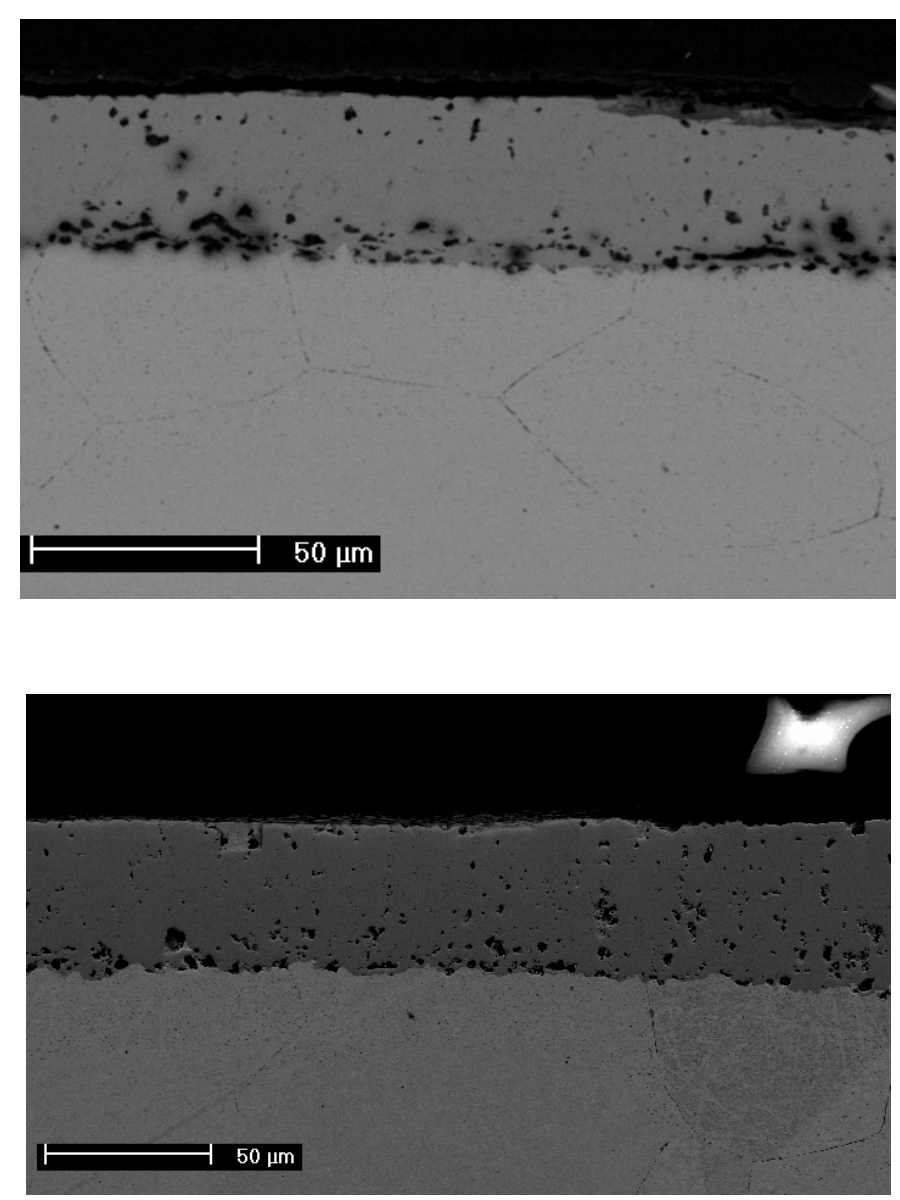

Figure 25 Cross-sections of Ni 200 tubes exposed for 600 hours at $800^{\circ} \mathrm{C}$. The top specimen was exposed with dry air inside and outside the tube. The bottom specimen was exposed with $\mathrm{Ar}-10 \% \mathrm{H}_{2} \mathrm{O}-4 \% \mathrm{H}_{2}$ inside the tube and dry air on the outside. The micrograph was taken from the side exposed to air.

\section{Task 4: Development of Durable Contacting Material (WVU)}

Sterling silver was tested in a high-temperature exposure experiment alongside pure silver to gain an understanding of the performance of copper-oxide in protecting against silver evaporation. Samples were weighed on a weekly basis and the observed mass changes were used to determine the reduction in thickness of the samples. Results from the evaporation data are shown in Figure 27.

Very early on it appears that all samples exhibit similar evaporation behavior, however, after several weeks it appears that the rate of loss for the pure silver samples is lower than the sterling silver sample. This trend continued throughout the 27 -week experiment. This is an unexpected result as the copper-oxide formed during oxidation was intended to protect the silver and reduce the rate of evaporation of the samples. 


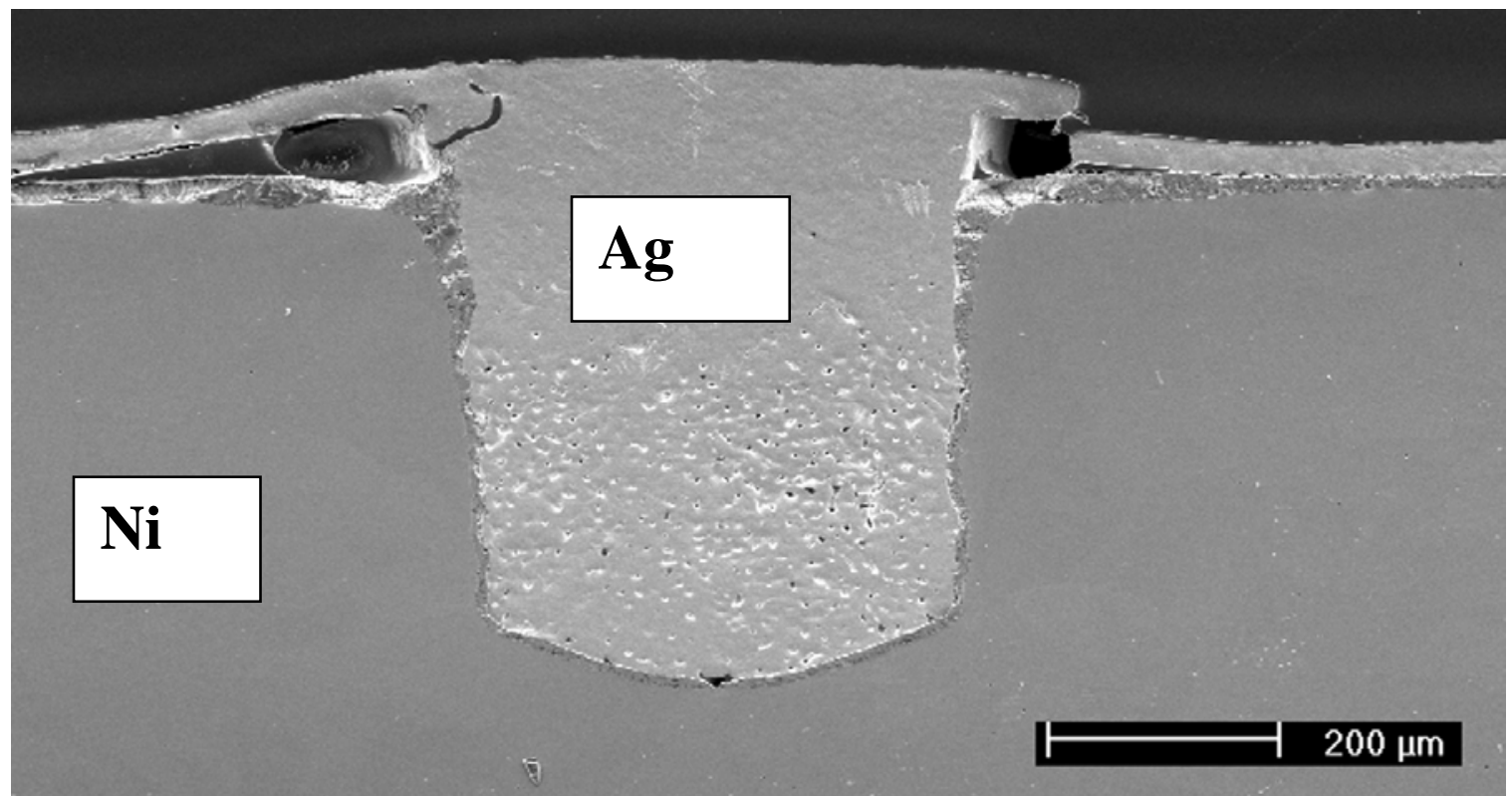

Figure 26. Silver Via, $800^{\circ} \mathrm{C} 100$ Hours, exposed under dual atmospheric conditions. The upper surface was exposed to dry air while the lower surface was exposed to simulated anode gas of $\mathrm{Ar}-10 \% \mathrm{H}_{2} \mathrm{O}-4 \% \mathrm{H}_{2}$.

Samples are also regularly examined for surface changes due to high-temperature exposure. Examples of SEM micrographs for exposed samples are shown in Figure 28. As shown, the sample surfaces exhibit clearly different behavior which may affect the evaporation rates of the samples.

Time-series analysis was conducted to evaluate a particular section of the surface of a sterling silver sample during high-temperature exposure. This analysis allows a better understanding of the evaporation characteristics of the samples as well as any interaction between the copper-oxide particles and silver in the sample. Figure 29 illustrates a time-series of backscatter micrographs for a typical sterling silver sample. The main changes that can be seen on the surface of the sample are the migration and agglomeration of the copper-oxide particles at the surface; silver can also be seen to recede at the edges of some copper-oxide particles indicated in the images. This indicates that copper-oxide is volatile under SOFC operating conditions to act as an appropriate protective oxide in the cermet. Further analysis of the interior regions of the exposed sterling silver samples revealed the coarsening of copper-oxide particles beneath the surface of the sample, indicating that this coarsening behavior may be an intrinsic phenomenon related to copper-oxide when exposed to an oxidizing environment. Figure 30 illustrates an example of SEM backscatter imaging of a typical interior section of a sterling silver sample after high-temperature exposure.

Some basic analyses were conducted using the SEM micrographs from the exposure experiments. It was noted that the silver visible between the copper-oxide particles on the surface of the sterling silver samples exhibited a much higher stepdensity, number of observable steps per unit length, than was observed at the surface of 
the pure silver samples. Figure 31 shows the difference in step-density observed for each type of sample.

In Summary, based on data collected over the six-month evaporation experiment as well as microstructure changes observed using time-series SEM analysis, it appears that copper oxide may be too volatile for use as a protective oxide in a contacting cermet for a solid-oxide fuel cell. The data indicates that the sterling silver sample lost mass more rapidly than its pure silver counterpart, possibly due to the inability of the surface microstructure to reach the least favorable orientation to evaporation. SEM analysis showed a much higher step density for sterling silver than for pure silver after high temperature exposure, illustrating a clear difference in surface microstructure, which could also affect the sample's vaporization rate. Time-series SEM analysis also illustrated migration and agglomeration of copper-oxide particles both at and below the surface of the sterling silver samples indicating possible issues of volatility with regard to copper-oxide. Strontium-doped lanthanum manganite (LSM) and cerium-oxide will likely be the focus of future work as they may possess better properties with regard to electrical conductivity as well as stability under SOFC operating conditions than those observed in copper-oxide.

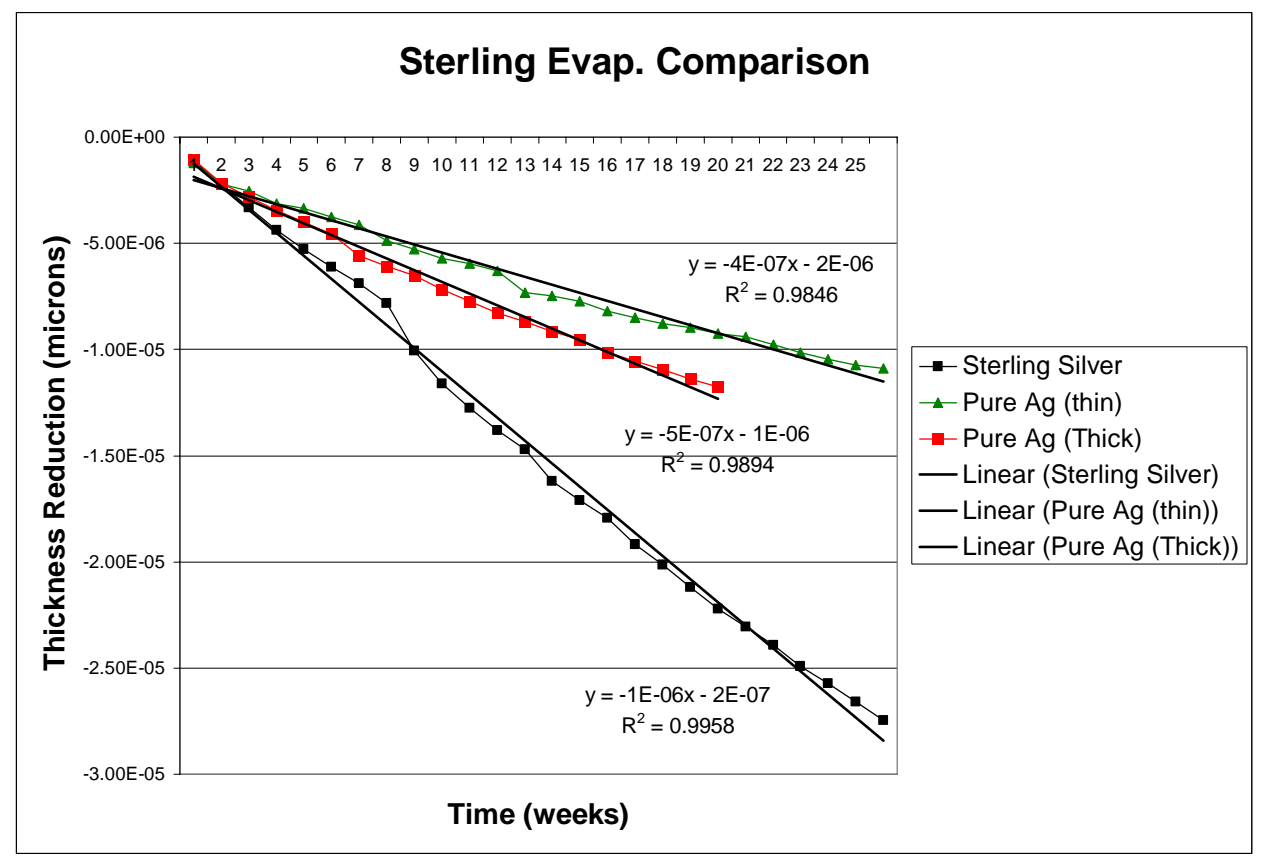

Figure 27. Comparison of thickness reductions for various silver samples. 
Sterling Silver
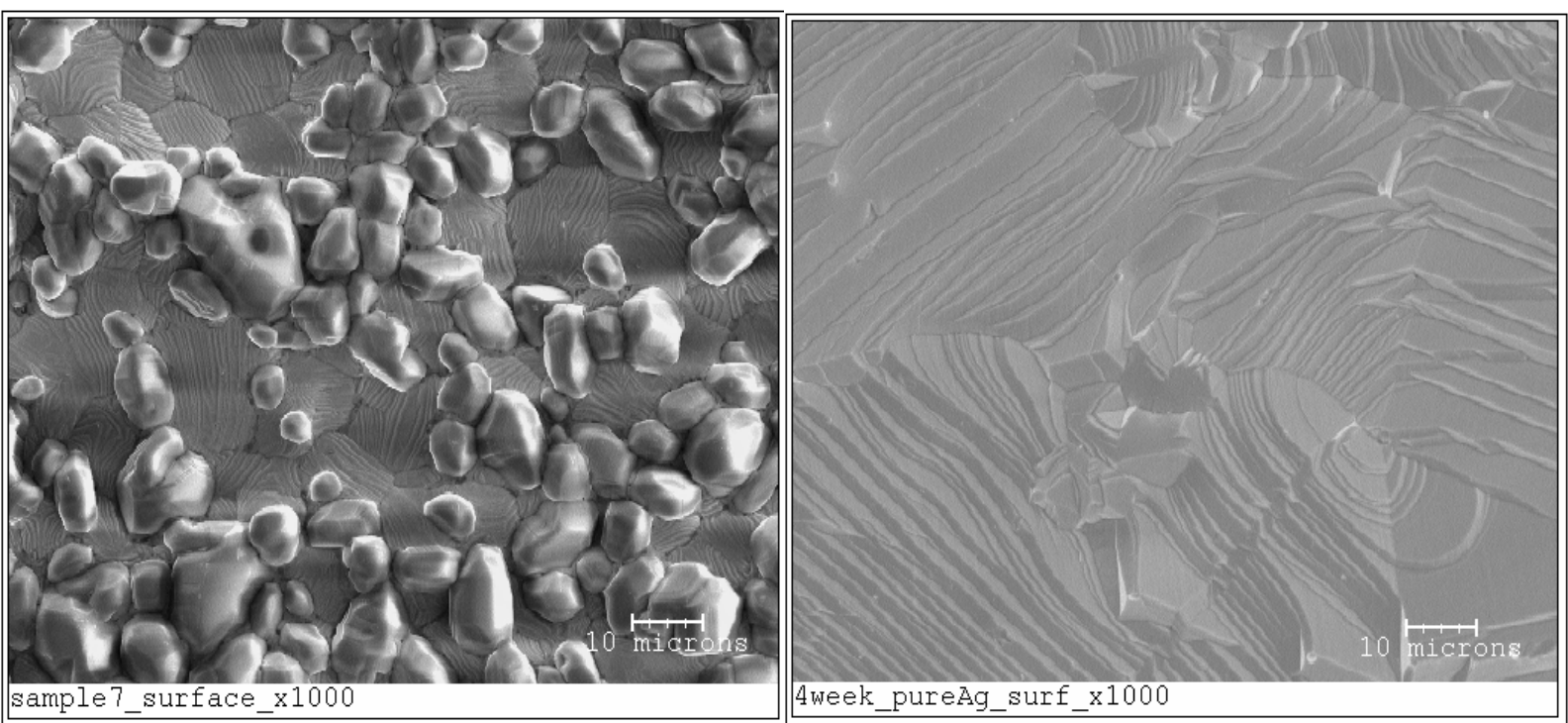

Figure 28. SEM micrograph comparison of sterling and pure silver samples after 3- week high-temperature exposure. 

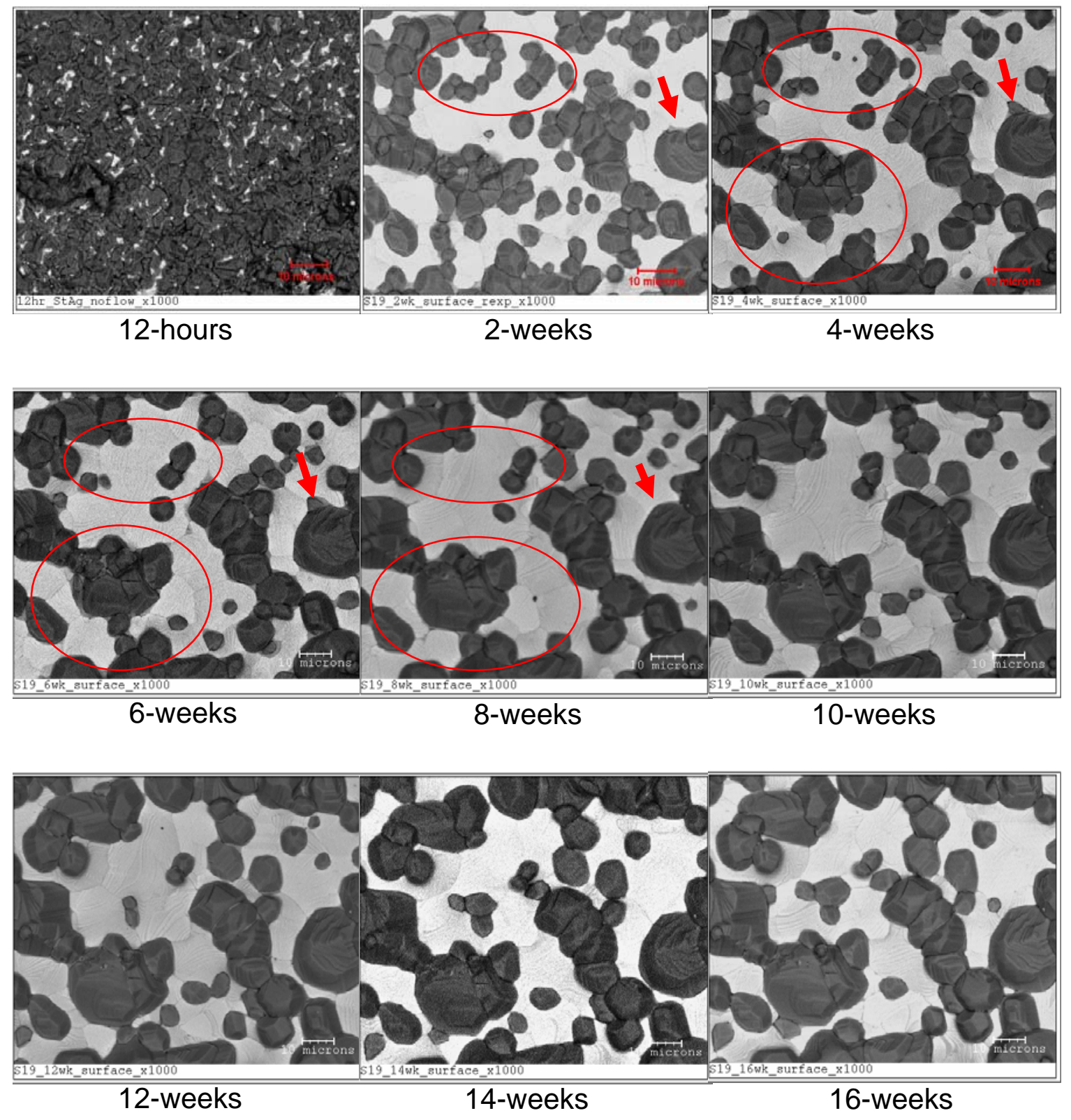

Figure 29. Time-series analysis of sterling silver surface during high-temperature. 


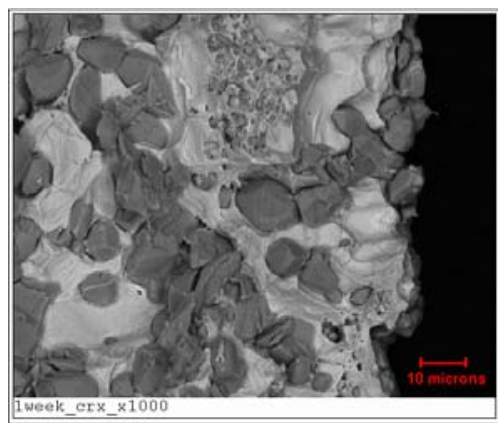

1-week

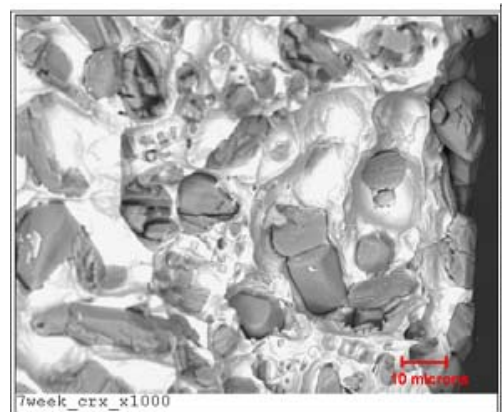

7-weeks

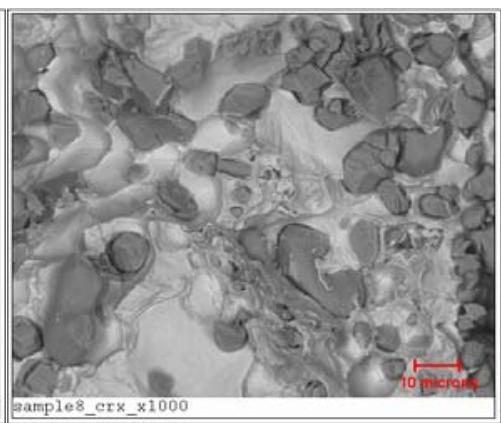

3-weeks

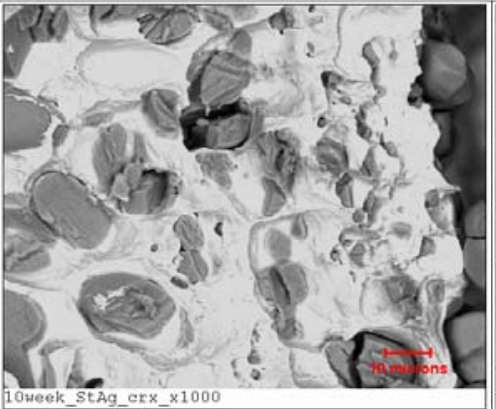

10-weeks

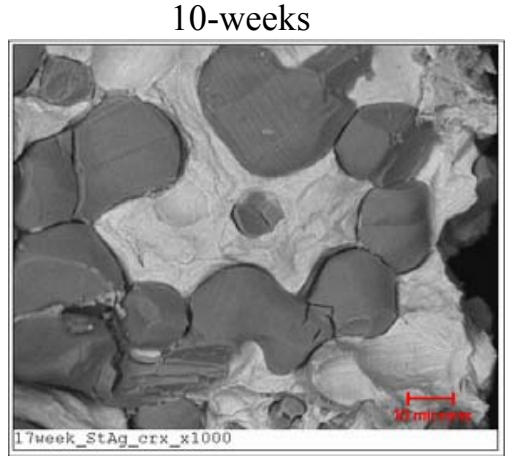

17-weeks

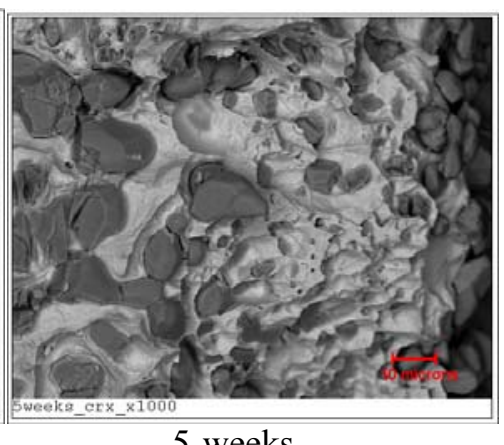

5-weeks

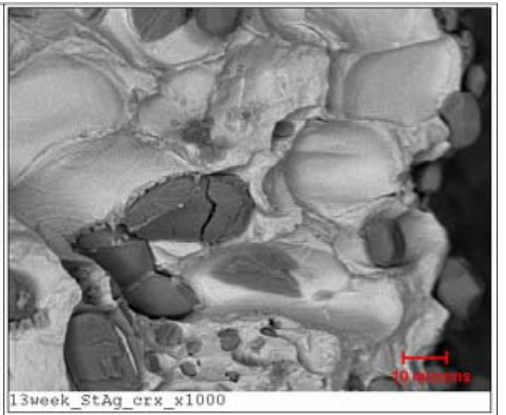

13-weeks

Figure 30. Fracture surfaces of sterling silver samples after high-temperature exposure. 


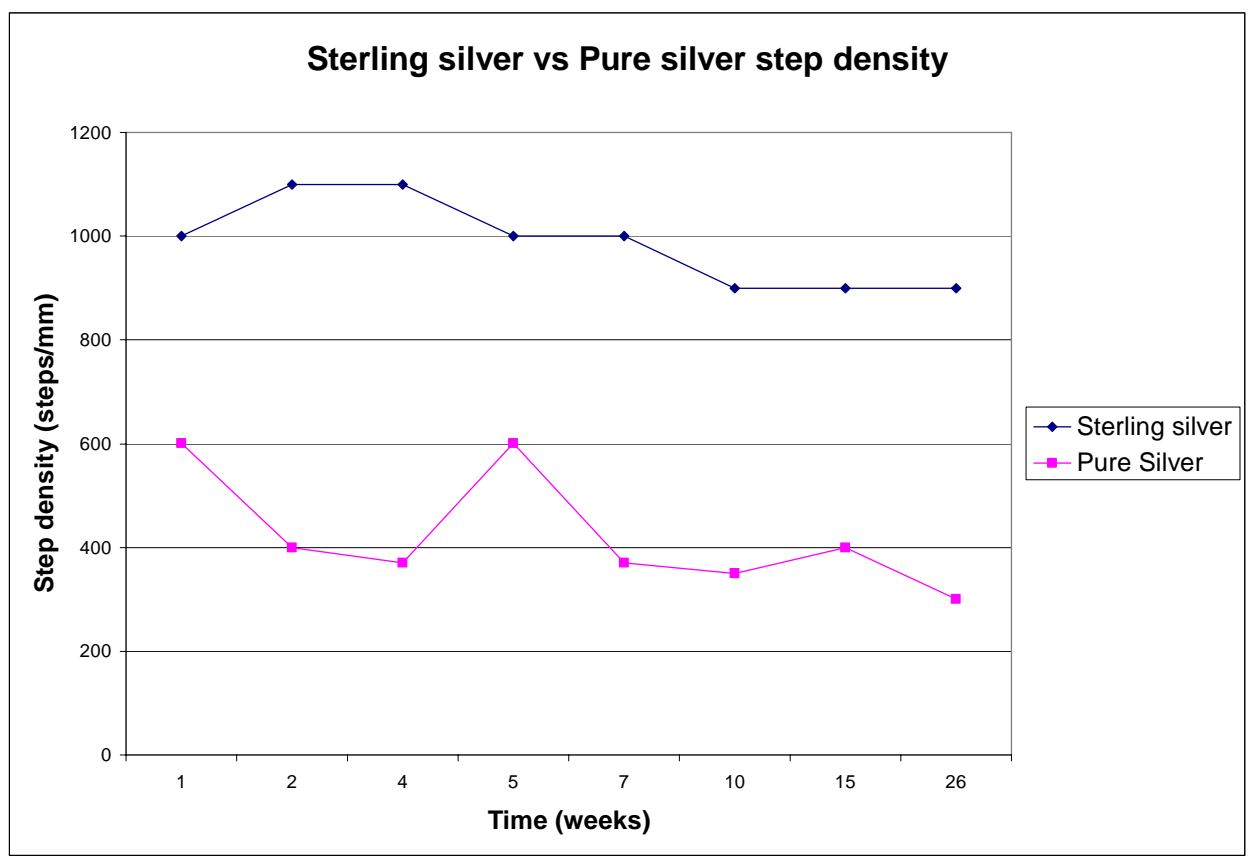

Figure 31. Step-densities for pure silver and sterling silver samples. 


\section{REFERENCES}

1. A. Vasinonta and J. L. Beuth, Eng. Fracture Mech., $\underline{68}, 843$ (2001).

2. R. A. Handoko, J. L. Beuth, G. H. Meier, F. S. Pettit, and M. J. Stiger, "Mechanisms for Interfacial Toughness Loss in Thermal Barrier Coating Systems," Durable Surfaces (D.R. Mumm, M.E. Walter, O. Popoola and W.O. Soboyejo, eds.), Proceedings of the Materials Division Symposium on Durable Surfaces, (2000) ASME International Mechanical Engineering Congress and Exposition, Orlando, November 2000, Trans Tech Publications, Switzerland, 2001, p. 165.

3. G. H. Meier and F. S. Pettit, "Fundamental Studies of the Durability of Materials for Interconnects in Solid Oxide Fuel Cells", Phase I Topical Report, DOE Award: DE FC26 02NT41578, June 30, 2003.

4. N. Dhanaraj, J. L. Beuth, G. H. Meier, F. S. Pettit, J. Hammer, and S. J. Laney, "Interfacial Fracture Testing to Evaluate, the Durability of SOFC Interconnect Alloys", Materials for the Hydrogen Economy (J. J. Petrovic, I. E. Anderson, T. M. Adams, G. Sandrock, C. F. Legzdins, J. W. Stevenson, and Z. G. Yang, eds.), Proc. Materials Science and Technology 2005, Pittsburgh, September 2005, pp 165-175. 
Appendix A 


\title{
The Oxidation of Ferritic Stainless Steels in Simulated Solid Oxide Fuel Cell Atmospheres
}

\author{
J. E. Hammer, S. J. Laney, R. W. Jackson, K. Coyne, F. S. Pettit, and G. H. Meier \\ Department of Materials Science and Engineering \\ University of Pittsburgh \\ Pittsburgh, PA
}

\begin{abstract}
The cyclic oxidation of a variety of chromia-forming ferritic stainless steels has been studied in the temperature range $700-900^{\circ} \mathrm{C}$ in atmospheres relevant to solid oxide fuel cell operation. The most detrimental environment at $800^{\circ} \mathrm{C}$ and $900^{\circ} \mathrm{C}$ was found to be air with $10 \%$ water vapor. This resulted in excessive oxide spallation or rapid scale growth. Impurities in the alloys, particularly $\mathrm{Al}$ and $\mathrm{Si}$, were found to have a significant effect on the oxidation behavior. Oxide growth was slow at $700^{\circ} \mathrm{C}$ but the higher Cr-content alloys were observed to form sigmaphase at this temperature. The sigma phase formation was accelerated by higher silicon contents and, remarkably, by the presence of water vapor in the exposure environment. Alloys containing Mn were observed to form an outer layer of $\mathrm{MnCr}_{2} \mathrm{O}_{4}$ over the chromia scale. The potential for this overlayer to suppress reactive evaporation of the chromia scales has been analyzed.
\end{abstract}

KEYWORDS: oxidation, ferritic steels, interconnects, oxide evaporation, sigma phase 


\section{INTRODUCTION}

Solid oxide fuel cells provide a potential way to generate electricity with high efficiency and low pollution. The operating principles of fuel cells have been known for over 100 years and low-temperature fuel cells provided the electric power on all the Gemini and Apollo spacecraft. However, fuel cells have not achieved widespread commercial use for a number of economic and technical reasons.

One of the most important technical challenges for planar solid oxide fuel cells, which operate in the temperature range $700-900^{\circ} \mathrm{C}$, is the design of interconnects (current collectors). These components, in addition to drawing off the electric current, must separate the anode compartment of one cell from the cathode compartment of the adjacent cell. This means that one side of an interconnect is exposed to the fuel, typically hydrogen or hydrocarbons in which the oxygen partial pressure is low, and the other side is exposed to the oxidant, which is typically air. The requirements for interconnects have been reviewed recently ${ }^{1-4}$. Interconnect material requirements include a variety of physical, chemical, and electrical properties. The optimal interconnect material would have the following properties:

1. Low electrical resistivity.

2. Impermeability to anode and cathode gases.

3. Stability in both anode and cathode gases under thermal cycling conditions.

4. Chemical compatibility with other cell components.

5. Close match in coefficient of thermal expansion with other components.

6. Good mechanical properties.

7. High thermal conductivity.

8. Ease of fabrication. 


\section{Low cost.}

Metallic interconnects are attractive in that they have favorable values of properties $2,6,7,8$, and 9. Metallic materials also have low electrical resistance but they react with the gases to form oxide layers, which generally have high electrical resistivity. Oxidation resistant alloys are designed to form one of three protective oxides: alumina, silica, or chromia. Of these the electrical resistivities of alumina and silica are much too high for interconnect applications. Exact values of the resistivities of oxides depend on numerous factors but approximate values of the resistivities of silica, alumina, and chromia at $800^{\circ} \mathrm{C}$ in air are presented in Table 1.

Chromia scales grow much faster than alumina or silica but the resistivity of chromia is sufficiently lower to allow chromia-forming alloys to be considered as a "compromise" as interconnects. The coefficient of thermal expansion of chromia-forming ferritic steels matches that of the ceramic components, particularly in the case of the common anode supported SOFCs. The oxidation behavior of this class of alloy under conditions relevant to SOFC operation is the subject of this paper.

\section{Previous Studies of Metallic Interconnect Materials}

A number of studies have been conducted on chromia-forming metallic interconnect materials, particularly with regard to their stability in the cathode and anode gases.

\section{Cathode Gas}

The cathode gas provides the oxidant for the cell and will generally consist of air. England and Vircar $^{5}$ oxidized thin foils of the commercial Ni-base alloys Inconel 625, Inconel 
718, Hastelloy X, and Haynes 230 in air under isothermal conditions at temperatures between 800 and $1100^{\circ} \mathrm{C}$. All the alloys formed scales consisting essentially of chromia and the apparent parabolic rate constants varied over more than an order of magnitude e.g. between $1 \times 10^{-15}$ and $2.8 \times 10^{-14} \mathrm{~g}^{2} / \mathrm{cm}^{4} \mathrm{~s}$ at $800^{\circ} \mathrm{C}$.

Quadakkers et $\mathrm{al}^{6}$ have studied chromium-based alloys since they have lower coefficients of thermal expansion than the nickel based alloys. The addition of a $\mathrm{Y}_{2} \mathrm{O}_{3}$ dispersion improved the mechanical strength and lowered the oxidation rates of the alloys. A significant problem with $\mathrm{Cr}$ (and chromia-forming alloys) which has been recognized for many years ${ }^{7}$ is the reactive evaporation of chromia scales. This is a particular problem in the cathode gas since the $\mathrm{CrO}_{3}$ partial pressure increases with oxygen partial pressure, as illustrated in Figure $1^{8}$. The volatile species are reduced at electrochemically active sites on the cathode during SOFC operation, which inhibits the required oxygen reduction ${ }^{9}$. Analysis of the $\mathrm{Cr}$ vapor species ${ }^{10}$ indicates water contents above about $0.01 \%$ in air result in partial pressures of $\mathrm{CrO}_{2}(\mathrm{OH})_{2}$ which exceed the partial pressure of $\mathrm{CrO}_{3}$. This will be discussed in more detail in a subsequent section of this paper.

A number of investigators have studied the behavior of ferritic stainless steels as interconnect materials since they have a good thermal expansion match with typical ceramic components of SOFCs. Huang et $\mathrm{al}^{11}$ studied the isothermal oxidation of ferritic $\mathrm{Fe}-26 \mathrm{wt} \% \mathrm{Cr}$ alloys in air reporting a $\mathrm{k}_{\mathrm{P}}$ of $8.8 \times 10^{-14} \mathrm{~g}^{2} / \mathrm{cm}^{4} \mathrm{~s}$ at $800^{\circ} \mathrm{C}$. Brylewski et al ${ }^{12}$ reported a similar value of $8.5 \times 10^{-14} \mathrm{~g}^{2} / \mathrm{cm}^{4} \mathrm{~s}$ for Fe-16 wt $\% \mathrm{Cr}$. Quadakkers et al ${ }^{13,14}$ have developed model alloys based on the philosophy of: 
i. Using La additions to slow the growth rate of the chromia scale and improve the adherence of the scale to the alloy.

ii. Making additions of $\mathrm{Ti}$ and $\mathrm{Mn}$ to form spinels on the chromia scale to reduce $\mathrm{CrO}_{3}$ evaporation.

iii. Maintaining Al and Si levels as low as possible to prevent the formation of electrically insulating alumina or silica layers.

(The last point is quite important in that many commercial Fe- and Ni-base alloys, which are nominally chromia-formers, contain sufficient $\mathrm{Al}$ and/or Si so that, under certain exposure conditions, alumina or silica can form between the chromia layer and the alloy.)

The work of Quadakkers et al has lead to the commercialization by ThyssenKrupp VDM of a ferritic alloy, Crofer 22 APU, specifically designed for fuel cell applications. Yang et al ${ }^{15}$ have reported the results of cursory studies of the oxidation behavior of this alloy.

The area specific resistance (ASR) was reported in Ref. 11 for scales formed during 24 hour exposures in air at $900^{\circ} \mathrm{C}$. The ASR measured at $900^{\circ} \mathrm{C}$ with $\mathrm{Ag}$ electrodes was on the order of $0.02 \Omega \mathrm{cm}^{2}$. Quadakkers et al ${ }^{13}$ performed in-situ measurements of the ASR of chromia scales forming at $800^{\circ} \mathrm{C}$ on one of the modified ferritic alloy alloys described above. The ASR (measured at $800^{\circ} \mathrm{C}$ ) after 100 hours of oxidation was approximately $0.01 \Omega \mathrm{cm}^{2}$ and increased to approximately $0.1 \Omega \mathrm{cm}^{2}$ after 8000 hours.

\section{Anode Gas}

The anode gas consists of the fuel (typically hydrogen or hydrocarbons) and the products of combustion (water vapor and, possibly, $\mathrm{CO}$ and $\mathrm{CO}_{2}$ ). England and Vircar ${ }^{16}$ oxidized thin 
foils of the commercial Ni-base alloys Inconel 625, Inconel 718, Hastelloy X, and Haynes 230 in hydrogen, which was saturated with water at $40^{\circ} \mathrm{C}$ under isothermal conditions at temperatures between 700 and $1100^{\circ} \mathrm{C}$. The growth rate of the chromia scales at $800^{\circ} \mathrm{C}$ were higher than those observed in $\operatorname{air}^{5}$ for the same alloys and the electrical resistance of the scales was higher than for those formed in air.

Quadakkers et al ${ }^{17-19}$ have studied pure $\mathrm{Cr}$ and yttria-dispersed $\mathrm{Cr}$ at 950 and $1000^{\circ} \mathrm{C}$ in $\mathrm{Ar} / \mathrm{H}_{2} / \mathrm{H}_{2} \mathrm{O}$ mixtures. They too observed larger mass gains in $\mathrm{H}_{2} / \mathrm{H}_{2} \mathrm{O}$ mixtures but correctly point out that this is the result of mass losses from $\mathrm{CrO}_{3}$ evaporation in air, which are minimal at the reduced oxygen partial pressures in $\mathrm{H}_{2} / \mathrm{H}_{2} \mathrm{O}$ mixtures. One rather surprising result of this study was that the chromia scales were substantially more adherent when formed in $\mathrm{H}_{2} / \mathrm{H}_{2} \mathrm{O}$ mixtures than in dry air. It is well documented that spallation of alumina scales is accelerated by water vapor ${ }^{20,21}$ so these results for chromia are in need of further study.

Quadakkers et al reported the chromia scales formed on ferritic stainless steels in simulated anode gas at $800^{\circ} \mathrm{C}$ were thinner than those formed in air $^{13,14}$. Brylewski et al ${ }^{12}$ reported similar values of $\mathrm{k}_{\mathrm{P}}$ for oxidation in $94 \mathrm{H}_{2} / 6 \mathrm{H}_{2} \mathrm{O}$ and air.

\section{Dual Atmosphere Exposures}

Yang et $\mathrm{al}^{22}$ observed a change in the oxide formed on stainless steels in air when a simulated anode gas was present on the opposite side of the specimen. They hypothesized that this is the result of $\mathrm{H}$ diffusing from the anode side and affecting the oxide growth on the cathode side. 
This paper presents results for the oxidation of ferritic stainless steels in single atmospheres which form a baseline for understanding oxidation in dual atmosphere conditions.

\section{EXPERIMENTAL}

\section{Cyclic Oxidation}

The cyclic oxidation of a range of ferritic stainless steels has been evaluated under a range of conditions pertinent to fuel cell operation. The alloys were: (Nominal compositions in $\mathrm{Wt} \%)$

- E-BRITE (Fe-26 Cr-1 Mo - $0.2 \mathrm{Si}$ )

- 26Cr Ferritic (Fe-26Cr-1-Mo-2Mn-4.5Ni-1Si-1Al)

- AL 453 (Fe-22 Cr-0.6 Al-0.3 Mn + 0.1Ce/La)

- Crofer22 APU (Fe-22Cr-0.5Mn-0.08 Ti-0.016P-0.06 La)

The exposure conditions included:

- $\mathrm{T}=900^{\circ} \mathrm{C}$ and $700^{\circ} \mathrm{C}$ (Limited experiments were performed at $800^{\circ} \mathrm{C}$ )

- One-Hour Cycles (45 min. hot, 15 min.cold)

- Atmospheres

- $\quad$ Dry Air (Simulated Cathode Gas)

- $\quad$ Air +0.1 atm $\mathrm{H}_{2} \mathrm{O}$ (Simulated Moist Cathode Gas)

- $\quad \mathrm{Ar} / \mathrm{H}_{2} / \mathrm{H}_{2} \mathrm{O}$ (Simulated Anode Gas)

$$
\left(p_{\mathrm{O}_{2}}=10^{-17} \text { atm at } 900^{\circ} \mathrm{C} \text { and } 10^{-20} \text { at } 700^{\circ} \mathrm{C}\right)
$$


The exposure apparatus used for these exposures is shown schematically in Figure 2.

\section{Specimen Characterization}

Following exposure the oxidation products and alloy microstructure were characterized using x-ray diffraction (XRD), scanning electron microscopy (SEM) and energy dispersive x-ray analysis (EDS).

\section{RESULTS AND DISCUSSION}

\section{Cyclic Oxidation at $900^{\circ} \mathrm{C}$}

The experiments at $900^{\circ} \mathrm{C}$ were designed as accelerated tests. The duration of the test was 2000 cycles, which corresponded to 1500 hours at temperature $\left(900^{\circ} \mathrm{C}\right)$. Based on the temperature dependence of the parabolic rate constants reported for oxidation of $\mathrm{Fe}-26 \mathrm{wt} \% \mathrm{Cr}$

in air ${ }^{11}$, exposure for 1500 hours at $900^{\circ} \mathrm{C}$ should result in a chromia scale thickness comparable to that formed after about 16,000 hours at $800^{\circ} \mathrm{C}$. Thus, if one can assume the same oxidation mechanisms at 800 and $900^{\circ} \mathrm{C}$, these experiments should simulate an exposure at $800^{\circ} \mathrm{C}$ for 16,000 hours of hot time. In the latter case 2000 cycles would correspond to the specimen being cycled to room temperature with a frequency of approximately twice per day. Since cyclic degradation can depend on cycle frequency, it is not clear how many cycles at $800^{\circ} \mathrm{C}$ would produce similar degradation. Correlation between the accelerated tests with operating conditions is an ongoing theme of this project.

The oxidation kinetics for exposure in dry air (simulated cathode gas) are presented in Figure 3. The mass gains for Crofer22 APU correspond to literature values for the isothermal 
oxidation of ferritic alloys in air ${ }^{11}$ while the mass gains for $\mathrm{Fe}-26 \mathrm{Cr}$ ferritic are somewhat smaller and those for $\mathrm{Al} 453$ are somewhat larger. The oxidation curves do not give evidence for substantial scale spallation. The results for duplicate specimens under all exposure conditions were in good agreement. Therefore, subsequent plots will present the average data for the two specimens in a single curve.

Figure 4 presents the corresponding oxidation kinetics in simulated anode gas. The mass gains for Fe-26 Cr ferritic and Crofer are similar and are similar to those reported for isothermal oxidation of ferritic alloys in hydrogen-water vapor atmospheres ${ }^{12}$. The mass gains for AL 453 are larger.

Figure 5 presents the oxidation kinetics in air containing $10 \%$ water vapor. This gas does not directly simulate a fuel cell atmosphere. However, with the use of air, there are the possibilities that the air has not been dried, small seal leakages occur, or hydrogen diffuses to the cathode side and reacts with oxygen; therefore, it is not unreasonable to anticipate that the cathode gas may contain water vapor in some situations. The mass changes for Fe-26Cr ferritic are similar to those in dry air. However, the mass gains are far larger for Crofer, and AL 453 than those observed in either of the other two atmospheres. These observations are consistent with measurements of oxide thickness (presented in Table 2) and metallographic observations to be described below. It is important to note that the simple analysis in the table can be compromised by both specimen deformation and internal oxidation, particularly in the case of Crofer, yielding significant differences between measured and calculated values.

Figure 6 presents cross-section micrographs of $\mathrm{Fe}-26 \mathrm{Cr}$ ferritic after exposures in all three atmospheres at $900^{\circ} \mathrm{C}$. The scales are similar and are consistent with the similar oxidation kinetics observed in the three environments. The external scale consists of $\mathrm{Cr}_{2} \mathrm{O}_{3}$ and there is a 
fine distribution of Al-rich precipitates in the alloy below the scale. Figure 7 shows more detail of the alloy/scale interface for Fe-26Cr. There is a substantial amount of silica at this interface. It is not clear if this phase was responsible for the lack of acceleration of scale growth for exposures in air $+10 \% \mathrm{H}_{2} \mathrm{O}$. However, it is believed that oxide spallation is primarily responsible for the thinner scales observed on $\mathrm{Fe} 26 \mathrm{Cr}$ in this atmosphere. Figure 8 shows a macroscopic surface photograph of Fe-26Cr ferritic after 847 cycles showing circular spalled areas. Other areas were also observed where there were circular areas of thin oxide, which appeared to have reformed in spalled areas on subsequent cycles. Spalling is also consistent with the data in Table 2. The experimental mass gain for Fe-26Cr Ferritic in wet air is substantially smaller than that calculated from the oxide thickness. The mass changes in air $+0.1 \mathrm{~atm} \mathrm{H}_{2} \mathrm{O}$ may also be influenced by evaporation of $\mathrm{CrO}_{2}(\mathrm{OH})_{2}$, as will be discussed below.

Figure 9 presents cross-section micrographs of Crofer after exposure in all three environments. The specimen exposed in dry air had a continuous layer of $\mathrm{MnCr}_{2} \mathrm{O}_{4}$ at the scale/gas interface with a chromia layer beneath. Figure 10 indicates some internal oxidation below the chromia layer. These oxides were found to be Al-rich, although $\mathrm{Al}$ is not listed as an intentional component of this alloy. The specimen exposed in wet air exhibited a very thick scale, which is consistent with the large mass gain in this atmosphere. However, $\mathrm{The} \mathrm{MnCr}_{2} \mathrm{O}_{4}$ is present as discontinuous particles at the scale/gas interface rather than as a continuous layer. Figure 11 shows a macroscopic photograph of a Crofer specimen oxidized in wet air. This specimen is severely warped, presumably because of the extensive oxidation. Specimens exposed in dry air and simulated anode gas did not exhibit this deformation. The specimen exposed in simulated anode gas showed very little $\mathrm{MnCr}_{2} \mathrm{O}_{4}$ at the scale/gas interface and the chromia scale appeared somewhat "friable". The micrograph of this specimen in Figure 10 also 
shows an inclusion running parallel to the rolling direction of the sheet. This was identified as a La-rich oxide. Similar inclusions, as well as Ti-nitrides were found throughout the as-received alloy.

Figures 12 and 13 present cross-section micrographs of AL 453 exposed in the three environments. The striking feature in all environments is the extensive internal oxidation of Al below the chromia scale. Table 2 indicates the measured mass gain of this alloy in all three environments is substantially larger than that calculated from the thickness of the external scale. The oxygen uptake in forming the internal oxides is responsible for this difference. An additional feature of this alloy is the appearance of a layer of metallic Fe-Cr between the internal oxidation zone and the external chromia scale. The origin of this layer has not yet been determined. One possibility is extrusion of metal out from the zone of internal oxidation as the alumina precipitates form. This phenomenon is discussed more fully below.

In summary, accelerated cyclic oxidation testing at $900^{\circ} \mathrm{C}$ has been investigated. The most detrimental environment was found to be air with $10 \%$ water vapor. This resulted in excessive oxide spallation from $\mathrm{Fe}-26 \mathrm{Cr}$ ferritic and rapid scale growth on Crofer22 APU and AL 453. Huczkowski et al. ${ }^{23}$ have explained the accelerated oxidation of Crofer as resulting from the internal oxidation of $\mathrm{Si}$ and $\mathrm{Al}$ causing metallic protrusions. This presumably increases the effective surface area of the alloy. However, Figure 9 does not indicate a significant difference in the amount of internal oxidation or metal protrusions between the specimens exposed in dry air and air plus water vapor. Therefore, it is not clear why the scale on Crofer grows faster in the presence of water vapor. 


\section{Cyclic Oxidation at $800^{\circ} \mathrm{C}$}

The accelerated oxide growth rate on Crofer at $900^{\circ} \mathrm{C}$, when exposed in air with $10 \%$ water vapor, prompted further investigation of this phenomenon at $800^{\circ} \mathrm{C}$. In addition to Crofer several other alloys were studied. These included JS-3, a model alloy (Fe-23Cr-0.39Mn-0.05Ti0.09La, wt $\%$ ), with Si and $\mathrm{Al}$ contents less than $0.01 \mathrm{wt} \%$, and a second heat of Crofer (termed "New Crofer") in which more care was used to reduce the Al and Si impurities, both provided by Dr. J. Quadakkers, Forschungszentrum, Jülich. E-brite and Fe-26Cr-Ferritic were also included in this experiment. The cyclic oxidation kinetics in air with $10 \%$ water vapor are presented in Figure 14. The Crofer from the original heat exhibited accelerated oxidation similar to that at $900^{\circ} \mathrm{C}$ whereas the Crofer from the second heat (with lower Si and Al impurities) and JS-3 did not exhibit this tendency. The $26 \mathrm{Cr}$ Ferritic and E-brite began to show mass losses after short times as a combined result of spallation and scale evaporation.

Figure 15 is a cross-section micrograph of Crofer after exposure for 2000 hours. It shows significant internal oxidation of $\mathrm{Al}$ and silica forming at the scale alloy interface. Figure 16 shows a cross-section of the purer Crofer from the second heat. There is substantially less internal oxidation but there is still a significant amount of metal protruding into the scale. Figure 17 shows a cross-section of JS-3. There is some internal oxidation but no metal protruding into

the scale. Huczkowski et al. ${ }^{23}$ observed most of the internal oxides to be $\mathrm{TiO}_{2}$. However, some of the particles in Figure 17 are alumina and silica.

\section{Cyclic Oxidation at $700^{\circ} \mathrm{C}$}

Figures 18,19 , and 20 show the mass change vs. exposure time for samples at $700^{\circ} \mathrm{C}$ in dry air, $\mathrm{Ar} / \mathrm{H}_{2} / \mathrm{H}_{2} \mathrm{O}$, and air +0.1 atm $\mathrm{H}_{2} \mathrm{O}$, respectively. In all cases, $\mathrm{AL} 453$ exhibited the 
largest mass gains, followed by Crofer and the $26 \mathrm{Cr}$ Ferritic alloy. In the moist air environment, the $26 \mathrm{Cr}$ alloy showed small initial mass gains, but began to lose mass after $\sim 400$ cycles.

Figure 21 presents cross-section micrographs of Fe-26Cr Ferritic after exposures in all three atmospheres at $700^{\circ} \mathrm{C}$. The scales are similar. The external scale consists of $\mathrm{Cr}_{2} \mathrm{O}_{3}$ and there is a fine distribution of Al-rich precipitates in the alloy below the scale and Si-rich particles are present at the scale/alloy interface. The experimental mass change for Fe-26Cr Ferritic in wet air was observed to go negative after about 400 cycles. As was the case of the $900^{\circ} \mathrm{C}$ experiments, the mass changes in air +0.1 atm $\mathrm{H}_{2} \mathrm{O}$ may be influenced by evaporation of $\mathrm{CrO}_{2}(\mathrm{OH})_{2}$, as will be discussed below. All of the Fe-26Cr specimens exposed at $700^{\circ} \mathrm{C}$ formed sigma-phase. The details of the formation of this undesirable brittle phase will be discussed in detail below.

Figure 22 presents cross-section micrographs of Crofer after exposure in all three environments. The specimen exposed in dry air had a layer of $\mathrm{MnCr}_{2} \mathrm{O}_{4}$ at the scale/gas interface with a chromia layer beneath although the layer was not as well developed as that at $900^{\circ} \mathrm{C}$. There was also formation of internal Al-rich oxides at this temperature and these oxides had a tendency to form into semi-continuous bands. Bands of Si-rich oxides formed at the alloy/chromia interface.

Figure 23 presents cross-section micrographs of AL 453 exposed in the three environments. In all environments there was extensive internal oxidation of Al below the chromia scale and these oxides formed virtually continuous films. Metallic regions were observed above the internal Al-oxides for the specimens exposed in air but were absent for exposures in SAG. 


\section{Oxide Evaporation}

A significant problem with $\mathrm{Cr}$ (and chromia-forming alloys), which has been recognized for many years ${ }^{7}$, is the reactive evaporation of chromia scales. The formation of $\mathrm{CrO}_{3}$ by the reaction

$$
\mathrm{Cr}_{2} \mathrm{O}_{3}(s)+\frac{3}{2} \mathrm{O}_{2}(g)=2 \mathrm{CrO}_{3}(g)
$$

becomes significant at high temperatures and high oxygen pressures. The oxygen pressure effect is illustrated in Fig. 1[8]. (In the presence of water vapor, the predominant evaporating species may become $\mathrm{CrO}_{2}(\mathrm{OH})_{2}$ whose partial pressure increases with increasing $\mathrm{H}_{2} \mathrm{O}$ partial pressure, as indicated in Figure $24^{10}$.) The evaporation of $\mathrm{CrO}_{3}$ results in the continuous removal of the protective $\mathrm{Cr}_{2} \mathrm{O}_{3}$ scale so the diffusive transport through it is rapid. The effect of the volatilization on the oxidation kinetics has been analyzed by Tedmon ${ }^{7}$. The instantaneous change in scale thickness is the sum of two contributions: thickening due to diffusion and thinning due to volatilization.

$$
\frac{d x}{d t}=\frac{k_{d}^{\prime}}{x}-k_{s}^{\prime}
$$

where $k_{d}^{\prime}$ is a constant describing the diffusive process and $k_{s}^{\prime}$ describes the rate of volatilization. This equation can be rearranged to yield 


$$
\frac{d x}{\left(\frac{k_{d}^{\prime}}{x}-k_{s}^{\prime}\right)}=d t
$$

which, upon integration, yields:

$$
\frac{-x}{k_{s}^{\prime}}-\frac{k_{d}^{\prime}}{k_{s}^{\prime 2}} \ln \left(k_{d}^{\prime}-k_{s}^{\prime} x\right)+C=t
$$

where $\mathrm{C}$ is an integration constant to be evaluated from the initial conditions. Taking $x=0$ at $t=0$

$$
t=\frac{k_{d}^{\prime}}{k_{s}^{\prime 2}}\left[-\frac{k_{s}^{\prime}}{k_{d}^{\prime}} x-\ln \left(1-\frac{k_{s}^{\prime}}{k_{d}^{\prime}} x\right)\right]
$$

Initially, when the diffusion through a thin scale is rapid, the effect of $\mathrm{CrO}_{3}$ volatilization is not significant but, as the scale thickens, the rate of volatilization becomes comparable and then equal to the rate of diffusive growth. This situation, paralinear oxidation, results in a limiting scale thickness, $x_{0}$, for which $\mathrm{d} x / \mathrm{d} t=0$. Setting this condition in equation 3 yields

$$
x_{o}=\frac{k_{d}^{\prime}}{k_{s}^{\prime}}
$$

This problem, which is more serious in rapidly flowing gases, is one of the major limitations on the high temperature use of $\mathrm{Cr}_{2} \mathrm{O}_{3}$ forming alloys and coatings. 
Evaporation is a particular problem in the cathode gas of solid oxide fuel cells (SOFCs) since the $\mathrm{CrO}_{3}$ partial pressure increases with oxygen partial pressure, as illustrated in Figure 1. The volatile species are reduced at electrochemically active sites on the cathode during SOFC operation, which inhibits the required oxygen reduction ${ }^{8}$. Analysis of the $\mathrm{Cr}$ vapor species ${ }^{10}$ indicates water contents above about $0.1 \%$ in air result in partial pressures of $\mathrm{CrO}_{2}(\mathrm{OH})_{2}$ which exceed the partial pressure of $\mathrm{CrO}_{3}$. Thus, maintaining the cathode gas as dry as possible is desirable.

Figures 1 and 24 are constructed for unit activities of $\mathrm{Cr}$ and $\mathrm{Cr}_{2} \mathrm{O}_{3}$, i.e. evaporation at high oxygen partial pressures occurs from pure chromia. However, examination of the equilibrium constant for reaction 1

$$
K_{1}=\frac{p_{\mathrm{CrO}_{3}}^{2}}{a_{\mathrm{Cr}_{2} \mathrm{O}_{3}} p_{\mathrm{O}_{2}}^{3 / 2}}
$$

shows that, for a fixed oxygen partial pressure, the partial pressure of $\mathrm{CrO}_{3}$ will decrease as the activity of chromia is reduced. Other things being equal, the evaporation rate should be directly proportional to the $\mathrm{CrO}_{3}$ partial pressure. Therefore, the presence of an outer oxide layer with reduced chromia activity could slow the scale evaporation. Coatings of $\mathrm{La}_{0.9} \mathrm{Sr}_{0.1} \mathrm{CrO}_{3}$ have been applied to ferritic alloys to limit $\mathrm{CrO}_{3}$ evaporation ${ }^{24}$.

The formation of a complex oxide over a chromia layer can also occur naturally during oxidation of some alloys. Spinels $\left(\mathrm{MCr}_{2} \mathrm{O}_{4}\right)$ have been observed to form over chromia scales growing on alloys containing the transition metals $\mathrm{Fe}, \mathrm{Ni}, \mathrm{Co}$, and $\mathrm{Mn}$. In some cases the spinels form before the chromia layer becomes continuous (transient oxidation) but in others the spinel 
forms by outward diffusion of the transition metal through the chromia layer. Outer layers containing Fe and Mn have been known to form on stainless steels for many years ${ }^{25}$. This is somewhat remarkable since the steel usually only contain about $1 \% \mathrm{Mn}$. The high mobility of Mn ions in chromia is also in agreement with theoretical studies ${ }^{26}$. Crystal field theory calculations of the difference in stabilization energies for cations on octahedral versus tetrahedral sites in the hexagonal oxide ion sublattice of chromia lead to the prediction that the mobility of divalent cations should increase in the order $\mathrm{Ni}^{2+}: \mathrm{Cu}^{2+}: \mathrm{Co}^{2+}: \mathrm{Fe}^{2+}: \mathrm{Mn}^{2+26}$. Figure 9 shows cross-sectional micrographs of Crofer 22 , which contains approximately $0.5 \mathrm{wt} \% \mathrm{Mn}$, after exposure at $900^{\circ} \mathrm{C}$ in dry air. An outer layer of $\mathrm{MnCr}_{2} \mathrm{O}_{4}$ can be observed at the scale/gas interface. This layer is particularly well developed for the specimen oxidized in dry air. The diffusion properties in the chromia will control the development of an outer spinel layer but the thermodynamic properties of the individual spinels will determine how much they decrease the activity of chromia. Tretjakow and Schmalzried ${ }^{27}$ performed an extensive study of the thermodynamic properties of the spinels of $\mathrm{Cr}$ with $\mathrm{Fe}, \mathrm{Ni}, \mathrm{Co}, \mathrm{Mg}$, and $\mathrm{Cu}$ over the temperature range 1000 to $1500 \mathrm{~K}$. They found that the standard Gibbs free energy change for the reaction

$$
\mathrm{MO}+\mathrm{Cr}_{2} \mathrm{O}_{3}=\mathrm{MCr}_{2} \mathrm{O}_{4}
$$

was very similar for all the spinels, which would suggest they all would be similarly effective in lowering the activity of chromia. Unfortunately, Mn was not included in this study and no data are listed for $\mathrm{MnCr}_{2} \mathrm{O}_{4}$ in the available thermodynamic data compilations [28]. In the present study the available thermodynamic data ${ }^{28}$ were used to catalog the properties of the spinels for 
which data are available and then to estimate the thermodynamic data for $\mathrm{MnCr}_{2} \mathrm{O}_{4}$. The data were used to estimate the partial pressure of $\mathrm{CrO}_{3}$ which would stand in equilibrium with each spinel at typical SOFC operating temperatures.

Thermodynamic Calculations

The standard Gibbs free energies of formation $\left(\Delta \mathrm{G}^{\circ}\right)$ for $\mathrm{Cr}_{2} \mathrm{O}_{3}, \mathrm{Al}_{2} \mathrm{O}_{3}, \mathrm{FeO}, \mathrm{NiO}, \mathrm{CoO}$, $\mathrm{MnO}, \mathrm{MgO}, \mathrm{FeCr}_{2} \mathrm{O}_{4}, \mathrm{NiCr}_{2} \mathrm{O}_{4}, \mathrm{CoCr}_{2} \mathrm{O}_{4}, \mathrm{MgCr}_{2} \mathrm{O}_{4}$, and $\mathrm{MnAl}_{2} \mathrm{O}_{4}$, were taken from reference 28 over the temperature range of interest 1000 to $1300 \mathrm{~K}$. Data for the reaction

$$
\mathrm{MnCr}_{2} \mathrm{O}_{4}+\mathrm{Al}_{2} \mathrm{O}_{3}=\mathrm{MnAl}_{2} \mathrm{O}_{4}+\mathrm{Cr}_{2} \mathrm{O}_{3}
$$

were reported at one temperature $(1373 \mathrm{~K})$ in reference 29 . This allowed the calculation of $\Delta \mathrm{G}^{\circ}$ for $\mathrm{MnCr}_{2} \mathrm{O}_{4}$ at $1373 \mathrm{~K}$ and estimates of the standard entropy change $\left(\Delta \mathrm{S}^{\circ}\right)$ for the reaction

$$
\mathrm{MnO}+\mathrm{Cr}_{2} \mathrm{O}_{3}=\mathrm{MnCr}_{2} \mathrm{O}_{4}
$$

were used to extrapolate the data to lower temperatures. Figure 25 shows $\Delta \mathrm{G}^{\circ}$ for reaction 8 for $\mathrm{Fe}, \mathrm{Ni}, \mathrm{Co}$, and $\mathrm{Mg}$. The data for $\mathrm{Fe}, \mathrm{Ni}$, and $\mathrm{Mg}$ are similar while the values for Co are somewhat more negative. Figure 26 presents the extrapolated data for Mn with the data for Ni as a basis for comparison. It is clear that $\mathrm{MnCr}_{2} \mathrm{O}_{4}$ is much more stable than the other spinels. The data from Figure 26 were used to calculate the equilibrium constant for reaction 10 which 
allowed the calculation of the activity of chromia, assuming saturation with MnO. Insertion of this value in equation 7 allowed calculation of the $\mathrm{CrO}_{3}$ partial pressure in equilibrium with $\mathrm{MnCr}_{2} \mathrm{O}_{4}$ in air. These values are plotted in Figure 27 along with those for unit activity of chromia and those for $\mathrm{LaCrO}_{3}$. (The latter were calculated by inserting the activity data for chromia in $\mathrm{LaCrO}_{3}$ from reference 10 and presumably refer to $\mathrm{La}_{2} \mathrm{O}_{3}$-saturation.) Figure 27 indicates that the $\mathrm{CrO}_{3}$ partial pressure and, therefore, evaporation rate from a chromia forming alloy could be reduced by two orders of magnitude if a layer of $\mathrm{MnO}$-saturated $\mathrm{MnCr}_{2} \mathrm{O}_{4}$ could be made to reliably form on the surface. A dense, artificially applied coating of $\mathrm{LaCrO}_{3}$ could, in principle, achieve another order of magnitude reduction.

It should be noted that the low values of $\mathrm{CrO}_{3}$ partial pressure indicated to be in equilibrium with $\mathrm{MnCr}_{2} \mathrm{O}_{4}$ and $\mathrm{LaCrO}_{3}$ in Figure 27 were calculated assuming $\mathrm{MnO}$ and $\mathrm{La}_{2} \mathrm{O}_{3}$ saturation, respectively. If layers of these compounds are present over a chromia film and begin to equilibrate with the underlying chromia the activity of chromia will increase and this will result in an increase in the $\mathrm{CrO}_{3}$ partial pressure. In the limit of the layers becoming $\mathrm{Cr}_{2} \mathrm{O}_{3}$ saturated the chromia activity will be unity and the $\mathrm{CrO}_{3}$ partial pressure will be given by the line for $\mathrm{Cr}_{2} \mathrm{O}_{3}$ in Figure 27. The rate and extent of such equilibration will be determined by transport in the outer layer as well as loss of $\mathrm{CrO}_{3}$ to the gas phase.

All of the above comments will also pertain to the reduction of the partial pressure of $\mathrm{CrO}_{2}(\mathrm{OH})_{2}$ over chromia-containing spinels in atmospheres containing water vapor. 
A number of the cross-section micrographs presented above indicate oxide-free metallic regions between the external chromia scale and a zone of internal oxidation. In the case of Crofer these regions were in the form of metallic globules protruding into the chromia scale, Figures $9,10,15,16$ and 22 . In the case of AL 453 a continuous, or nearly continuous, region formed below the chromia scale, Figures 12, 13, and 23.

These regions have formed by plastic flow of metal from the zone of internal oxidation because of stresses produced by the volume increase associated with the internal oxide particles. This phenomenon was apparently first reported by Darken ${ }^{30}$ for the internal oxidation of Ag-base alloys. It was studied in detail by Guruswamy et $\mathrm{al}^{31}$ who observed oxide-free Ag nodules on the surface of Ag-In alloys after internal oxidation in air at temperatures in the range $500-700^{\circ} \mathrm{C}$. It was proposed that dislocation pipe-diffusion controlled creep was the mode of stress relief and $\mathrm{Ag}$ transport. Similar observations have been made for the internal oxidation of $\mathrm{Ni}-\mathrm{Al}{ }^{32}$ and $\mathrm{Ni}-$ $\mathrm{Al}-\mathrm{Si}^{33,34}$ alloys. The amount of metal transported has been observed to be proportional to the volume of internal oxides produced. This is qualitatively the result of the current investigation in that there is a much larger oxide-free region for AL453 than Crofer which is consistent with a larger internal oxide volume for AL453. Such a region has apparently formed locally above a single large internal oxide particle in $26 \mathrm{Cr}$ Ferritic in Figure 21a. The previous observations of this phenomenon have generally been for the case of internal oxidation with no external scale formation. Guan et $\mathrm{al}^{35}$ studied the internal oxidation of Ni-Al-Si alloys under a NiO scale but did not report an oxide-free region for an oxidation temperature which had produced an oxidefree layer of $\mathrm{Ni}$ on the surface in the absence of an external scale. Huczkowski et $\mathrm{al}^{23}$ show several examples of metallic protrusions under chromia scales and comment that they can accelerate the oxidation rate. 


\section{$\underline{\text { Sigma-Phase Formation }}$}

Figure 21 shows that a second phase formed in the Fe-26 Cr ferritic alloy during exposure at $700^{\circ} \mathrm{C}$. Figure 28 shows the XRD pattern for a Fe-26 Cr ferritic specimen exposed for 2000 hours at $700^{\circ} \mathrm{C}$ in air +0.1 atm $\mathrm{H}_{2} \mathrm{O}$. Many of the peaks match with the chromia lines, the ferrite lines, or the sigma phase lines. This analysis proved that the sample did in fact contain the sigma phase.

The approximate compositions of the sigma phase and the ferrite were determined by EDS analysis. The results show significant increases in the amount of chromium $(\sim 35 \mathrm{wt} \%)$ and molybdenum (3-4 wt\%) in the sigma phase regions when compared to the initial composition. The surrounding ferrite is slightly depleted of those elements. The silicon content appears to not be greatly affected, with only a slight enrichment in the sigma phase.

Figure 29 shows E-brite that had been exposed in dry air at $700^{\circ} \mathrm{C}$ in 50 hour increments to 500 hours. Only a small amount of the sigma phase is seen after 200 hours, but with time, more is seen in each successive micrograph. The sigma-phase nucleates at intersections of ferrite grain boundaries with the free surface and propagates inward.

The micrographs of Fe-26 Cr ferritic exposed in dry air at $700^{\circ} \mathrm{C}$ in 50 hour increments up to 500 hours are shown in Figure 30. Again, there is only a small amount of sigma phase observed in the sample exposed for 200 hours. As the exposure time is increases, the amount of sigma phase also increases.

The sigma phase was observed only in E-brite and $\mathrm{Fe}-26 \mathrm{Cr}$ ferritic that had been exposed at $700^{\circ} \mathrm{C}$ in the three atmospheres that were studied. This can be explained if the Fe-Cr phase diagram is examined (see Figure 31). E-brite and Fe-26Cr ferritic both contain $26 \%$ chromium, 
which is more than the other alloys that were investigated. In Figure 31 , point $\mathrm{A}\left(700^{\circ} \mathrm{C}, 26 \%\right.$ chromium) is within the region where sigma forms, but point $\mathrm{B}\left(900^{\circ} \mathrm{C}, 26 \%\right.$ chromium $)$ is outside of this region. However, sigma phase formation is also strongly influenced by other elements in the alloy.

E-brite contains $1.0 \%$ molybdenum and $0.2 \%$ silicon. The Fe- $26 \mathrm{Cr}$ ferritic also contains $1.0 \%$ molybdenum, but has approximately $1.0 \%$ silicon. Additions of molybdenum and silicon will increase the rate of sigma phase formation ${ }^{36}$. However, $\mathrm{Fe}-26 \mathrm{Cr}$ ferritic contains considerably more silicon than E-brite. It has been reported that $\mathrm{Si}$ is extremely potent in accelerating sigmaphase formation ${ }^{37,38}$. This was indeed observed in that the formation of sigma-phase was more extensive in $\mathrm{Fe}-26 \mathrm{Cr}$ ferritic than E-brite. Tetsui et a ${ }^{38}$ have reported that a high purity $\mathrm{Fe}-30 \mathrm{Cr}$ alloy did not form sigma phase after 500 hours at $650^{\circ} \mathrm{C}$. Therefore, alloy purity may be an important avenue of study for production of high-Cr interconnects which are resistant to sigmaphase formation.

The development of the sigma phase was observed to be strongly influenced by the environment in which the specimens were exposed. Figure 32 shows a cross-section of $\mathrm{Fe}-26 \mathrm{Cr}$ ferritic which was exposed in dry air for 2000 cycles. The sigma phase, which nucleated at the surface, has penetrated a distance of approximately $50 \mu \mathrm{m}$ into the alloy. Figure 33 show a cross-section of the same alloy which was exposed in simulated anode gas for 2000 cycles. Sigma phase was observed to form all the way to the center of the $1 \mathrm{~mm}$ thick specimen. Similarly, Figure 34 shows the cross-section of a specimen exposed for 2000 cycles in air plus $10 \%$ water vapor. The sigma phase has formed all the way to the center of the specimen and the volume fraction of sigma phase appears to be even larger than that in Figure 33. Figures 33 and 34 suggest that the presence of water vapor is influencing the nucleation and/or growth of the 
sigma phase. This somewhat remarkable result of a metallic phase transformation being influenced by an external atmosphere is the subject of continuing experiments.

\section{SUMMARY AND CONCLUSIONS}

The cyclic oxidation of a variety of ferritic stainless steels has been studied in the temperature range $700-900^{\circ} \mathrm{C}$ in atmospheres relevant to solid oxide fuel cell operation. The most detrimental environment at $800^{\circ} \mathrm{C}$ and $900^{\circ} \mathrm{C}$ was found to be air with $10 \%$ water vapor. This resulted in excessive oxide spallation from Fe-26Cr ferritic and E-brite and rapid scale growth on Crofer22 APU and AL 453. The oxidation behavior of the alloys varied considerably based on the Cr concentration and the presence of other minor elements, whether added intentionally (e.g. reactive elements) or remaining as impurities (e.g.Si, Al).

Oxide growth was slow at $700^{\circ} \mathrm{C}$ but the higher $\mathrm{Cr}$-content alloys were observed to form sigma-phase at this temperature. The sigma phase formation was accelerated by higher silicon contents and, remarkably, by the presence of water vapor in the exposure environment.

Alloys containing $\mathrm{Mn}$ were observed to form an outer layer of $\mathrm{MnCr}_{2} \mathrm{O}_{4}$ over the chromia scale. The potential for this overlayer to suppress reactive evaporation of the chromia scales has been analyzed.

\section{ACKNOWLEDGEMENTS}

Financial support of this research by the U. S. Department of Energy through SECA Award No. DE-FC26-02NT41578 and contributions of alloys by P. Singh and Z. Yang (Pacific Northwest 
National Laboratory), J. Rakowski (ATI Allegheny Ludlum), and J. Quadakkers (Research Center - Jülich) are gratefully acknowledged.

\section{REFERENCES}

1. Z. G. Yang, J. W. Stevenson, and P. Singh, Adv. Mater. Proc., 161 (6), 34 (2003).

2. W. Z. Zhu and S. C. Deevi, Mater. Sci. Eng., A348, 227 (2003)

3. Z. G. Yang, K. S. Weil, D. M. Paxton, and J. W. Stevenson, J. Electrochem. Soc., 150, A1188 (2003).

4. W. J. Quadakkers, J. Piron-Abellan, V. Shemet and L. Singheiser, Materials At High Temperatures, $\underline{20}, 115$ (2003).

5. D. M. England and A. V. Virkar, J. Electrochem. Soc., 146, 3196 (1999).

6. W. J. Quadakkers, H. Greiner, and W. Köck, "Metals and Alloys for High Temperature SOFC Application”, Proc. First European Solid Oxide Fuel Cell Forum, U. Bossel, ed. 1994, p.525.

7. C. S. Tedmon, J. Electrochem. Soc., 113, 766 (1966).

8. N. Birks and G. H. Meier, Introduction to High Temperature Oxidation of Metals, Edward Arnold, London, 1983.

9. W. J. Quadakkers, H. Greiner, W. Köck, H. P Buchkremer, K. Hilpert, and D. Stöver, “The Chromium Base Metallic Bipolar plate - Fabrication, Corrosion and Cr Evaporation”, Proc. Second European Solid Oxide Fuel Cell Forum, B. Thorstensen, ed. 1996, p.297. 
10. K. Hilpert, D. Das, M. Miller, D. H. Peck, and R. Weiss, J. Electrochem. Soc., 143, 3642 (1996).

11. K. Huang, P. Y. Hou, and J. B. Goodenough, Solid State Ionics, 129, 237 (2000).

12. T. Brylewski, M. Nanko, T. Maruyama, and K. Przybylski, Solid State Ionics, $\underline{143}, 131$ (2001).

13. W. J. Quadakkers, T. Malkow, J. Pirón-Abellán, U. Flesch, V. Shemet, and L. Singheiser, "Suitability of Ferritic Steels for Application as Construction Materials for SOFC Interconnects", Proc. Fourth European Solid Oxide Fuel Cell Forum, A. J. McEvoy, ed. 2000, p.827.

14. J. Pirón-Abellán, V. Shemet, F. Tietz, L. Singheiser, W. J. Quadakkers, and A. Gil, "Ferritic Steel Interconnect for Reduced Temperature SOFC”, Proc. Solid Oxide Fuel Cells VII, H. Yokokawa and S. C. Singhal, eds., The Electrochem. Soc., 2001, p. 811.

15. Z. G. Yang, J. S. Hardy, M. S. Walker, G. Xia, S. P. Simner, and J. W. Stevenson, J. Electrochem. Soc., 151, A1825 (2004).

16. D. M. England and A. V. Virkar, J. Electrochem. Soc., 148, A330 (2001).

17. A.Gil, H. J. Penkalla, M. Hänsel, J. Norton, W. Köck, and W. J. Quadakkers, “The Oxidation Behaviour of Cr Based ODS Alloys in $\mathrm{H}_{2} / \mathrm{H}_{2} \mathrm{O}$ at $1000^{\circ} \mathrm{C}$ ', IX Conf. On Electron Microscopy of Solids, 1996, p. 441.

18. W. J. Quadakkers, J. F. Norton, J. Penkalla, U. Breuer, A. Gil, T. Rieck, and M. Hänsel, "SNMS and TEM Studies on the Oxidation Behaviour of Cr-Based ODS Alloys", Microscopy of Oxidation 3, S. B. Newcomb and J. A. Little, eds., Inst. of Materials, 1996, p.221. 
19. W. J. Quadakkers, J. F. Norton, S. Canetoli, K. Schuster, and A. Gil, "Hot Stage Microscopy of the Nucleation and Growth of Oxide Scales on Cr and Cr-Based Alloys", Microscopy of Oxidation 3, S. B. Newcomb and J. A. Little, eds., Inst. of Materials, 1996, p. 609.

20. R. Janakiraman, G. H. Meier, and F. S. Pettit, Metall. and Mater. Trans. A, $\underline{\text { 30A, } 2905}$ (1999).

21. M. C. Maris-Sida, G. H. Meier, and F. S. Pettit, Metall. and Mater. Trans. A, 34A, 2609 (2003).

22. Z. G. Yang, M.S. Walker, P. Singh and J. W. Stevenson, Electrochem. And Solid State Letters, $\underline{6}$, B35 (2003).

23. P. Huczkowski, N. Christiansen, V. Shemet, J. Piron-Abellan, L. Singheiser, and W. J. Quadakkers, J. Fuel Cell Sci. and Tech. (Trans. ASME), 1, 31 (2004).

24. C. Gindorf, L. Singheiser, and K. Hilpert, Steel Research, $\underline{72,} 528$ (2001).

25. J. E. Antill, K. A. Peakall, and J. B. Warburton, Corros. Sci., $\underline{8}, 689$ (1968).

26. M. G. C. Cox, B. McEnaney, and V. D. Scott, Phil. Mag., $\underline{26}$, 839 (1972).

27. J. D. Tretjakow and H. Schmalzried, Berichte der Bunsengesellschaft, $\underline{69}, 396$ (1965).

28. I. Barin, Thermochemical Data of Pure Substances, VCH Verlagsgesellschaft, Weinheim, 1993.

29. T. Jacob and G. N. K. Iyengar, J. Amer. Ceram. Soc., $\underline{69}, 487$ (1986).

30. L.S. Darken, Trans. Amer. Soc. Metals, $\underline{54}, 600$ (1961).

31. S. Guruswamy, S. M. Park, J. P. Hirth, and R. A. Rapp, Oxid. Metals, 26 , 77 (1986).

32. F. H. Stott and G. C. Wood, Mater. Sci. and Tech., $\underline{4}, 1072$ (1988).

33. H. C. Yi, S. W. Guan, W. W. Smeltzer, and A. Petric, Acta Metall. Mater., $\underline{42,} 981$ (1994). 
34. S. W. Guan, H. C. Yi, and W. W. Smeltzer, Oxid. Metals, $\underline{41}, 377$ (1994).

35. S. W. Guan, H. C. Yi, and W. W. Smeltzer, Oxid. Metals, 41, 389 (1994).

36. G. F. Vander Voort, "Embrittlement of Steels.” ASM Handbook, Volume 1, Properties and Selection: Irons, Steels, and High-Performance Alloys, Tenth Edition, ASM International, Materials Park, Ohio, 1990, p. 689 - 736.

37. I. Yano and K. Abiko, Phys. Stat. Sol., 160, 449 (1997).

38. T. Tetsui, M. Shinohara, and K. Abiko, Phys. Stat. Sol., 160, 459 (1997). 


\section{LIST OF FIGURES}

Figure 1. Vapor species diagram for the Cr-O system at $1250 \mathrm{~K}$ from Ref. 7.

Figure 2. Schematic diagram of the apparatus used for cyclic oxidation exposures with controlled partial pressures of water vapor.

Figure 3. Weight Change Vs Time plots for duplicate specimens of ferritic alloys exposed in dry air (simulated cathode gas) at $900^{\circ} \mathrm{C}$ using one-hour cycles.

Figure 4. Weight Change Vs Time plots for duplicate specimens of ferritic alloys exposed in $\mathrm{Ar} / \mathrm{H}_{2} / \mathrm{H}_{2} \mathrm{O}$ (simulated anode gas) at $900^{\circ} \mathrm{C}$ using one-hour cycles.

Figure 5. Weight Change Vs Time plots for duplicate specimens of ferritic alloys exposed in air $+10 \% \mathrm{H}_{2} \mathrm{O}$ (simulated moistened cathode gas) at $900^{\circ} \mathrm{C}$ using one-hour cycles.

Figure 6. Cross - section micrographs of $\mathrm{Fe}-26 \% \mathrm{Cr}$ ferritic after exposure in dry air (a.), air $+10 \% \mathrm{H}_{2} \mathrm{O}\left(\right.$ b.) , and $\mathrm{Ar} / \mathrm{H}_{2} / \mathrm{H}_{2} \mathrm{O}$ (c.) atmospheres at $900^{\circ} \mathrm{C}$.

Figure 7. Cross - section micrographs of $\mathrm{Fe}-26 \% \mathrm{Cr}$ ferritic after exposure in dry air (a.), air $+10 \% \mathrm{H}_{2} \mathrm{O}$ (b.), and $\mathrm{Ar} / \mathrm{H}_{2} / \mathrm{H}_{2} \mathrm{O}$ (c.) atmospheres at $900^{\circ} \mathrm{C}$ showing details of the alloy/scale interface. 
Figure 8. Macroscopic photograph showing freshly spalled and re-grown areas on the surface of Fe-26Cr Ferritic (847 cycles, 1/10atm $\mathrm{H}_{2} \mathrm{O}$ )

Figure 9. Cross - section micrographs of Crofer after exposure in dry air (a.), air $+10 \%$ $\mathrm{H}_{2} \mathrm{O}$ (b.), and $\mathrm{Ar} / \mathrm{H}_{2} / \mathrm{H}_{2} \mathrm{O}$ (c.) atmospheres at $900^{\circ} \mathrm{C}$

Figure 10. Cross-section micrographs of Crofer after exposure in dry air (a.), air $+10 \% \mathrm{H}_{2} \mathrm{O}$ (b.), and $\mathrm{Ar} / \mathrm{H}_{2} / \mathrm{H}_{2} \mathrm{O}$ (c.) atmospheres at $900^{\circ} \mathrm{C}$, showing more detail of the scales.

Figure 11. Macroscopic photograph of a Crofer specimen exposed in air $+10 \% \mathrm{H}_{2} \mathrm{O}$ showing extensive warpage.

Figure 12 Cross-section micrographs of AL453 after exposure in dry air (a.), air $+10 \% \mathrm{H}_{2} \mathrm{O}$ (b.), and $\mathrm{Ar} / \mathrm{H}_{2} / \mathrm{H}_{2} \mathrm{O}$ (c.) atmospheres at $900^{\circ} \mathrm{C}$.

Figure 13. Cross-section micrographs of AL453 after exposure in dry air (a.), air $+10 \% \mathrm{H}_{2} \mathrm{O}$ (b.), and $\mathrm{Ar} / \mathrm{H}_{2} / \mathrm{H}_{2} \mathrm{O}$ (c.) atmospheres at $900^{\circ} \mathrm{C}$, showing more detail of the scales.

Figure 14. Weight Change Vs Time plots for duplicate specimens of ferritic alloys exposed in air $+10 \% \mathrm{H}_{2} \mathrm{O}$ (simulated moistened cathode gas) at $800^{\circ} \mathrm{C}$ using one-hour cycles. 
Figure 15. Cross-section micrograph of Crofer after exposure in air $+0.1 \mathrm{~atm} \mathrm{H}_{2} \mathrm{O}$ for 2000 hours at $800^{\circ} \mathrm{C}$.

Figure 16. Cross-section micrograph of "New Crofer" after exposure in air $+0.1 \mathrm{~atm} \mathrm{H}_{2} \mathrm{O}$ for 2000 hours at $800^{\circ} \mathrm{C}$.

Figure 17. Cross-section micrograph of JS-3 after exposure in air $+0.1 \mathrm{~atm} \mathrm{H}_{2} \mathrm{O}$ for 2000 hours at $800^{\circ} \mathrm{C}$.

Figure 18. Weight Change Vs Time plots for duplicate specimens of ferritic alloys exposed in dry air (simulated cathode gas) at $700^{\circ} \mathrm{C}$ using one-hour cycles.

Figure 19. Weight Change Vs Time plots for duplicate specimens of three ferritic alloys exposed in $\mathrm{Ar} / \mathrm{H}_{2} / \mathrm{H}_{2} \mathrm{O}$ (simulated anode gas) at $700^{\circ} \mathrm{C}$ using one-hour cycles.

Figure 20. Weight Change Vs Time plots for duplicate specimens of ferritic alloys exposed in air $+10 \% \mathrm{H}_{2} \mathrm{O}$ (simulated moistened cathode gas) at $700^{\circ} \mathrm{C}$ using one-hour cycles.

Figure 21. Cross - section micrographs of $\mathrm{Fe}-26 \% \mathrm{Cr}$ ferritic alloy after exposure in atmospheres of dry air (a.), $\mathrm{Ar} / \mathrm{H}_{2} / \mathrm{H}_{2} \mathrm{O}$ (b.), and air $+10 \% \mathrm{H}_{2} \mathrm{O}$ (c.) for 2000 one hour cycles at $700^{\circ} \mathrm{C}$. 
Figure 22. Cross - section micrographs of Crofer 22APU after exposure in atmospheres of dry air (a.), $\mathrm{Ar} / \mathrm{H}_{2} / \mathrm{H}_{2} \mathrm{O}$ (b.), and air $+10 \% \mathrm{H}_{2} \mathrm{O}$ (c.) for 2000 one hour cycles at $700^{\circ} \mathrm{C}$.

Figure 23. Cross - section micrographs of AL 453 after exposure in atmospheres of dry air (a.), $\mathrm{Ar} / \mathrm{H}_{2} / \mathrm{H}_{2} \mathrm{O}$ (b.), and air $+10 \% \mathrm{H}_{2} \mathrm{O}$ (c.) for 2000 one hour cycles at $700^{\circ} \mathrm{C}$.

Figure 24 Plot showing the effect of water vapor on the volatility of $\mathrm{Cr}_{2} \mathrm{O}_{3}$ at $950^{\circ} \mathrm{C}$ after Ref. [10].

Figure 25 Standard free energy as a function of temperature changes for the reaction of transition metal oxides with chromia to form spinel.

Figure 26 Standard free energy changes for the reactions of $\mathrm{NiO}$ and $\mathrm{MnO}$ with chromia to form the respective chromates. (The two lines for $\mathrm{MnCr}_{2} \mathrm{O}_{4}$ were obtained by using two different techniques for estimating $\Delta \mathrm{S}^{\circ}$.)

Figure 27. Partial pressures of $\mathrm{CrO}_{3}$ in equilibrium with $\mathrm{Cr}_{2} \mathrm{O}_{3}, \mathrm{La}_{2} \mathrm{O}_{3}$-saturated $\mathrm{LaCrO}_{3}$, and $\mathrm{MnO}$-saturated $\mathrm{MnCr}_{2} \mathrm{O}_{4}$ as a function of temperature.

Figure 28. X-ray diffraction pattern for $26 \mathrm{Cr}$ Ferritic alloy exposed at $700^{\circ} \mathrm{C}$ in air $+0.1 \mathrm{~atm}$ $\mathrm{H}_{2} \mathrm{O}$ for 2000 hours. 
Figure 29. Cross-sections of E-brite exposed at $700^{\circ} \mathrm{C}$ in dry air in 50 hour increments after a) 200 hours, b) 250 hours, c) 300 hours, d) 350 hours, e) 400 hours, f) 450 hours, and g) 500 hours.

Figure 30. Cross-sections of $26 \mathrm{Cr}$ Ferritic exposed at $700^{\circ} \mathrm{C}$ in dry air in 50 hour increments after a) 200 hours, b) 250 hours, c) 300 hours, d) 350 hours, e) 400 hours, f) 450 hours, and g) 500 hours.

Figure 31. The Fe-Cr phase diagram showing regions in which $\sigma$-phase can form.

Figure 32. Cross-section of $26 \mathrm{Cr}$ Ferritic exposed at $700^{\circ} \mathrm{C}$ in dry air for 2000 hours showing $\sigma$-phase only formed near the surface.

Figure 33. Cross-section of $26 \mathrm{Cr}$ Ferritic exposed at $700^{\circ} \mathrm{C}$ in $\mathrm{Ar} / \mathrm{H}_{2} / \mathrm{H}_{2} \mathrm{O}$ for 2000 hours showing $\sigma$-phase formed throughout the cross-section.

Figure 34. Cross-section of $26 \mathrm{Cr}$ Ferritic exposed at $700^{\circ} \mathrm{C}$ in air $+0.1 \mathrm{~atm} \mathrm{H}_{2} \mathrm{O}$ for 2000 hours showing $\sigma$-phase formed throughout the cross-section. 
Table 1 Approximate Electrical Resistivities of Oxides in Air at $800^{\circ} \mathrm{C}$.

\begin{tabular}{c|c}
\hline Oxide & Resistivity $\left(\Omega^{\star} \mathrm{cm}^{2}\right)$ \\
\hline $\mathrm{SiO}_{2}$ & $10^{6}$ \\
$\mathrm{Al}_{2} \mathrm{O}_{3}$ & $10^{8}$ \\
$\mathrm{Cr}_{2} \mathrm{O}_{3}$ & $10^{2}$ \\
\hline
\end{tabular}


Table 2: $\quad$ Comparison of oxide thicknesses and weight gains per area for three ferritic alloys exposed at $900^{\circ} \mathrm{C}$ in $\mathrm{Ar} / \mathrm{H}_{2} / \mathrm{H}_{2} \mathrm{O}$, air, and air $+10 \% \mathrm{H}_{2} \mathrm{O}$

\begin{tabular}{c|c|c|c|c|c}
\hline Alloy & Atmosphere & Time $(\mathrm{hr})$ & $\begin{array}{c}\text { Average Oxide } \\
\text { Thickness }(\mu \mathrm{m})\end{array}$ & $\begin{array}{c}\text { Calculated } \Delta \mathrm{m} / \mathrm{A} \\
\left(\mathrm{mg} / \mathrm{cm}^{2}\right)\end{array}$ & $\begin{array}{c}\text { Measured } \Delta \mathrm{m} / \mathrm{A} \\
\left(\mathrm{mg} / \mathrm{cm}^{2}\right)\end{array}$ \\
\hline Crofer & Dry Air & 2000 & 8 & 1.3201 & 2.1916 \\
Crofer & Air +0.1 atm $\mathrm{H}_{2} \mathrm{O}$ & 2000 & 13.5 & 2.2276 & 1.9964 \\
Crofer & Ar $/ \mathrm{H}_{2} / \mathrm{H}_{2} \mathrm{O}$ & 2005 & 20 & 3.3001 & 11.2230 \\
AL 453 & Dry Air & 2000 & 8.75 & 1.4444 & 2.5033 \\
$\mathrm{AL} \mathrm{453}$ & Air +0.1 atm $\mathrm{H}_{2} \mathrm{O}$ & 2000 & 7.5 & 1.2375 & 1.0790 \\
$\mathrm{AL} \mathrm{453}$ & Ar/ $\mathrm{H}_{2} / \mathrm{H}_{2} \mathrm{O}$ & 2005 & 11.5 & 1.8976 & 0.7079 \\
$\mathrm{Fe}-26 \mathrm{Cr}$ & Dry Air & 2000 & 4.5 & 0.7425 & 3.4825 \\
$\mathrm{Fe}-26 \mathrm{Cr}$ & Air $+0.1 \mathrm{~atm} \mathrm{H}_{2} \mathrm{O}$ & 2000 & 6 & 0.9900 & 3.0840 \\
$\mathrm{Fe}-26 \mathrm{Cr}$ & Ar/ $\mathrm{H}_{2} / \mathrm{H}_{2} \mathrm{O}$ & 2005 & 8.5 & 1.4025 & 6.1166 \\
\hline
\end{tabular}




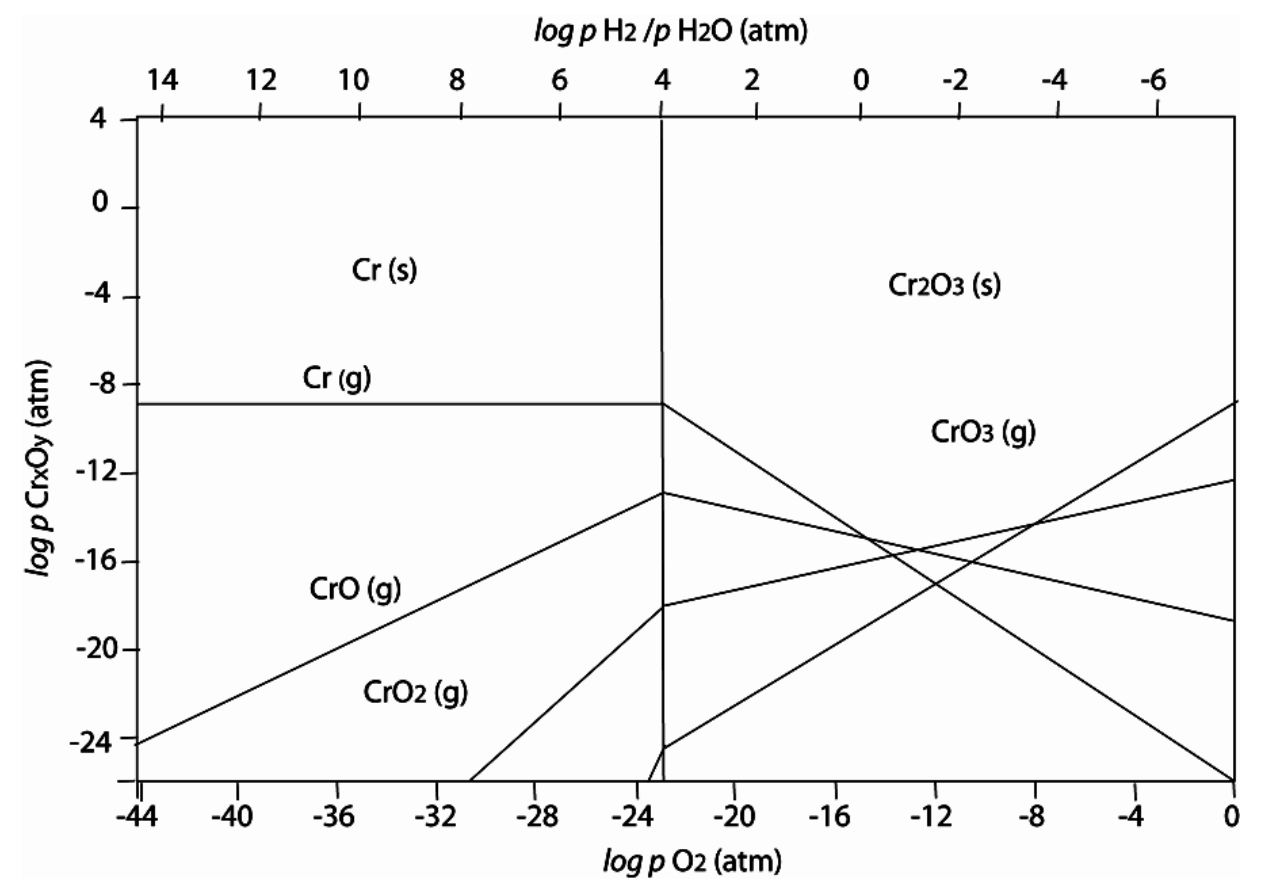

Figure 1. Vapor species diagram for the Cr-O system at $1250 \mathrm{~K}$ from Ref. 7. 

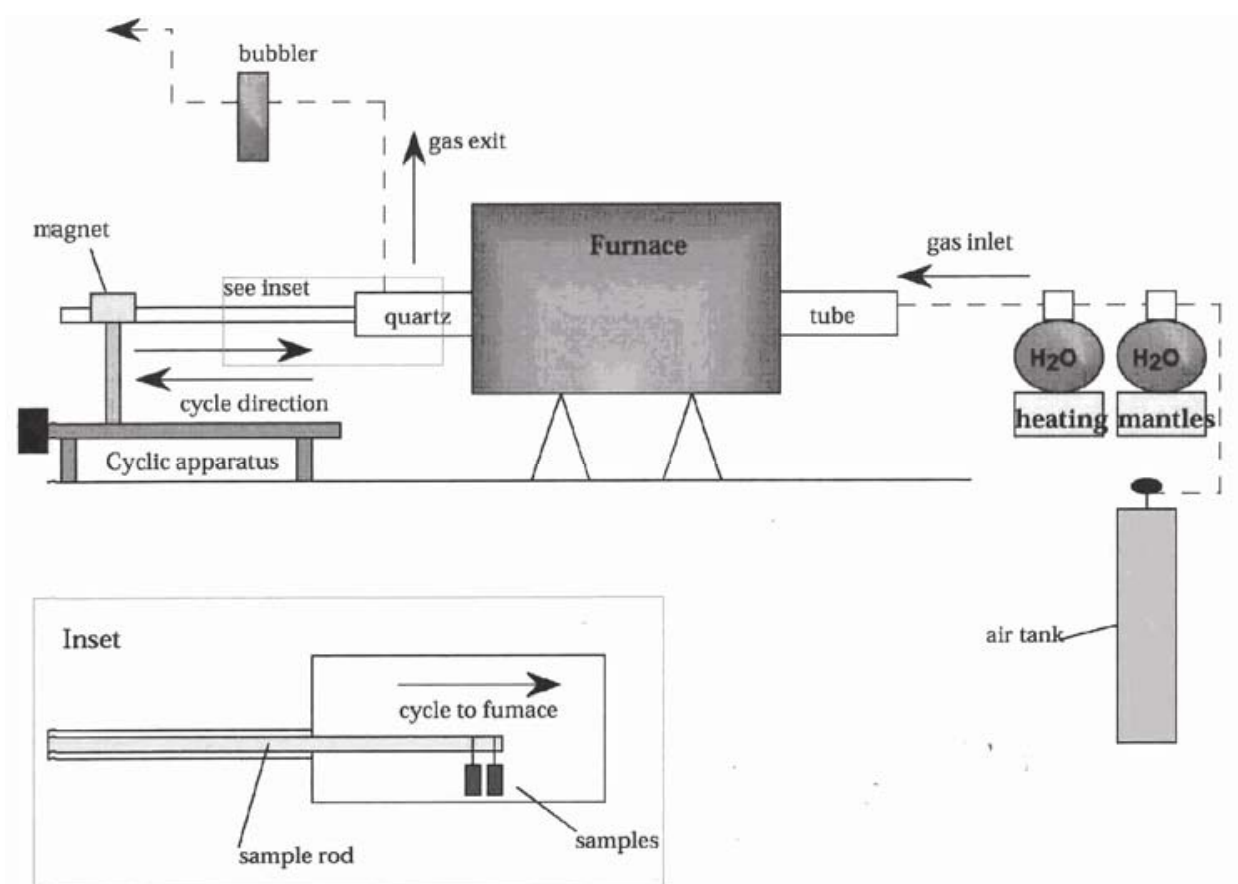

Figure 2 Schematic diagram of the apparatus used for cyclic oxidation exposures with controlled partial pressures of water vapor. 


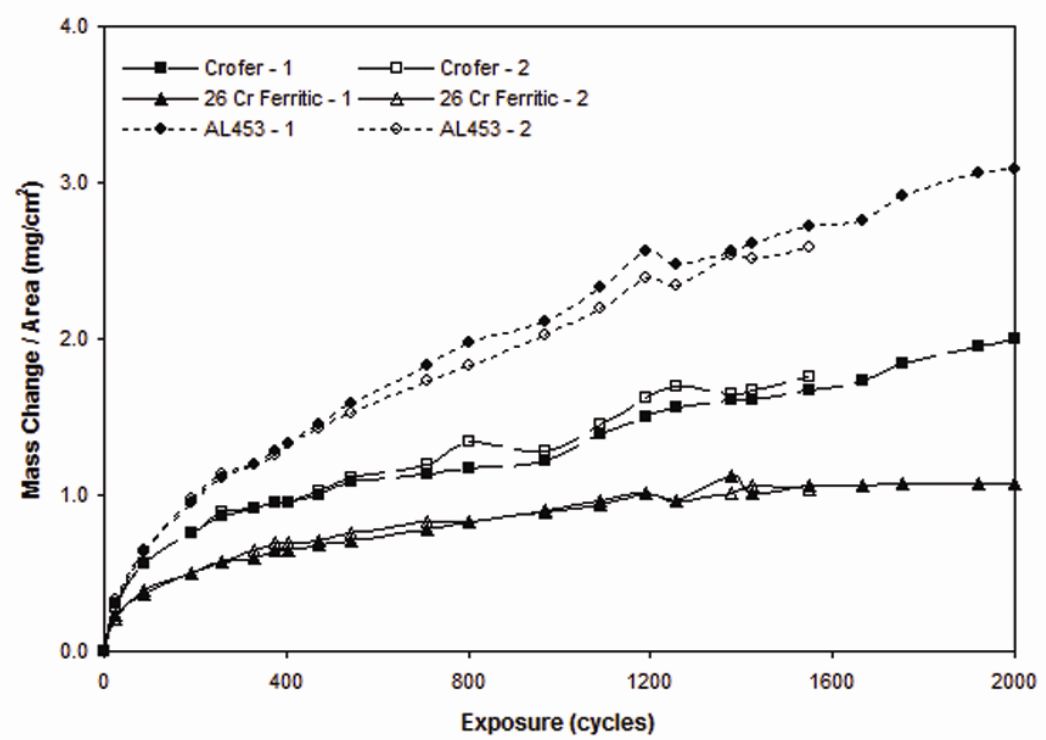

Figure 3. Weight Change Vs Time Plots for duplicate specimens for ferritic alloys exposed in dry air (simulated cathode gas) at $900^{\circ} \mathrm{C}$ using one - hour cycles. 


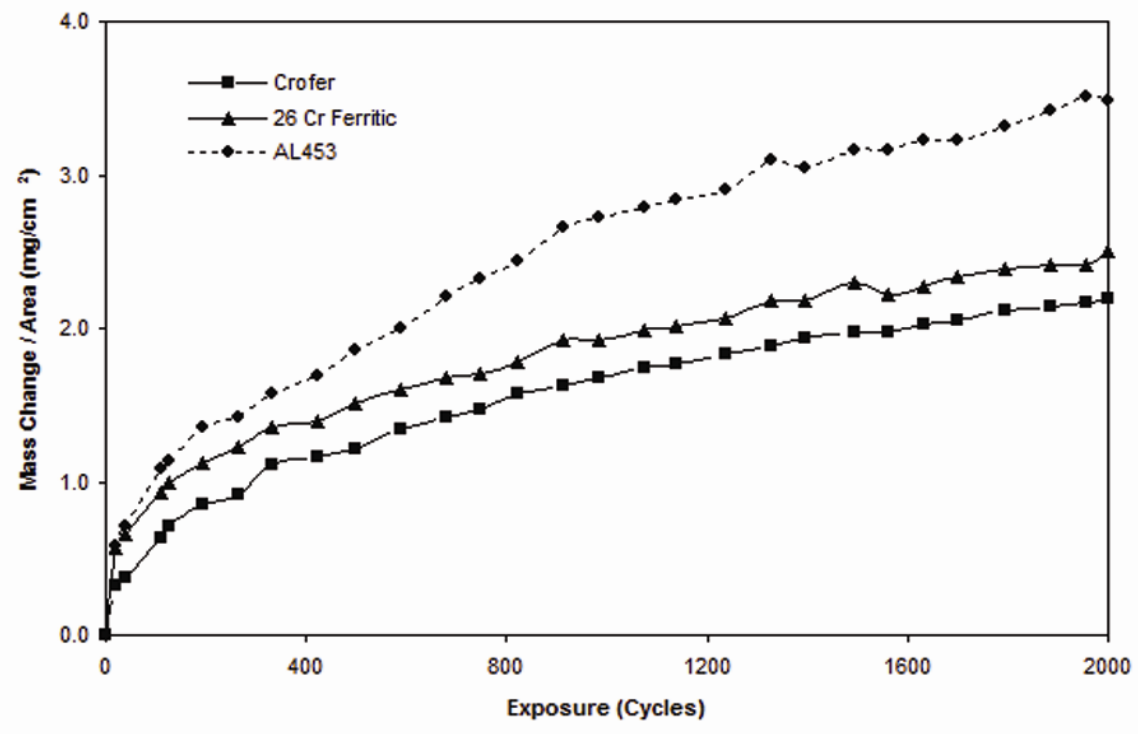

Figure 4. Weight Change Vs Time plots for duplicate specimens of ferritic alloys exposed in $\mathrm{Ar} / \mathrm{H}_{2} / \mathrm{H}_{2} \mathrm{O}$ (simulated anode gas) at $900^{\circ} \mathrm{C}$ using one - hour cycles. 


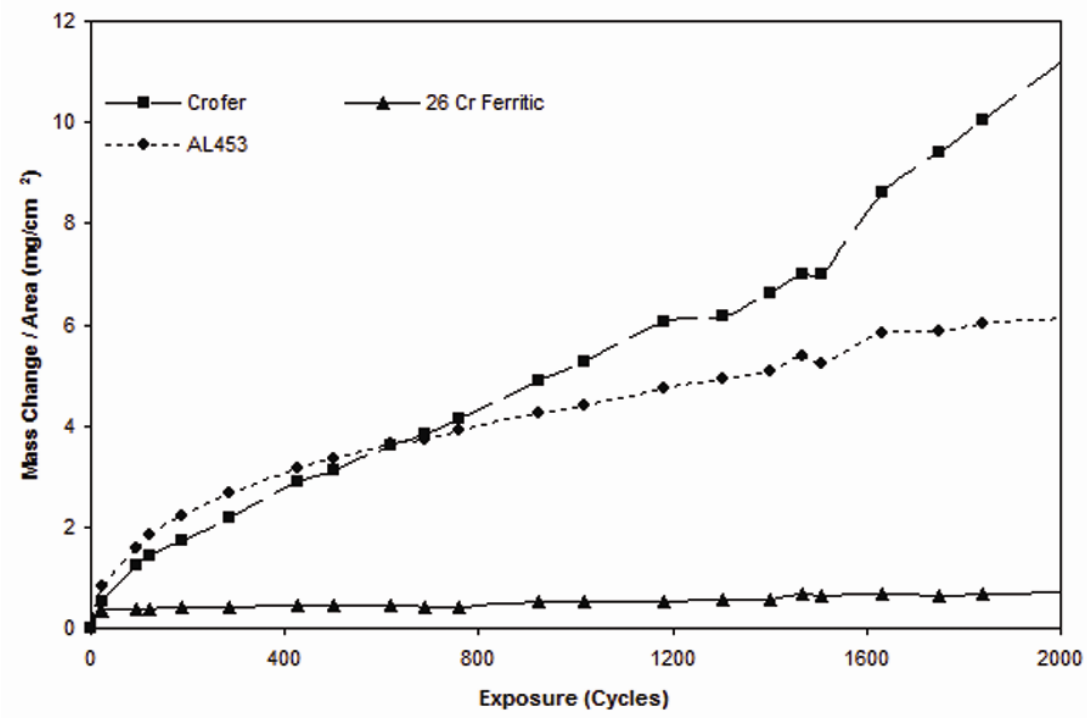

Figure 5. Weight Change Vs Time plots for duplicate specimens of ferritic alloys exposed in air $+10 \% \mathrm{H}_{2} \mathrm{O}$ (simulated moistened cathode gas) at $900^{\circ} \mathrm{C}$ using one - hour cycles. 

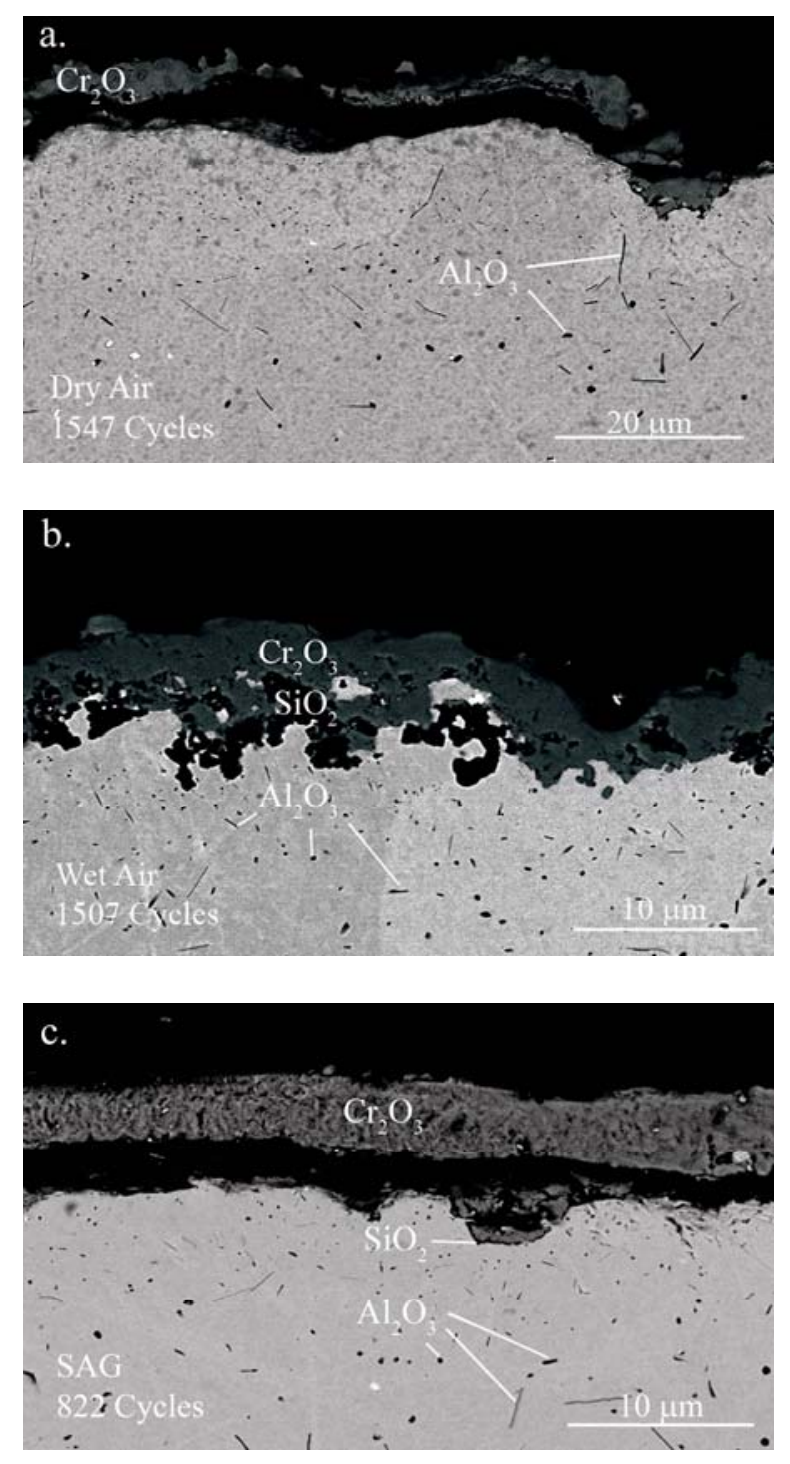

Figure 6. Cross - section micrographs of $\mathrm{Fe}-26 \% \mathrm{Cr}$ ferritic after exposure in dry air (a.), air + $10 \% \mathrm{H}_{2} \mathrm{O}$ (b.), and $\mathrm{Ar} / \mathrm{H}_{2} / \mathrm{H}_{2} \mathrm{O}$ (c.) atmospheres at $900^{\circ} \mathrm{C}$. 

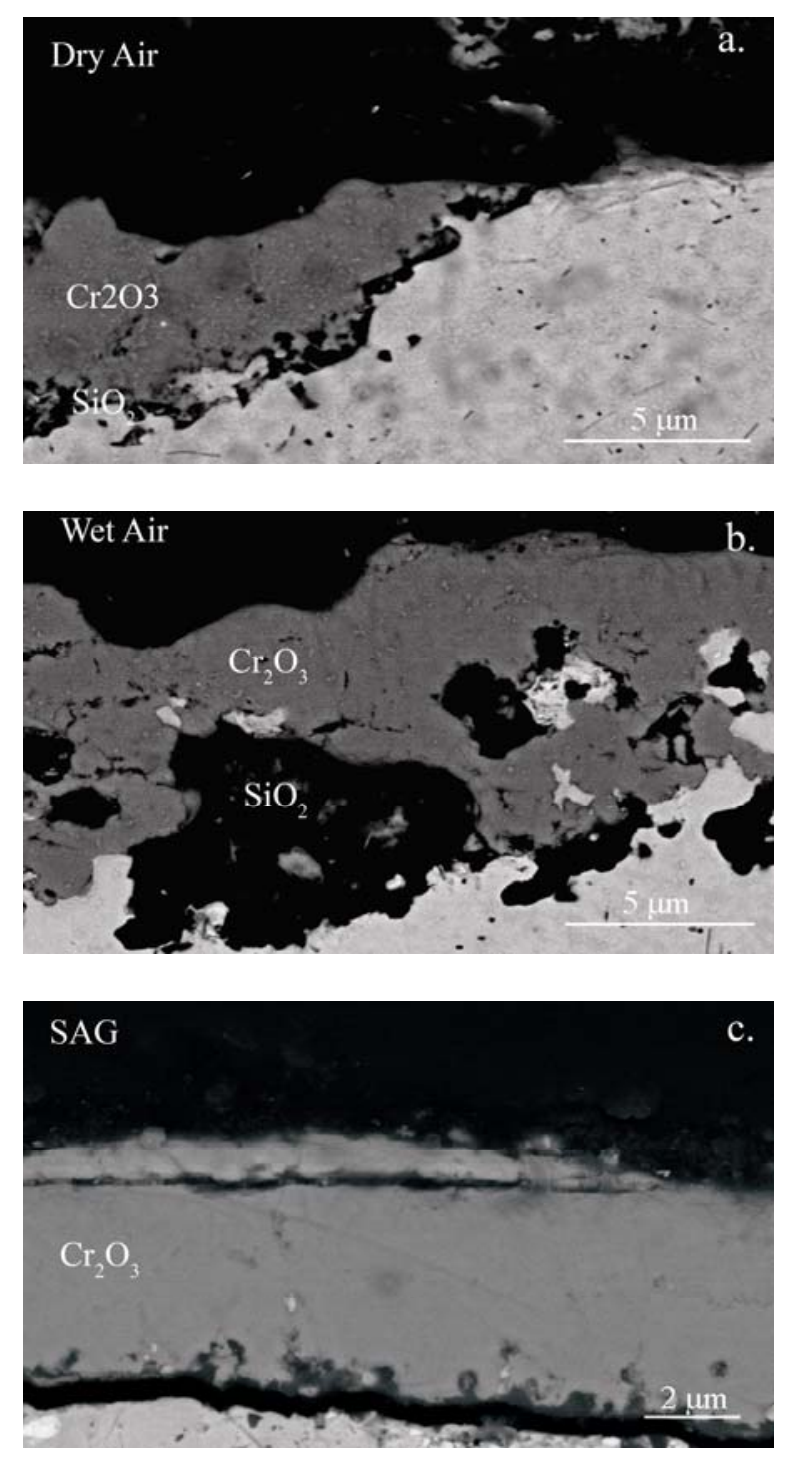

Figure 7. Cross - section micrographs of Fe- $26 \% \mathrm{Cr}$ ferritic after exposure in dry air (a.), air + $10 \% \mathrm{H}_{2} \mathrm{O}$ (b.), and $\mathrm{Ar} / \mathrm{H}_{2} / \mathrm{H}_{2} \mathrm{O}$ (c.) atmospheres at $900^{\circ} \mathrm{C}$ showing details of the alloy/scale interface. 


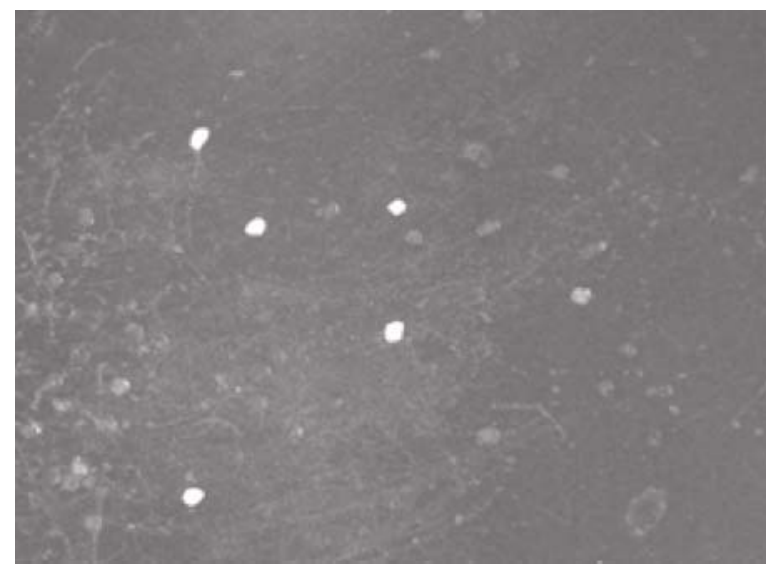

Figure 8. Macroscopic photograph showing freshly spalled and re-grown areas on the surface of $\mathrm{Fe}-26 \mathrm{Cr}$ ferritic (847 cycles, 1/10atm $\mathrm{H}_{2} \mathrm{O}$ ) 

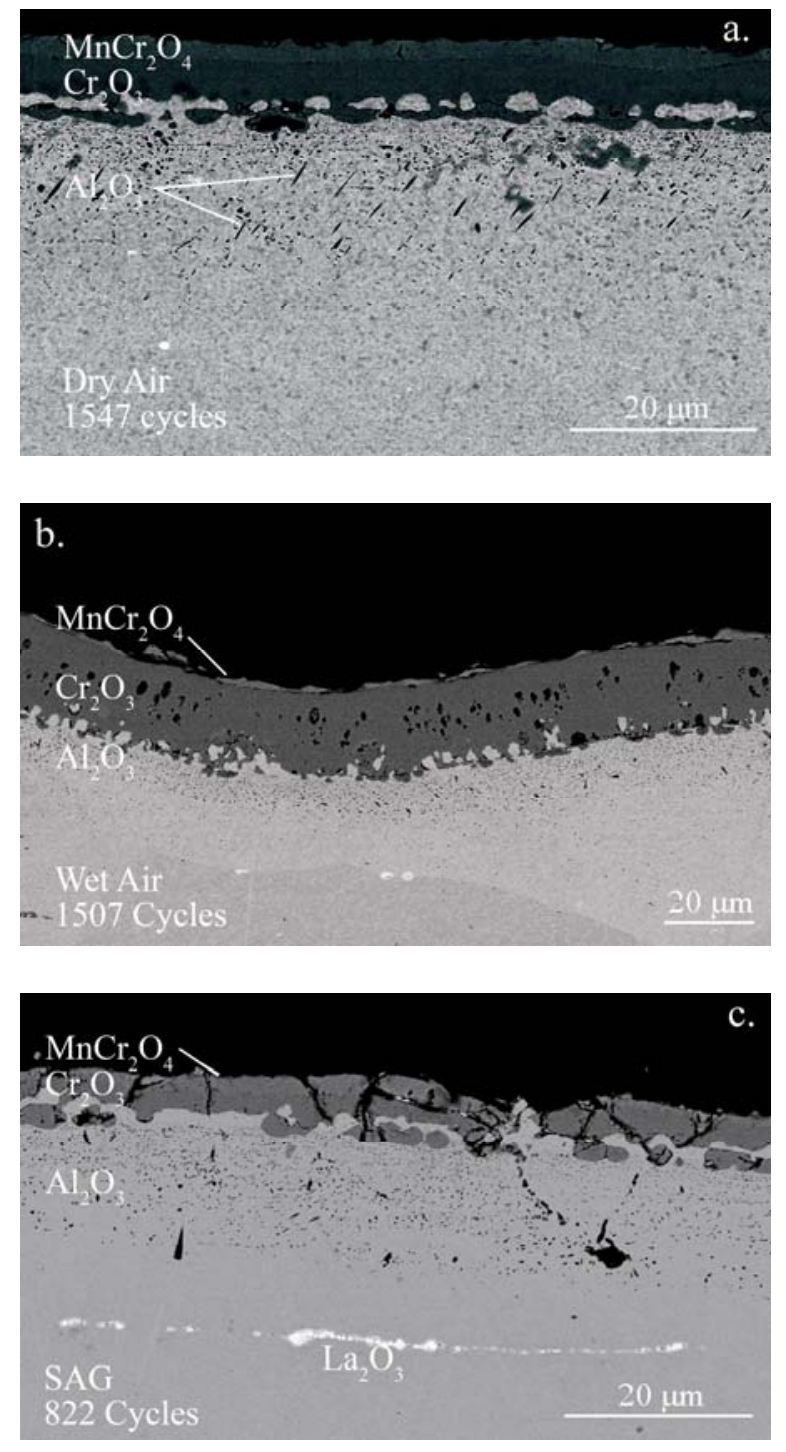

Figure 9. Cross - section micrographs of Crofer after exposure in dry air (a.), air $+10 \% \mathrm{H}_{2} \mathrm{O}$ (b.), and $\mathrm{Ar} / \mathrm{H}_{2} / \mathrm{H}_{2} \mathrm{O}$ (c.) atmospheres at $900^{\circ} \mathrm{C}$ 

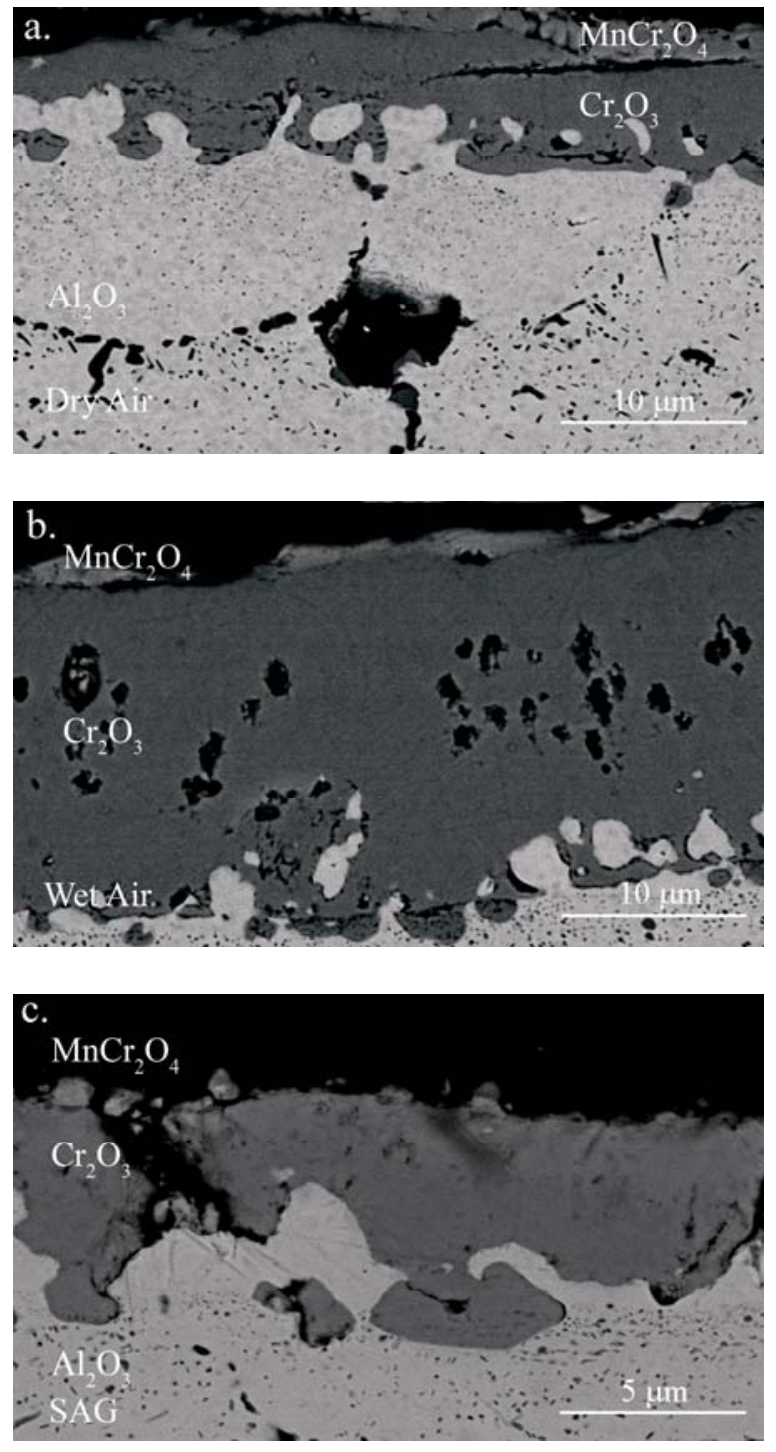

Figure 10. Cross-section micrographs of Crofer after exposure in dry air (a.), air $+10 \% \mathrm{H}_{2} \mathrm{O}$ (b.), and $\mathrm{Ar} / \mathrm{H}_{2} / \mathrm{H}_{2} \mathrm{O}$ (c.) atmospheres at $900^{\circ} \mathrm{C}$, showing more detail of the scales. 


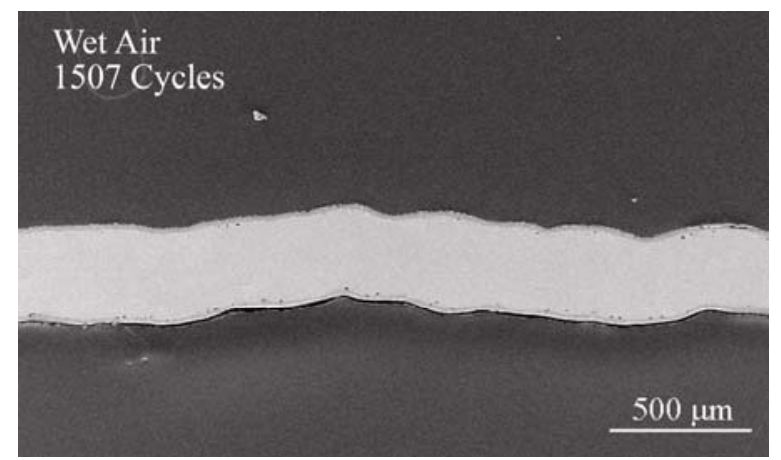

Figure 11. Macroscopic photograph of a Crofer specimen exposed in air $+10 \% \mathrm{H}_{2} \mathrm{O}$ showing extensive warpage. 

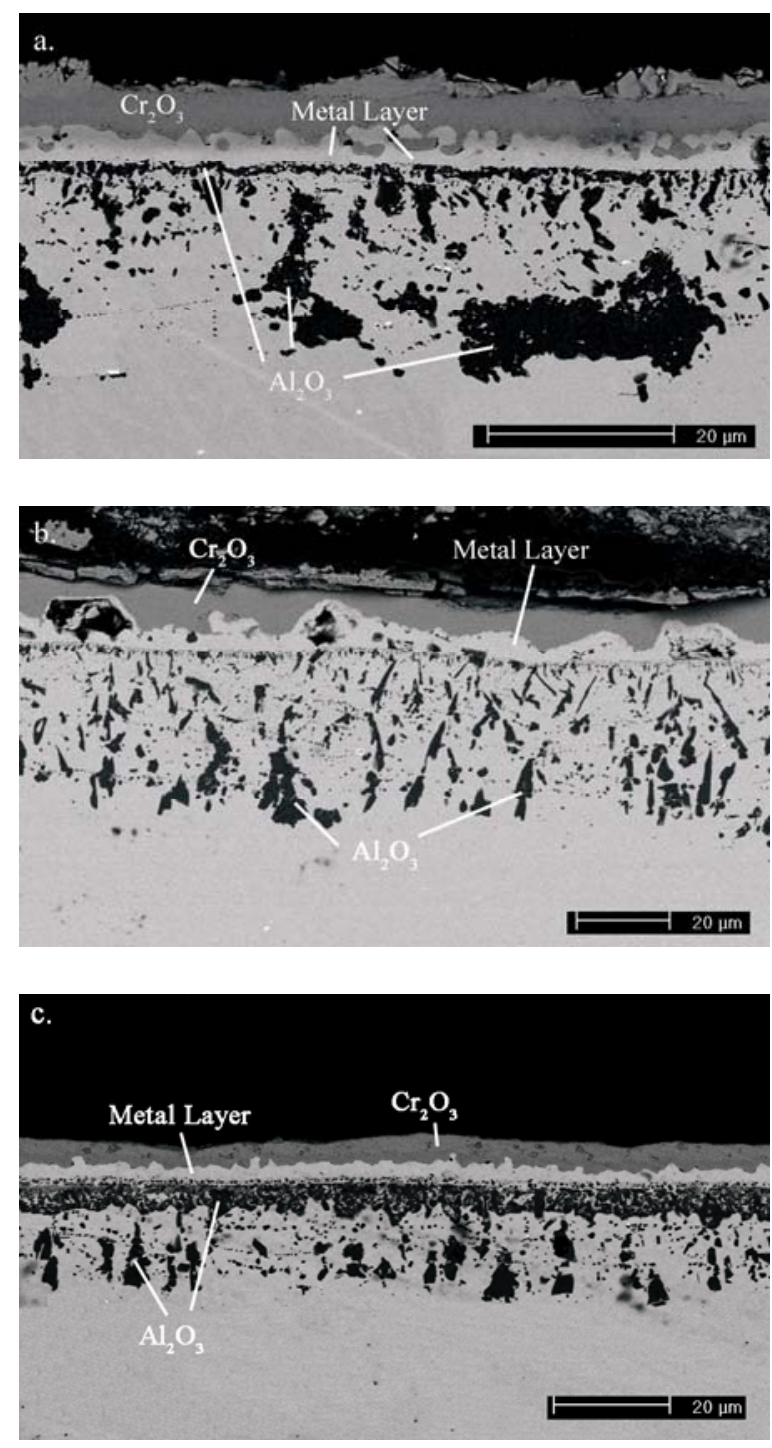

Figure 12 Cross-section micrographs of AL453 after exposure in dry air (a.), air $+10 \% \mathrm{H}_{2} \mathrm{O}$ (b.), and $\mathrm{Ar} / \mathrm{H}_{2} / \mathrm{H}_{2} \mathrm{O}$ (c.) atmospheres at $900^{\circ} \mathrm{C}$. 

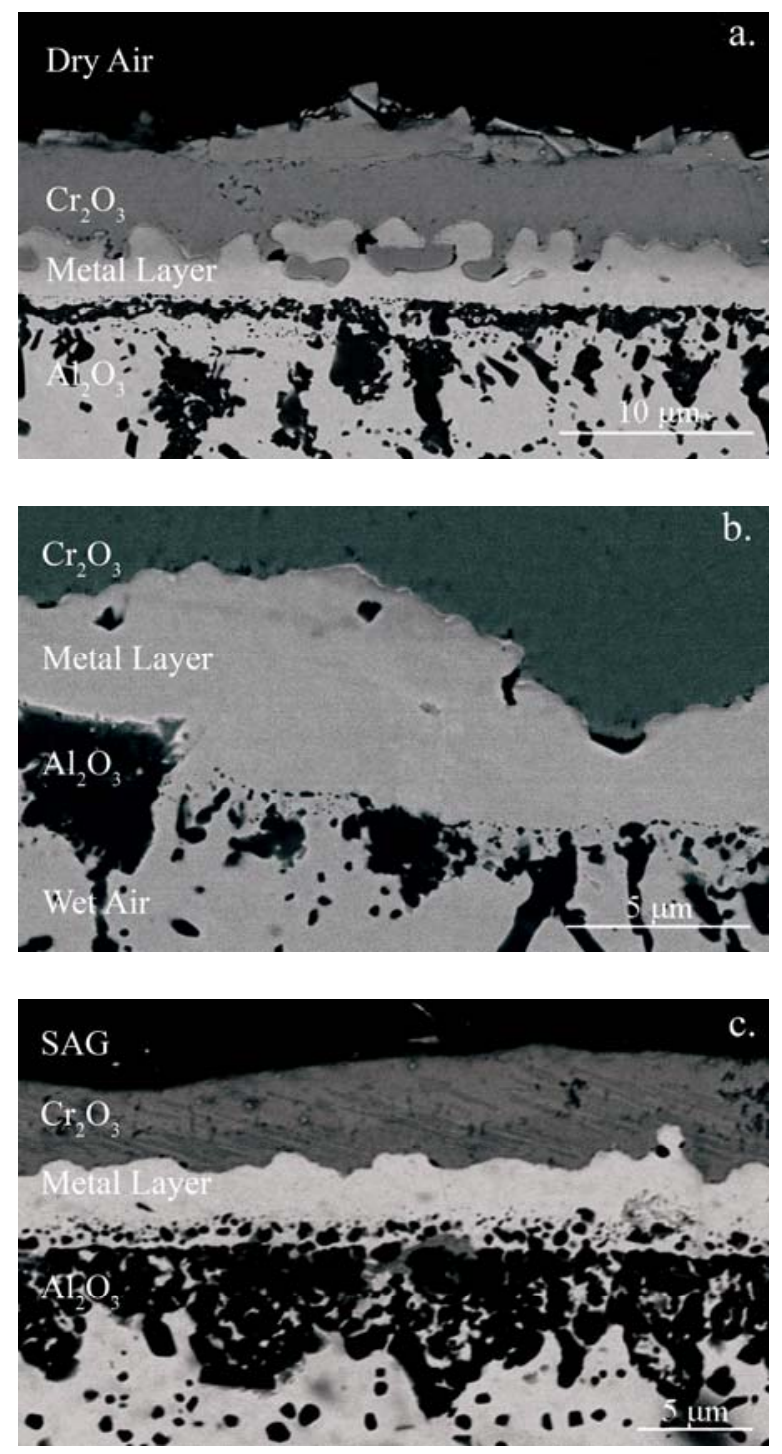

Figure 13. Cross-section micrographs of AL453 after exposure in dry air (a.), air $+10 \% \mathrm{H}_{2} \mathrm{O}$ (b.), and $\mathrm{Ar} / \mathrm{H}_{2} / \mathrm{H}_{2} \mathrm{O}$ (c.) atmospheres at $900^{\circ} \mathrm{C}$, showing more detail of the scales. 


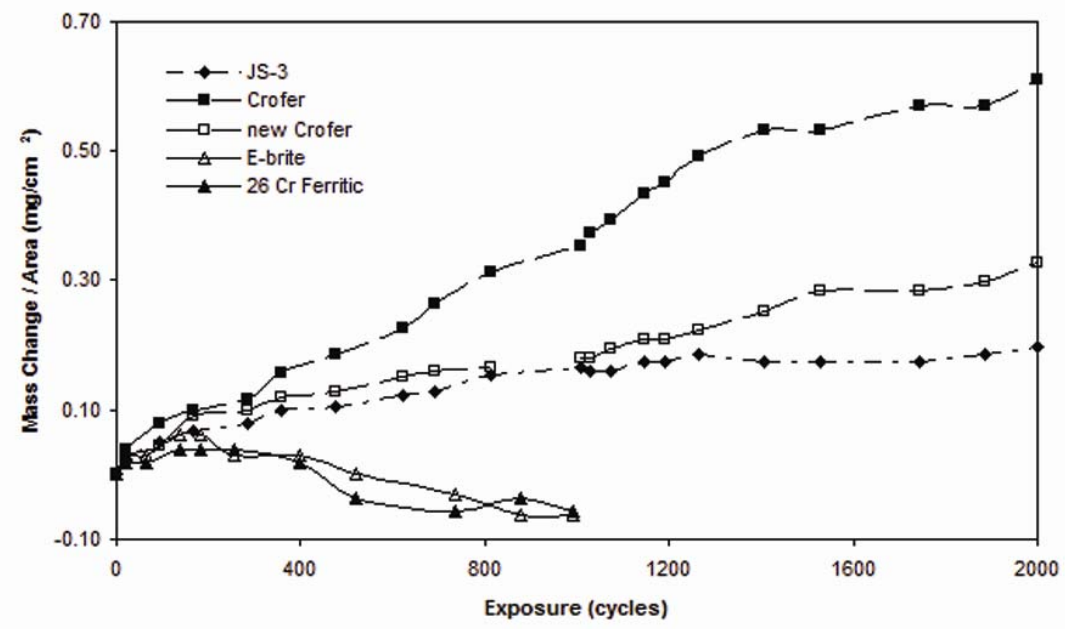

Figure 14. Weight Change Vs Time plots for duplicate specimens of ferritic alloys exposed in air $+10 \% \mathrm{H}_{2} \mathrm{O}$ (simulated moist cathode gas) at $800^{\circ} \mathrm{C}$ using one - hour cycles. 


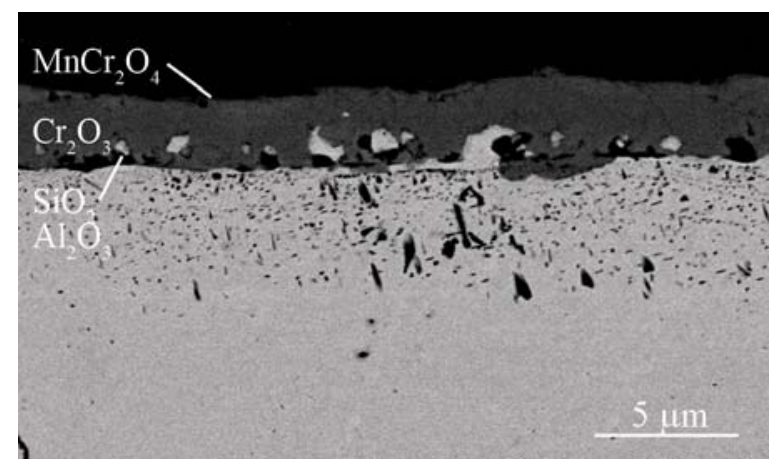

Figure 15. Cross-section micrograph of Crofer after exposure in air $+0.1 \mathrm{~atm} \mathrm{H}_{2} \mathrm{O}$ for 2000 hours at $800^{\circ} \mathrm{C}$. 


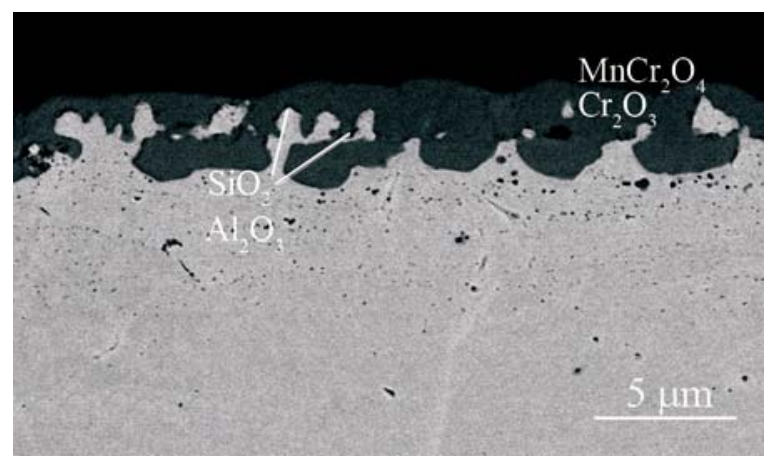

Figure 16. Cross-section micrograph of "New Crofer" after exposure in air +0.1 atm $\mathrm{H}_{2} \mathrm{O}$ for 2000 hours at $800^{\circ} \mathrm{C}$. 


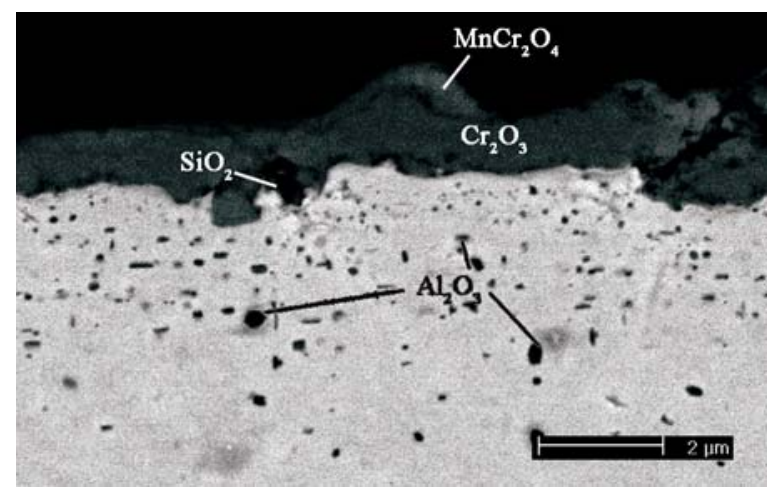

Figure 17. Cross-section micrograph of JS-3 after exposure in air $+0.1 \mathrm{~atm} \mathrm{H}_{2} \mathrm{O}$ for 2000 hours at $800^{\circ} \mathrm{C}$. 


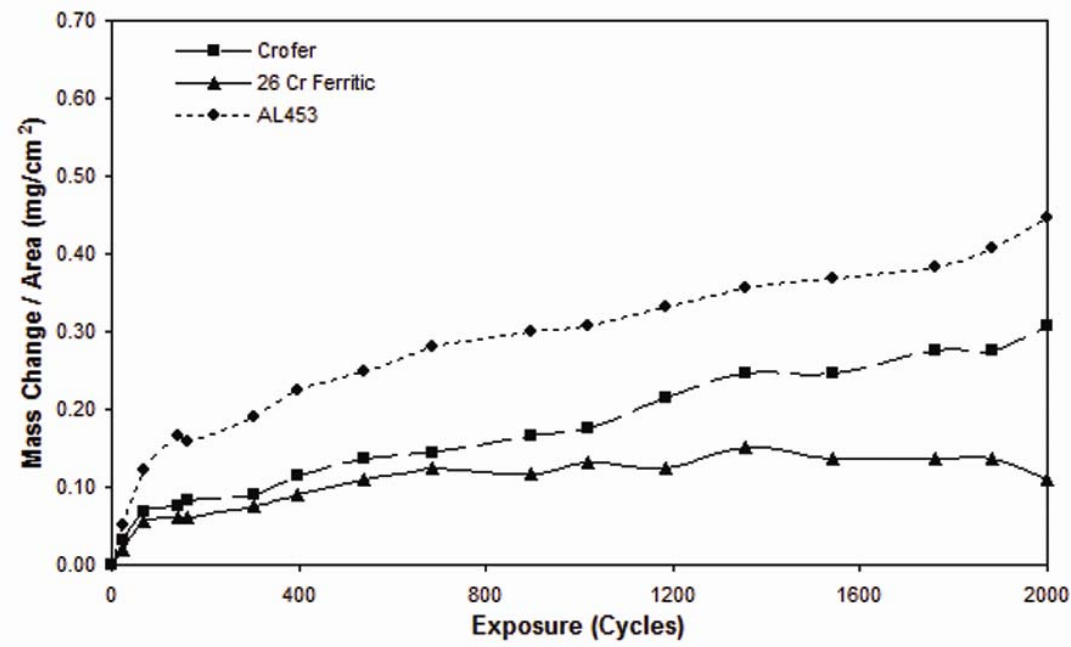

Figure 18. Weight Change Vs. Time plots for duplicate specimens of ferritic alloys exposed in dry air (simulated cathode gas) at $700^{\circ} \mathrm{C}$ using one - hour cycles. 


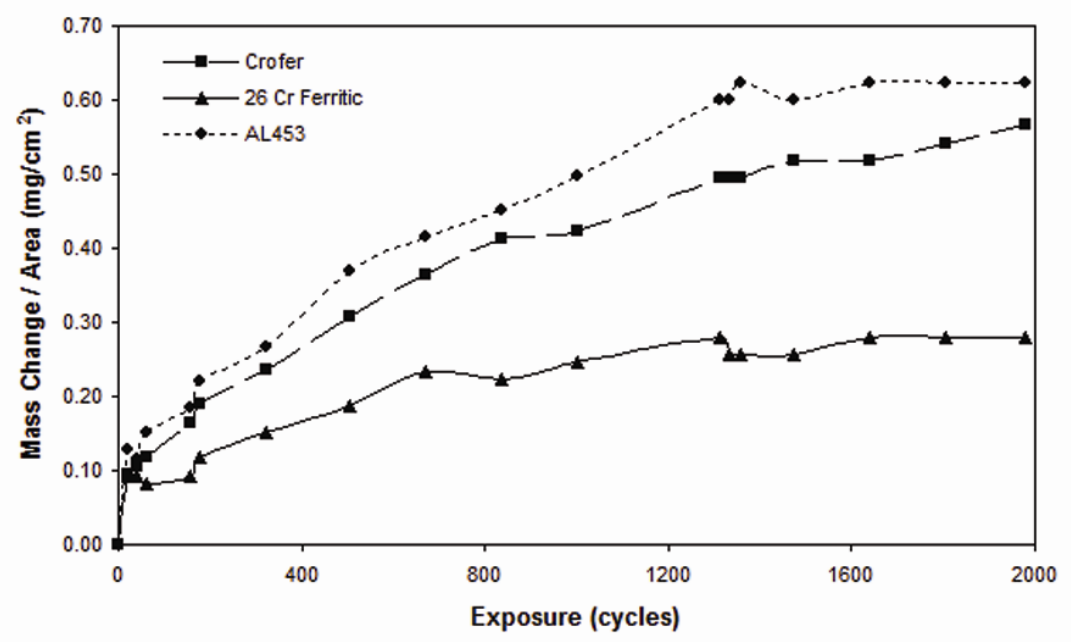

Figure 19. Weight Change Vs Time plots for duplicate specimens of three ferritic alloys exposed in $\mathrm{Ar} / \mathrm{H}_{2} / \mathrm{H}_{2} \mathrm{O}$ (simulated anode gas) at $700^{\circ} \mathrm{C}$ using one - hour cycles. 


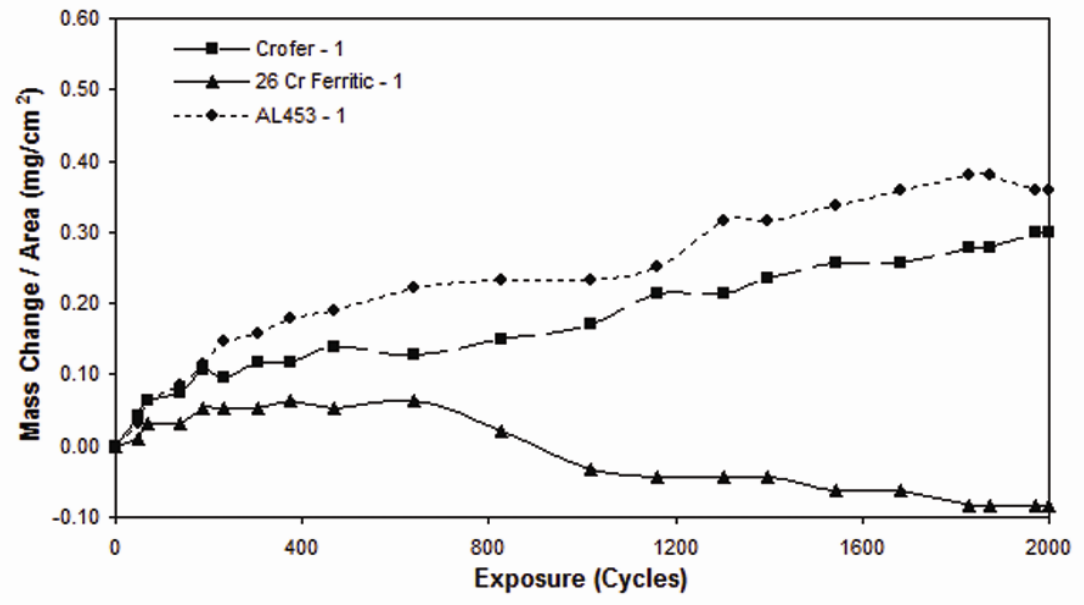

Figure 20. Weight Change Vs Time plots for duplicate specimens of ferritic alloys exposed in air $+10 \% \mathrm{H}_{2} \mathrm{O}$ (simulated moist cathode gas) at $700^{\circ} \mathrm{C}$ using one hour cycles 

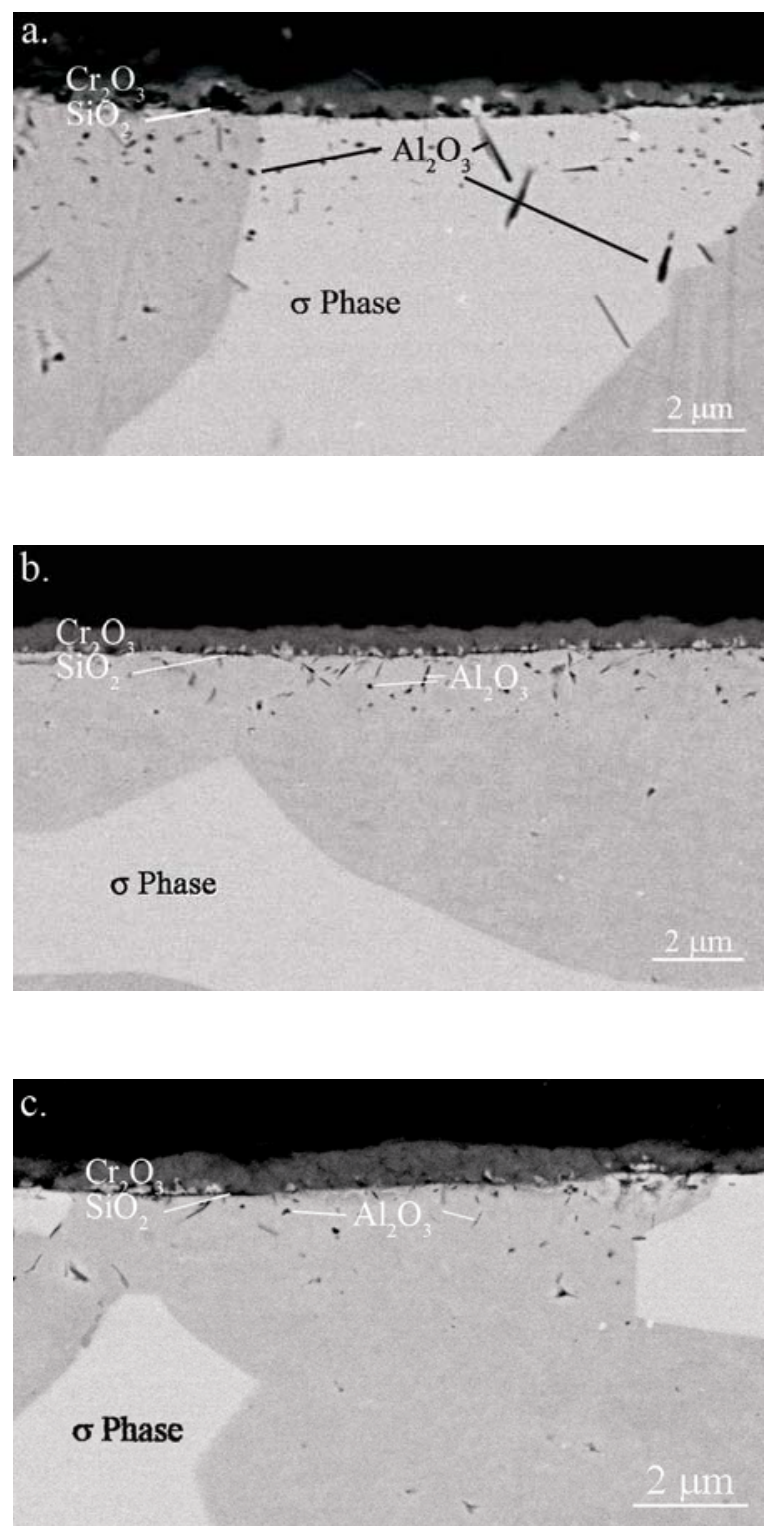

Figure 21. Cross - section micrographs of $\mathrm{Fe}-26 \% \mathrm{Cr}$ ferritic alloy after exposure in atmospheres of dry air (a.), $\mathrm{Ar} / \mathrm{H}_{2} / \mathrm{H}_{2} \mathrm{O}$ (b.), and air $+10 \% \mathrm{H}_{2} \mathrm{O}$ (c.) for 2000 one hour cycles at $700^{\circ} \mathrm{C}$. 

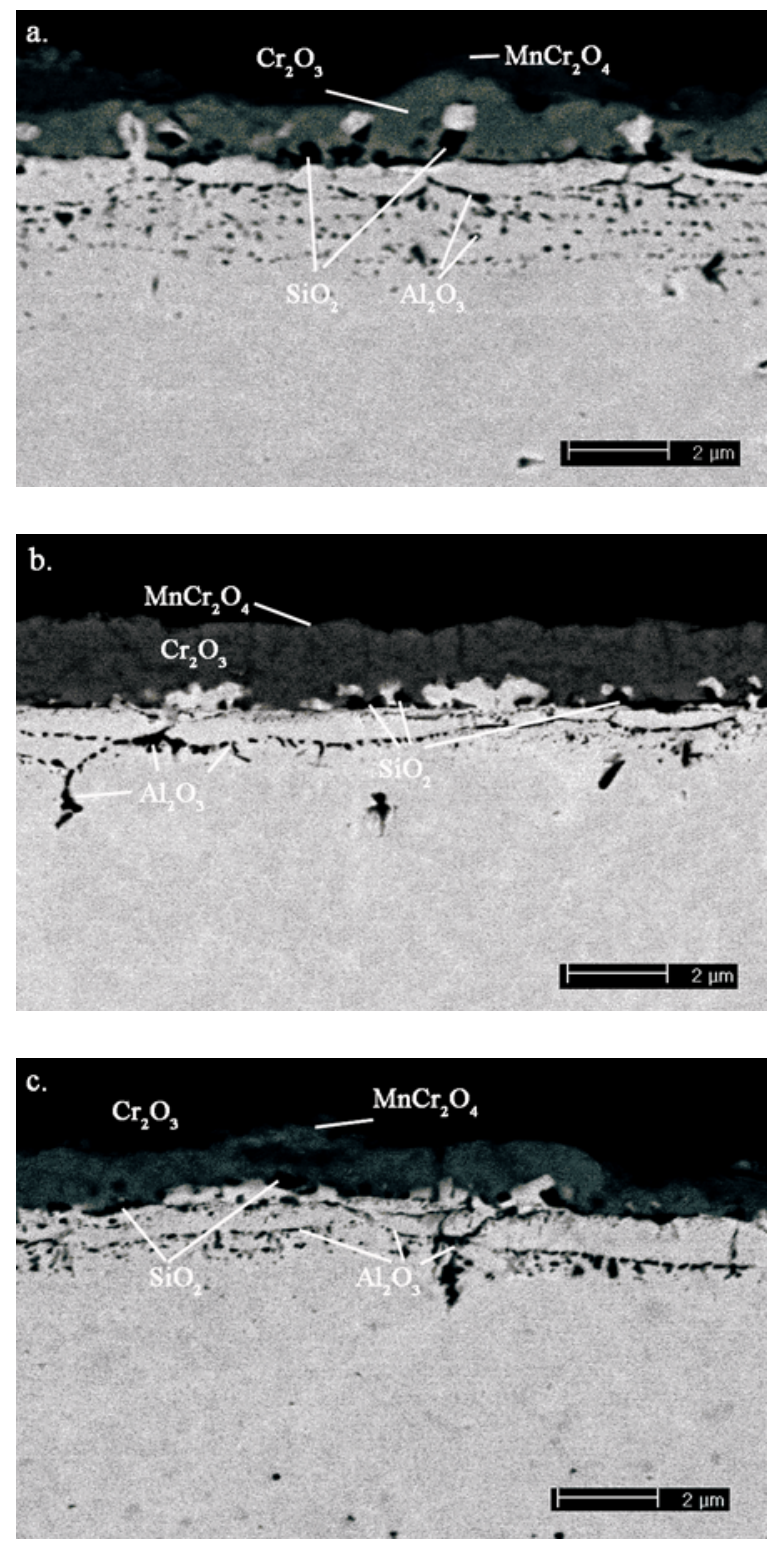

Figure 22. Cross - section micrographs of Crofer 22APU after exposure in atmospheres of dry air (a.), $\mathrm{Ar} / \mathrm{H}_{2} / \mathrm{H}_{2} \mathrm{O}$ (b.), and air $+10 \% \mathrm{H}_{2} \mathrm{O}$ (c.) for 2000 one hour cycles at $700^{\circ} \mathrm{C}$. 

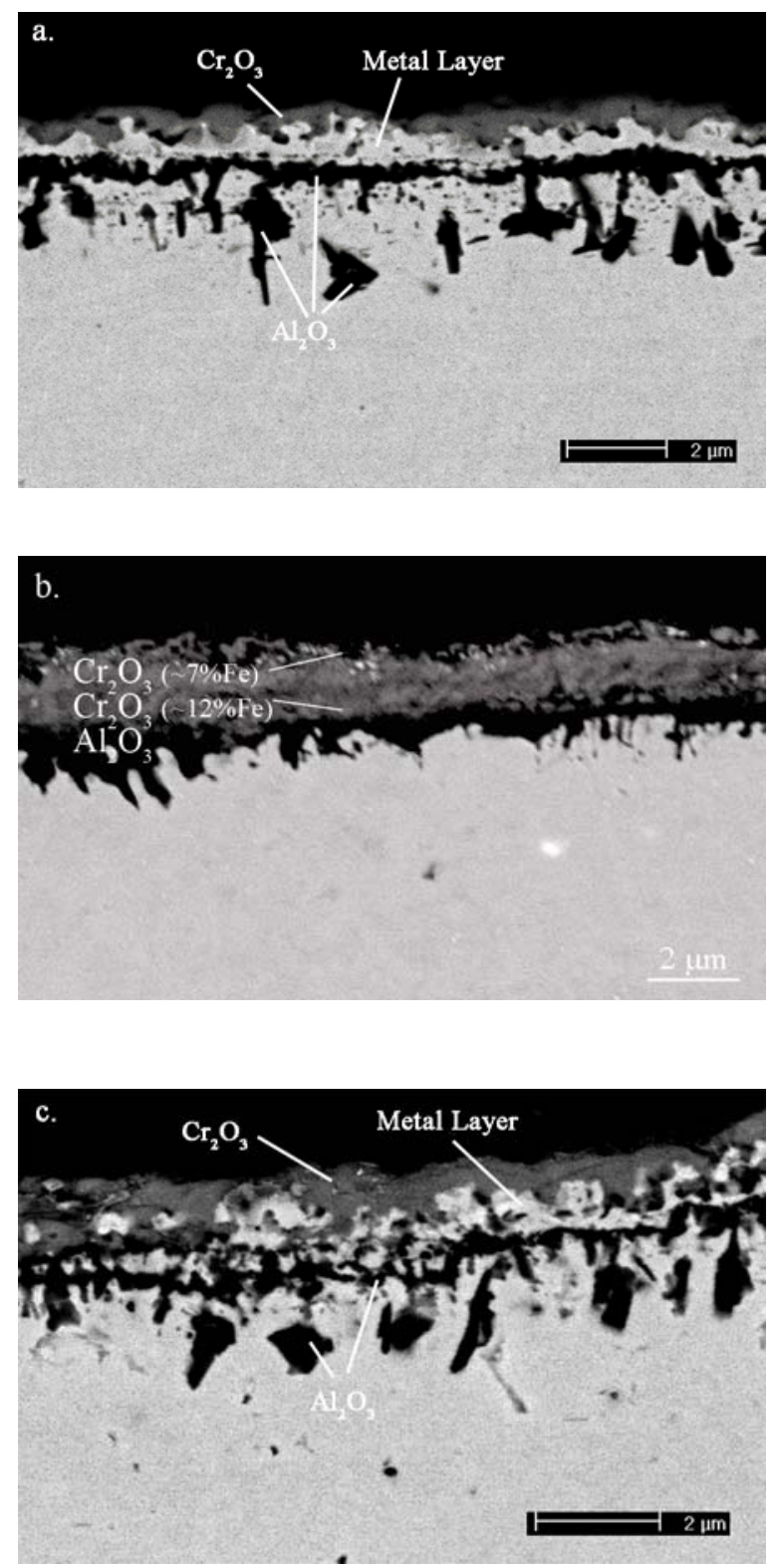

Figure 23. Cross - section micrographs of AL 453 after exposure in atmospheres of dry air (a.), $\mathrm{Ar} / \mathrm{H}_{2} / \mathrm{H}_{2} \mathrm{O}$ (b.), and air $+10 \% \mathrm{H}_{2} \mathrm{O}$ (c.) for 2000 one hour cycles at $700^{\circ} \mathrm{C}$. 


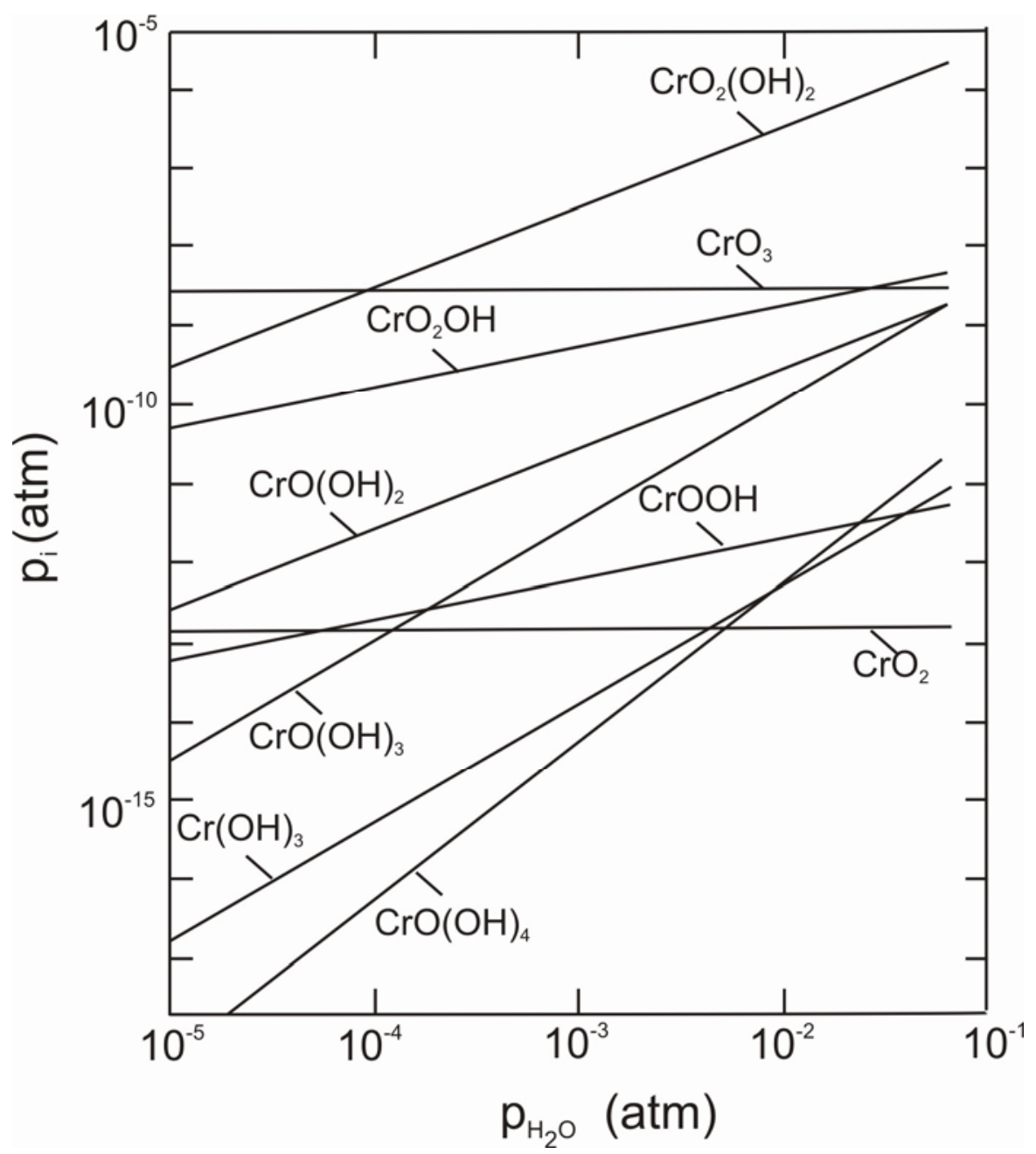

Figure 24 Plot showing the effect of water vapor on the volatility of $\mathrm{Cr}_{2} \mathrm{O}_{3}$ at $950^{\circ} \mathrm{C}$ after Ref. [10]. 


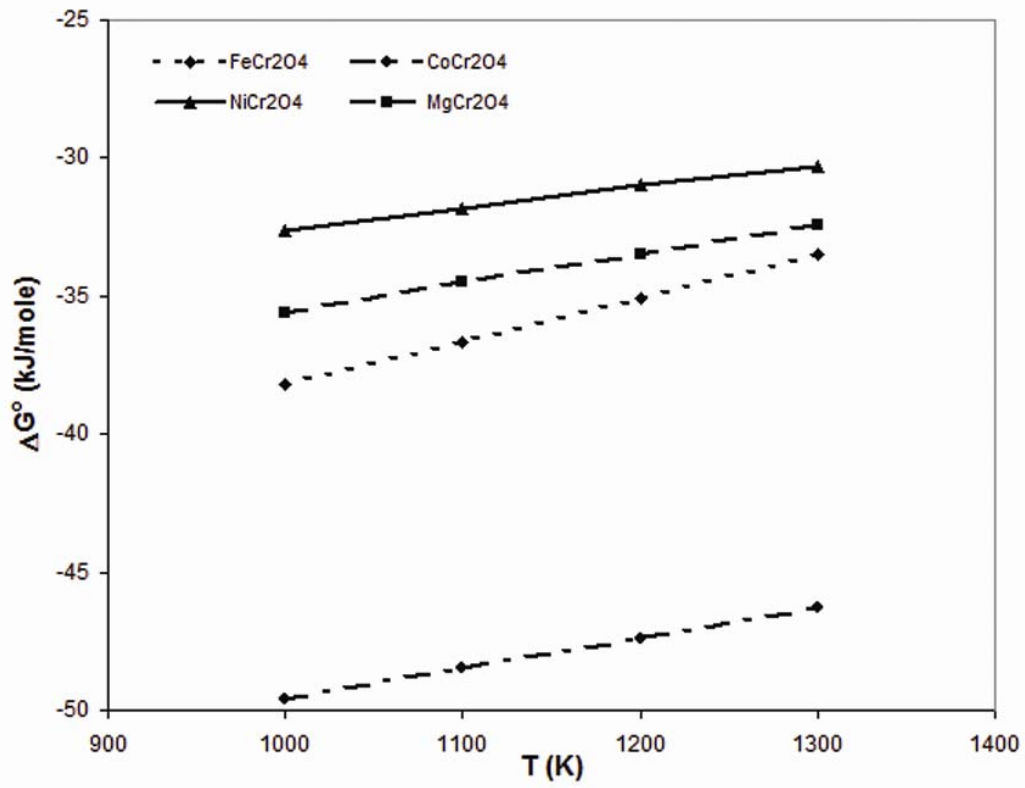

Figure 25 Standard free energy as a function of temperature changes for the reaction of transition metal oxides with chromia to form spinel. 


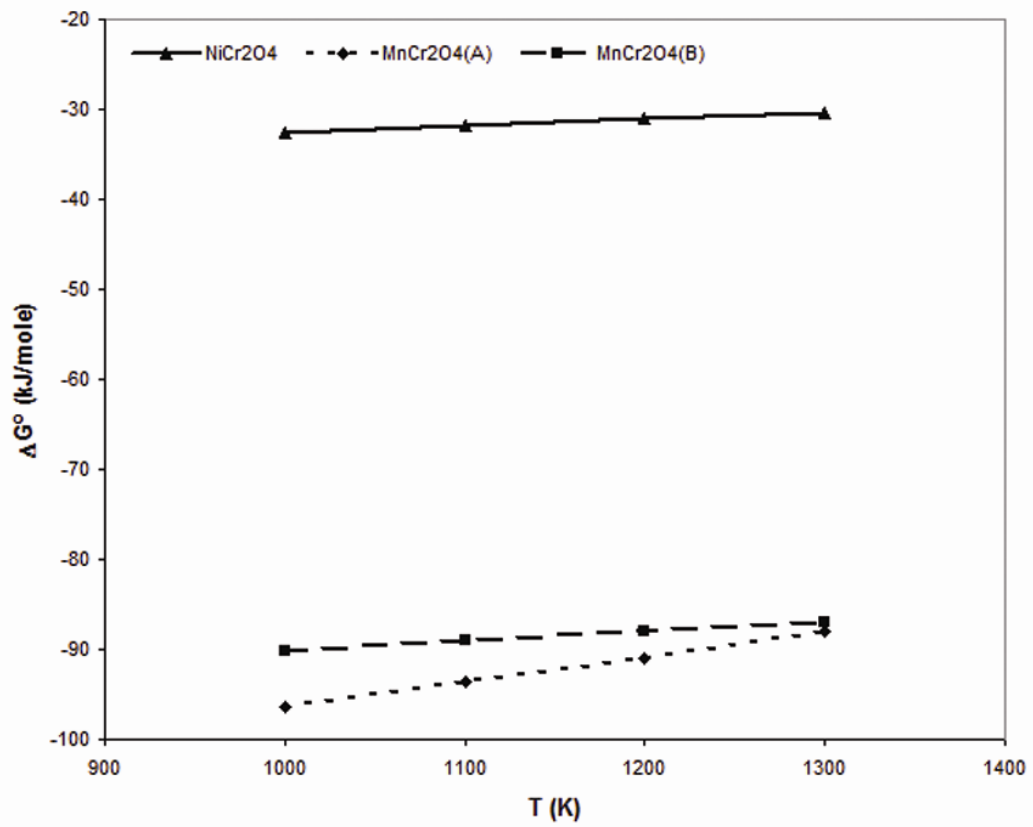

Figure 26 Standard free energy changes for the reactions of $\mathrm{NiO}$ and $\mathrm{MnO}$ with chromia to form the respective chromates. (The two lines for $\mathrm{MnCr}_{2} \mathrm{O}_{4}$ were obtained by using two different techniques for estimating $\Delta \mathrm{S}^{\circ}$.) 


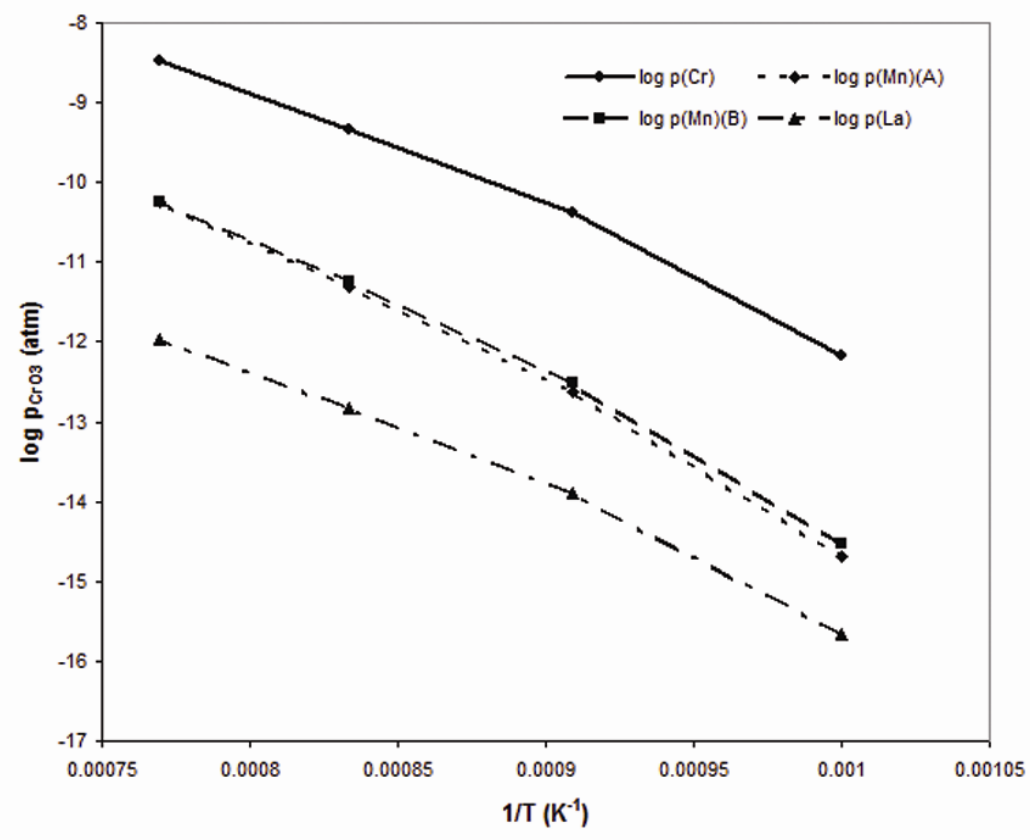

Figure 27 Partial pressures of $\mathrm{CrO}_{3}$ in equilibrium with $\mathrm{Cr}_{2} \mathrm{O}_{3}, \mathrm{La}_{2} \mathrm{O}_{3}$-saturated $\mathrm{LaCrO}_{3}$, and $\mathrm{MnO}$-saturated $\mathrm{MnCr}_{2} \mathrm{O}_{4}$ as a function of temperature. 


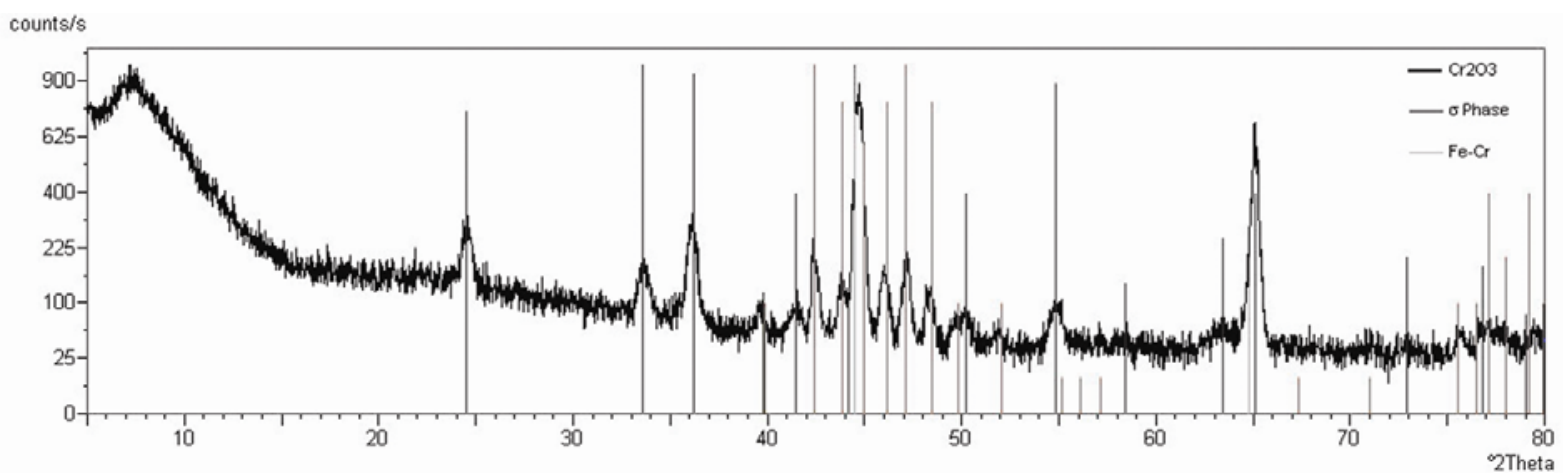

Figure 28. X-ray diffraction pattern for $26 \mathrm{Cr}$ Ferritic alloy exposed at $700^{\circ} \mathrm{C}$ in air $+0.1 \mathrm{~atm}$ $\mathrm{H}_{2} \mathrm{O}$ for 2000 hours. 

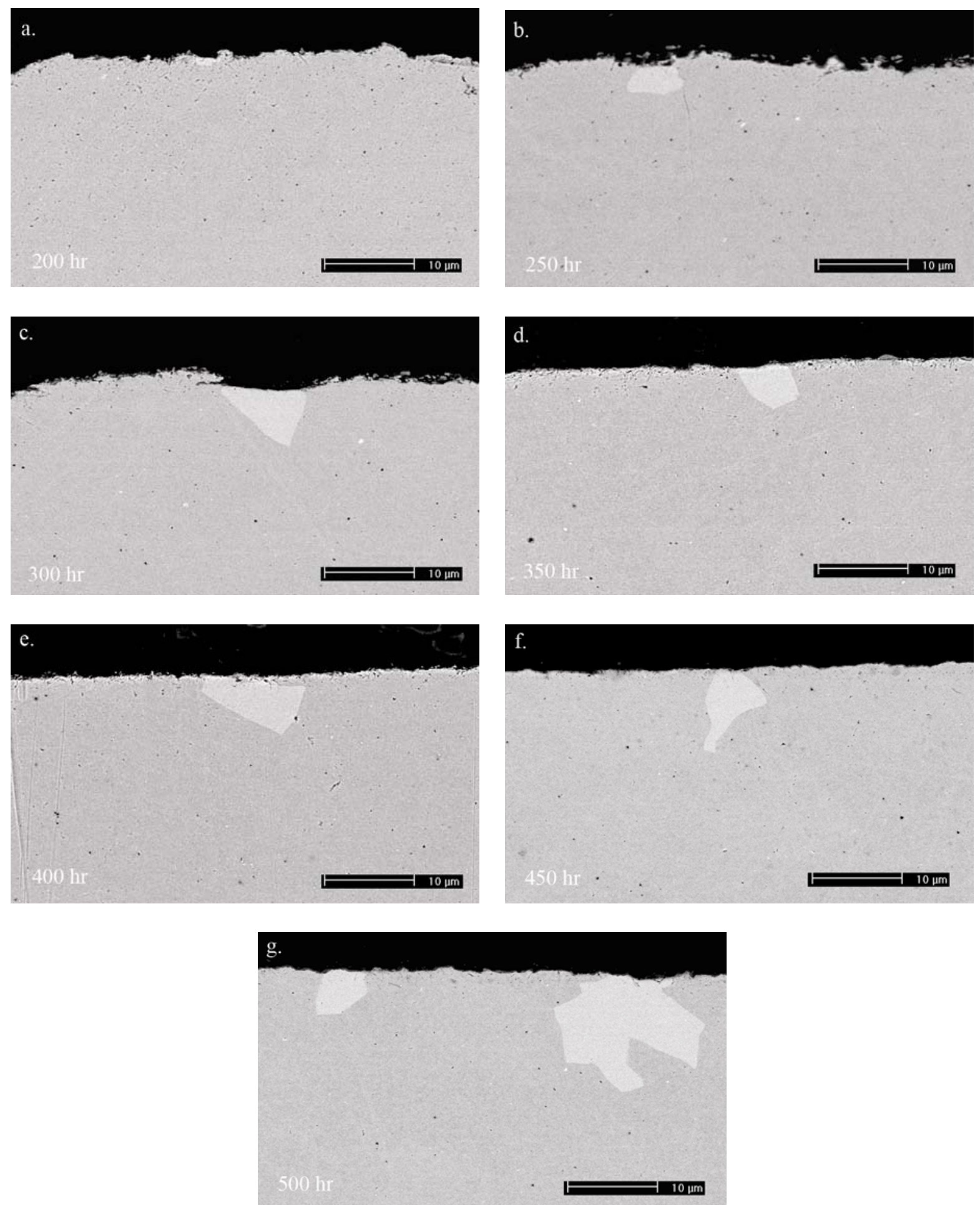

Figure 29. Cross-sections of E-brite exposed at $700^{\circ} \mathrm{C}$ in dry air in 50 hour increments after a) 200 hours, b) 250 hours, c) 300 hours, d) 350 hours, e) 400 hours, f) 450 hours, and g) 500 hours. 

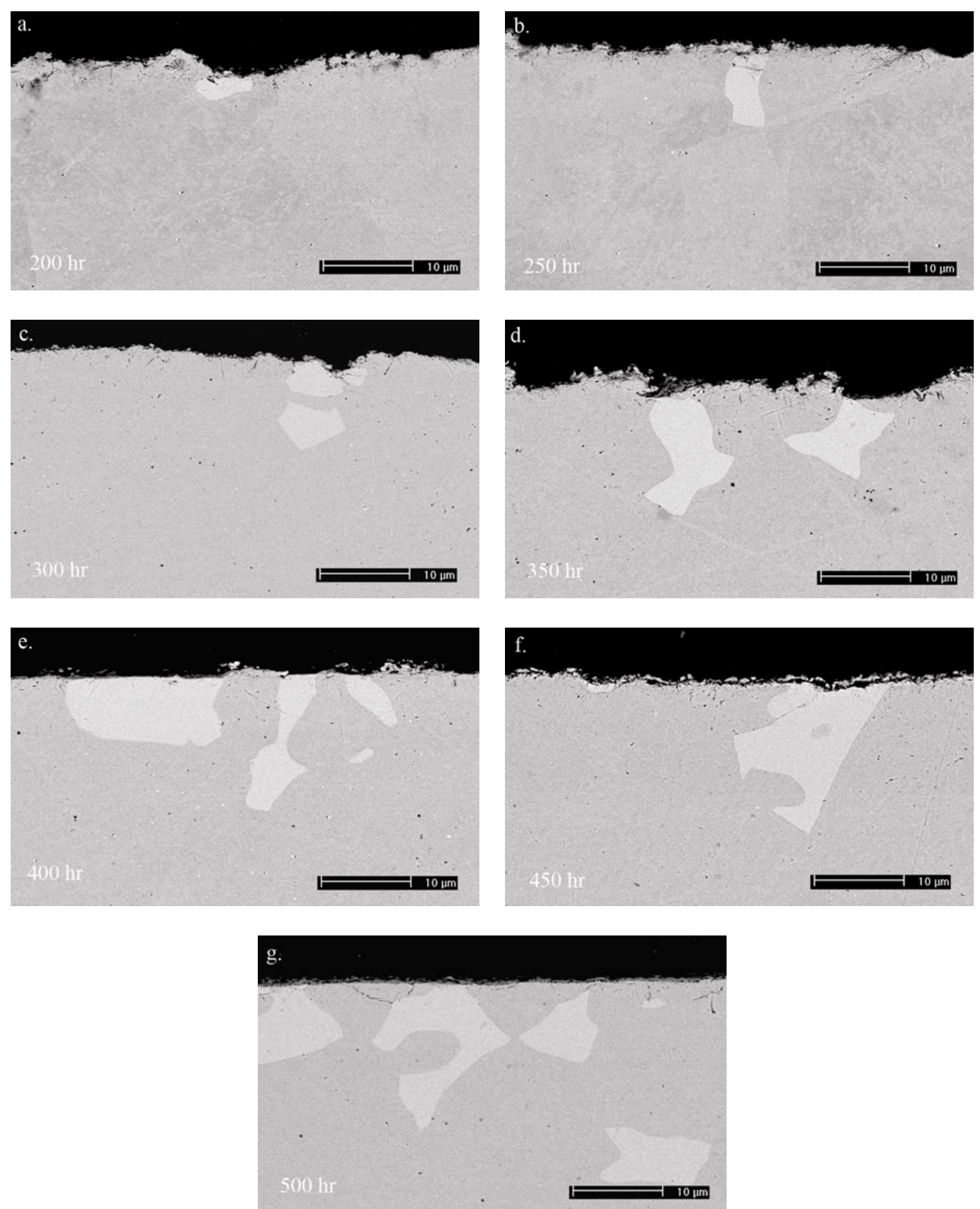

Figure 30. Cross-sections of $26 \mathrm{Cr}$ Ferritic exposed at $700^{\circ} \mathrm{C}$ in dry air in 50 hour increments after a) 200 hours, b) 250 hours, c) 300 hours, d) 350 hours, e) 400 hours, f) 450 hours, and g) 500 hours. 


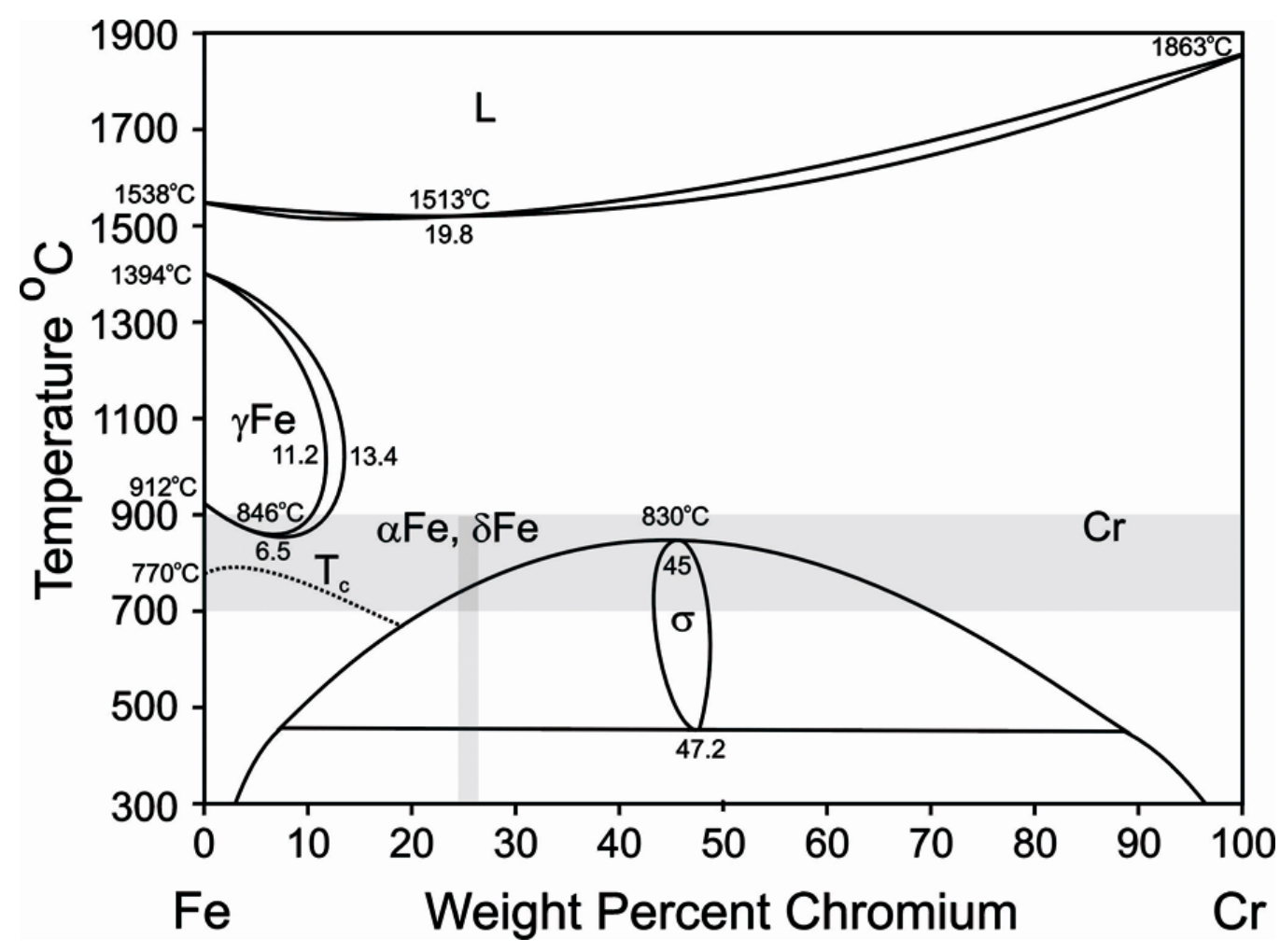

Figure 31. The Fe-Cr phase diagram showing regions in which $\sigma$-phase can form. 


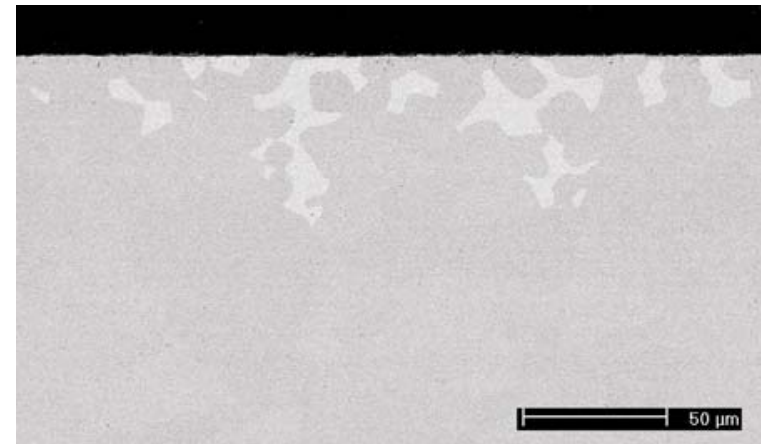

Figure 32. Cross-section of $26 \mathrm{Cr}$ Ferritic exposed at $700^{\circ} \mathrm{C}$ in dry air for 2000 hours showing $\sigma$-phase only formed near the surface. 


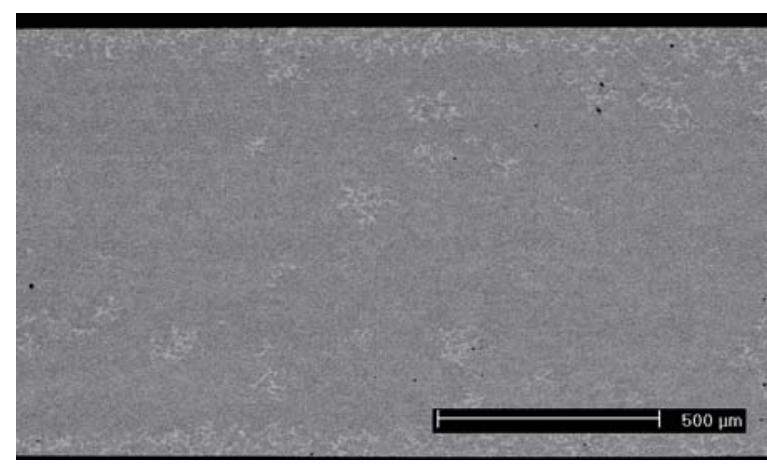

Figure 33. Cross-section of $26 \mathrm{Cr}$ Ferritic exposed at $700^{\circ} \mathrm{C}$ in $\mathrm{Ar} / \mathrm{H}_{2} / \mathrm{H}_{2} \mathrm{O}$ for 2000 hours showing $\sigma$-phase formed throughout the cross-section. 


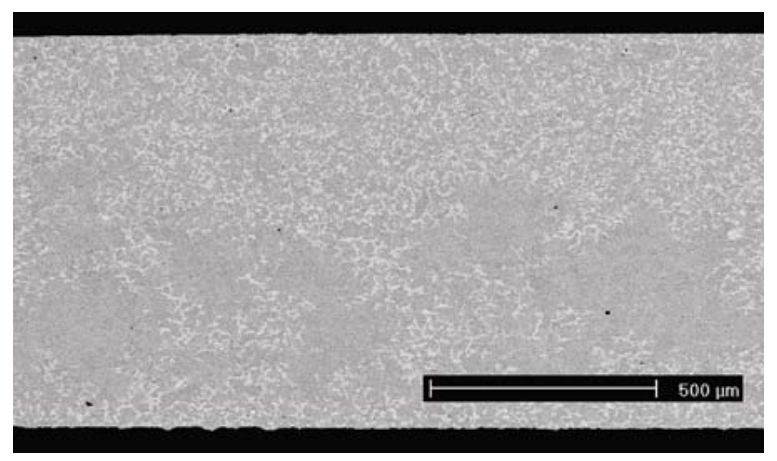

Figure 34. Cross-section of $26 \mathrm{Cr}$ Ferritic exposed at $700^{\circ} \mathrm{C}$ in air +0.1 atm $\mathrm{H}_{2} \mathrm{O}$ for 2000 hours showing $\sigma$-phase formed throughout the cross-section. 
APPENDIX B 


\title{
Interfacial Fracture Testing to Evaluate the Durability of SOFC Interconnect Alloys
}

\author{
Nandhini Dhanaraj ${ }^{1}$, Jack Beuth $^{1}$, Gerald Meier ${ }^{2}$, Frederick Pettit ${ }^{2}$, Julie Hammer ${ }^{2}$ and Scot Laney ${ }^{2}$ \\ ${ }^{1}$ Department of Mechanical Engineering, Carnegie Mellon University, Pittsburgh, PA, 15213 \\ ${ }^{2}$ Department of Material Science and Engineering, University of Pittsburgh, Pittsburgh, PA, 15260
}

Keywords: Solid Oxide Fuel Cells, Interconnects, Indentation, Interfacial Fracture Toughness

\begin{abstract}
In this paper, fundamental thermo-mechanical aspects of the durability of solid oxide fuel cell (SOFC) interconnect alloys are investigated. A key failure mechanism for interconnects is the spallation of the chromia scale that forms on the alloy, as it is exposed to fuel cell environments. Indentation testing methods to measure the critical energy release rate $\left(G_{c}\right)$ associated with the spallation of chromia scale/alloy systems are described, as are methods for analyzing the tests. Experimental results are then presented for the indentation of ferritic interconnect alloys with grown chromia scales. Results from specimens subjected to simulated SOFC environments are used to understand the mechanisms leading to scale spallation and the effects of different environments on scale/alloy durability. Results from shortterm exposure indentation tests are related to results from longer-term exposure TGA experiments. This work forms the basis for understanding the interplay between chromia spallation and two other interconnect failure mechanisms.
\end{abstract}

\section{Introduction}

In order to perform its function, the optimal interconnect material for planar solid oxide fuel cells (SOFCs) should be impermeable to the anode and cathode gases, have high thermal conductivity, high electrical conductivity and good formability. Ferritic stainless steels, which have the above mentioned properties, have been identified as candidate materials for low temperature SOFC interconnects. Past studies have also shown that ferritic stainless steels have a better thermal expansion match with typical ceramic components of solid oxide fuel cells (SOFCs) than competing nickel-based alloys [1-3].

One of the major concerns associated with the successful operation of low temperature planar SOFCs is interconnect durability. The key factors affecting the life of interconnects are: (i) thickening of the chromia scale, which grows on the surfaces of the interconnect as it is exposed to the cathode and anode gases, leading to unacceptable electrical resistance levels; (ii) spallation of the chromia scale, leading to unacceptable increases in electrical resistance through the detached scale and alloy; and (iii) evaporation of the chromia scale where evaporated chromium can affect cathode function.

The problem of chromia evaporation associated with chromia forming alloys such as ferritic stainless steels, has been recognized and studied for many years [4]. Recent studies [1-3, 5] of chromia evaporation from SOFC interconnects have shown that the addition of elements like titanium and manganese to the ferritic interconnects can reduce evaporation. Coatings of $\mathrm{La}_{0.9} \mathrm{Sr}_{0.1} \mathrm{CrO}_{3}$ have also been applied to ferritic alloys to limit $\mathrm{CrO}_{3}$ evaporation [6]. Thickening of the chromia scale, leading to 
increased resistance, has also been studied [1,2] and it has been found that this problem can be controlled by the addition of elements like lanthanum, which tend to slow down the growth rate of chromia and also improve its adherence to the alloy substrate. Albeit the spallation problem has been considered from a metallurgical point of view, the mechanics of the adherence of chromia scales to interconnect alloys has not received widespread attention.

An accelerated testing protocol is presented in this paper to address the spallation issue. It involves performing indentation tests on specimens that are exposed to either simulated cathode gas (Air +0.1 atm $\left.\mathrm{H}_{2} \mathrm{O}\right)$ or simulated anode gas $\left(\mathrm{Ar} / \mathrm{H}_{2} / \mathrm{H}_{2} \mathrm{O}\right)$ environments for short time periods and using the results to predict long-term behavior. For the purposes of this paper, test results for a $26 \mathrm{Cr}$ ferritic stainless steel exposed to the above mentioned environments at $900^{\circ} \mathrm{C}$ are discussed.

\section{Indentation Technique for Determining Chromia Scale Adhesion}

\section{Description of the Test}

The indent test employed in this study was first proposed by Drory and Hutchinson [7] as a means for measuring interfacial toughness in brittle coating systems. It was then adapted for use on thermal barrier coating systems by Ma [8]. In this test, the specimen, which is typically a $16 \times 5 \times 1 \mathrm{~mm}$ ferritic stainless steel wafer with an adherent chromia scale formed during cyclic exposure to either simulated cathode gas or anode gas, is placed in a Rockwell hardness tester. The specimen is indented in the tester using a brale $\mathrm{C}$ indenter.

A schematic diagram of the indentation process is shown in Figure 1. The chromia scale is penetrated by the indenter and the plastic deformation of the underlying substrate induces compressive radial strains in the substrate, away from the indent crater. This strain is transferred to the scale (the in-plane strains in the scale and substrate are matched at the interface) and the associated scale stress acts to drive the radial extension of an interface crack thereby inducing oxide scale debonding.

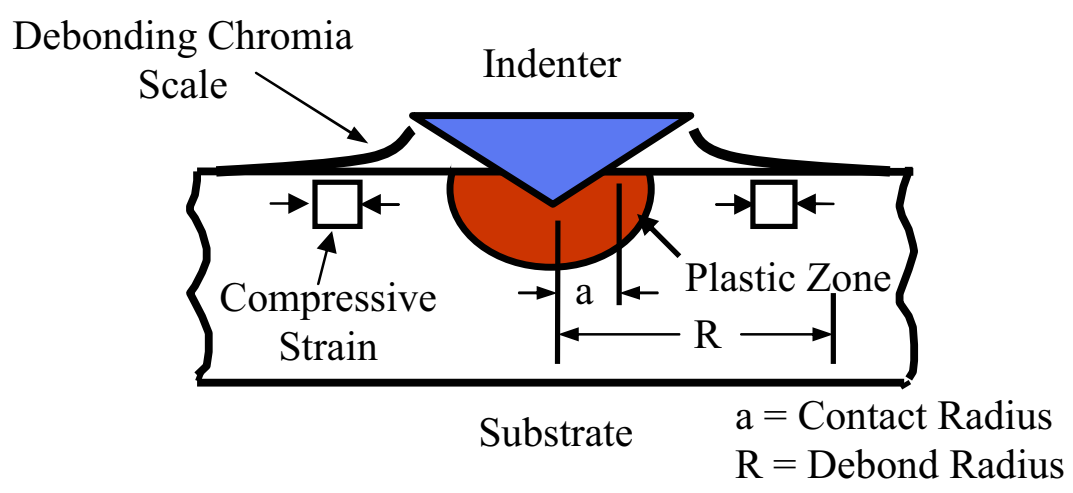

Figure 1 Schematic of the Indentation Test

\section{Mechanics of Chromia Scale Spallation}

The decoherence of a chromia scale from an interconnect alloy can be modeled as a fracture mechanics problem. Fracture mechanics principles require that a debond crack will grow along the oxide/alloy interface when $\mathrm{G}=\mathrm{G}_{\mathrm{c}}$. The quantity $\mathrm{G}$ is the energy release rate, defined as the stored elastic energy in the scale that is released during debonding per unit newly created crack face area. $G$ is the quantity driving debonding. $G_{c}$ is the critical energy release rate, which can be treated as a property of the interface. $G_{c}$ is the quantity resisting debonding. For the case of a residually stressed thin oxide scale on a thick substrate, the formula $\mathrm{G}=\mathrm{G}_{\mathrm{c}}$ becomes: 


$$
\frac{\sigma^{2} t(1-v)}{E}=G_{c}
$$

where $\sigma$ is the equal biaxial residual stress in the scale, $t$ is the scale thickness, $\mathrm{E}$ is the scale elastic modulus and $v$ is the scale Poisson's ratio. In using this formula, it is assumed that the scale has completely spalled off, relaxing in-plane stresses and strains in both directions.

The chromia thickness is determined by the rates of diffusion of chromium and/or oxygen through the scale. The residual stress level in the scale is determined by stresses which arise during oxide formation (growth stresses), stresses produced during cool-down from elevated temperatures due to thermal expansion mismatch between the oxide and the alloy (thermal stresses), and any stress relaxation which may occur. In addition to equal biaxial residual stresses, stresses in the scale can also include uniaxial applied stresses from mechanical loading of the scale. The idea of the fracture testing described above is to increase the stress in the scale via mechanical loading, increasing the elastic energy stored in the scale and inducing spallation much earlier than it would normally occur.

\section{Debond Behavior}

The indentation test described above was performed on two sets of $26 \mathrm{Cr}$ ferritic specimens with test loads of 60,100 and $150 \mathrm{~kg}$. Figures 2 and 3 show scanning electron microscope (SEM) images (viewed from above) of two indented specimens exposed to simulated cathode gas (SCG) and simulated anode gas (SAG), respectively. As indicated in Figs. 2 and 3, a change in the exposure environment greatly changes the debond behavior. The specimens exposed in simulated cathode gas (SCG) show a nonuniform flaking of the chromia scale in the near-indent region, with the density of the flaking decreasing with increasing distance from the center of the indentation (and decreasing energy release rate). This behavior suggests the presence of a non-uniform interfacial toughness and a scale that is easily broken up. In contrast, specimens exposed to simulated anode gas (SAG) show a more uniform peeling of an intact chromia scale. This debonding behavior is indicative of a more coherent scale and perhaps more uniform adhesion.

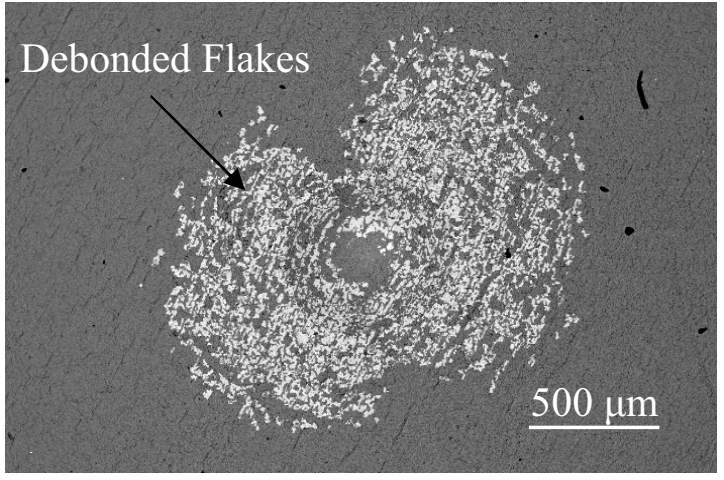

Figure 2 SEM Image of an Indented 26 Cr Ferritic Alloy Exposed to SCG at $900^{\circ} \mathrm{C}$ for $100 \mathrm{hrs}$

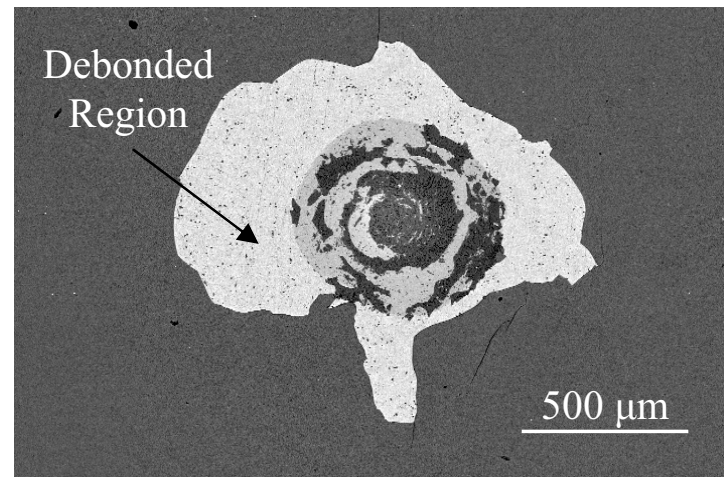

Figure 3 SEM Image of an Indented $26 \mathrm{Cr}$ Ferritic Alloy Exposed to $\mathrm{SAG}$ at $900^{\circ} \mathrm{C}$ for $264 \mathrm{hrs}$

These qualitative behaviors are consistent with long-term weight gain measurements on the same $26 \mathrm{Cr}$ ferritic alloy (see Figure 4). For the SCG case, the specific weight measurements are nearly constant after $50 \mathrm{hrs}$ of exposure. This is consistent with the idea that chromia evaporation may be limiting scale growth and/or that flaking of thicker or more weakly bonded portions of the scale is occurring. In contrast, for the SAG case, weight gains continue out to $2000 \mathrm{hrs}$ of exposure. This is consistent with 
there being less chromia evaporation and no flaking away of pieces of the chromia scale. Findings detailed in the section on experimental results also show essentially unchanging debond behavior for specimens exposed to SCG for 100 and $200 \mathrm{hrs}$ (consistent with the steady-state specific weight data) and changing debond behavior for specimens exposed in SAG for 264 and $364 \mathrm{hrs}$ (consistent with the weight gains seen in Figure 4 for this case).

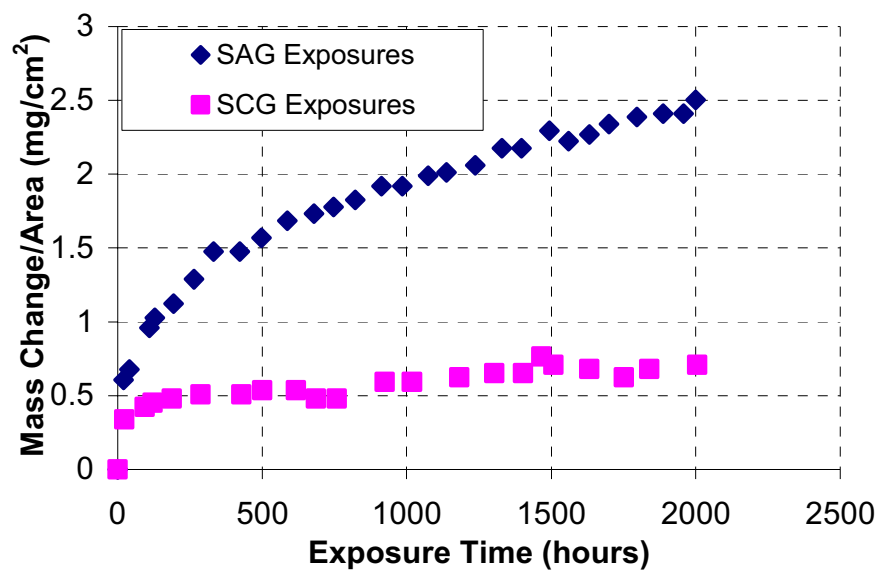

Figure 4 Specific Weight Gain Plots for the $26 \mathrm{Cr}$ Ferritic Alloy Exposed to SAG and SCG at $900^{\circ} \mathrm{C}$

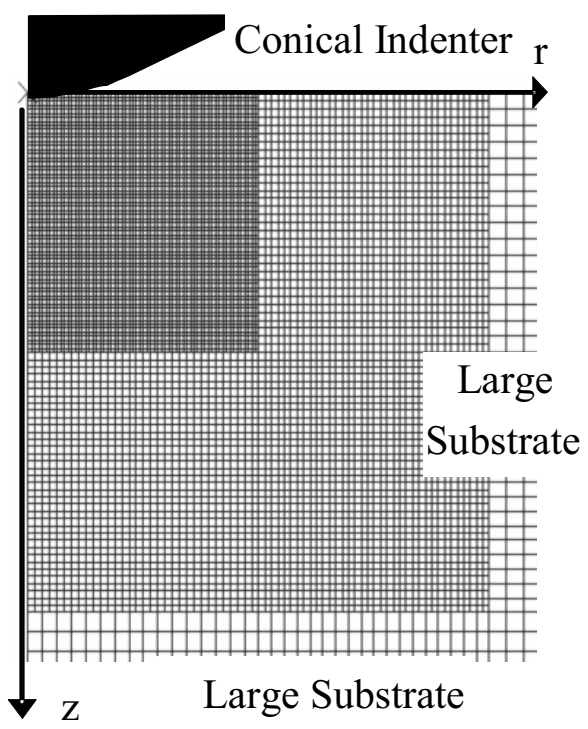

Figure 5 Typical Axisymmetric Finite Element Mesh Used in the Indentation Simulations

\section{Analysis of the Test}

\section{Finite Element Model Description}

The indentation test was simulated using the commercial finite element software ABAQUS. A 2-D axisymmetric model of an elastic-plastic substrate and a rigid indenter was used as shown in Figure 5. Two different sized substrates were studied, a large substrate model - large enough to experience strains and displacements identical to an infinitely large substrate and a typical SOFC test specimen model having a substrate radius of $8 \mathrm{~mm}$ and a depth of $1 \mathrm{~mm}$. Surface strain results used in energy release rate calculations from these two types of models agreed, indicating that for indent loads up to $150 \mathrm{~kg}$, a $1 \mathrm{~mm}$ thick SOFC specimen behaves like a large substrate. The rigid indenter was modeled to have an included angle and a tip radius identical to that of the actual conical indenter. The elastic-plastic behavior of the substrate was obtained from the stress-strain curve for the commercial alloy E-BRITE, a similar $26 \mathrm{Cr}$ ferritic alloy with lower levels of Si.

The substrates were meshed with four-noded bilinear axisymmetric elements with a total of 12757 elements and 13058 nodes. The grid beneath the indenter was highly refined with element sizes ranging from 3-6 $\mu \mathrm{m}$. In addition, elements were chosen to possess the characteristics of reduced integration and hybrid formulations, which help reduce run time and provide more accurate results in the near indent region, which is subjected to extensive plasticity and exhibits nearly incompressible behavior. The model is of the interconnect substrate, excluding the chromia scale on top. In the actual specimens, the chromia scale thickness is small compared to the size of the indentation strain field. As a result, the scale does not constrain the deformation of the substrate and a model excluding the scale is appropriate. Inplane substrate surface strains are transferred directly to the scale. Thus, in-plane surface strains from 
the model are used within thin coating fracture mechanics formulas described in the next section to calculate energy release rate values.

\section{Fracture Mechanics Calculations}

The energy release rate, $G$, is calculated from the strains obtained from the top surface of the numerical indentation model. The equations used for $\mathrm{G}$ calculations were originally formulated for a single-layered coating system by Drory and Hutchinson [7]. The total radial strain, $\varepsilon_{\mathrm{r}}$, and circumferential strain, $\varepsilon_{\theta}$, in a single layered coating system can be calculated by combining a biaxial residual strain, $\varepsilon_{0}$, corresponding to the residual stress, with the strains obtained from the numerical indentation model, $\varepsilon^{n}$. The strains are given as

$$
\varepsilon_{r}=\varepsilon_{r}^{n}+\varepsilon_{o} ; \quad \varepsilon_{\theta}=\varepsilon_{\theta}^{n}+\varepsilon_{o}
$$

where

$$
\varepsilon_{r}^{n}=\frac{d U}{d r} ; \quad \varepsilon_{\theta}^{n}=\frac{U}{r}
$$

In eq (3), $U$ is the radial displacement on the top surface of the substrate. Also the biaxial residual strain is given as

$$
\varepsilon_{o}=\frac{\sigma_{\text {oxide }}\left(1-v_{\text {oxide }}\right)}{E_{\text {oxide }}} \text {. }
$$

The formula for calculating the critical energy release rate is given as:

$$
G=\frac{1}{2\left(1-v_{\text {oxide }}^{2}\right)}\left[E_{\text {oxide }} t_{\text {oxide }}\left(\varepsilon_{r}+v_{\text {oxide }} \varepsilon_{\theta}\right)^{2}\right],
$$

where it is assumed that only the radial stress and strain are released as the crack front extends in the radial direction.

In the above equations, $E_{\text {oxide, }}, \mathrm{t}_{\text {oxide }}$ and $v_{\text {oxide }}$ are the Young's modulus, thickness and Poisson's ratio of the chromia scale and $\sigma_{\text {oxide }}$ is the equal biaxial residual stress in the scale. Since the energy release rate, $G$, equals the critical energy release rate, $G_{c}$, resisting crack extension, the calculated $G$ values in eq (5) yield $G_{c}$ values in the tests. Because mechanical properties of chromia scales are not as readily available, as a first approximation the properties of an alumina scale have been used in the calculations. The thickness data were measured from cross section SEM images and residual stresses were obtained from $\mathrm{x}$-ray diffraction (XRD) measurements performed at the University of Pittsburgh.

\section{Indentation Test Analysis Results}

The critical energy release rate, $G=G_{c}$, calculated from the simulation results is plotted against the radial distance, $\mathrm{R}$, from the indenter normalized by the contact radius of the indenter, a (see Figure 1). Figure 6 shows such a plot for a large substrate model subjected to an indent load of $60 \mathrm{~kg}$ under frictionless conditions. The different curves represent different oxide thicknesses, with the lowermost curve corresponding to an oxide thickness of $0.25 \mu \mathrm{m}$ and the uppermost curve corresponding to a thickness of $4 \mu \mathrm{m}$. 


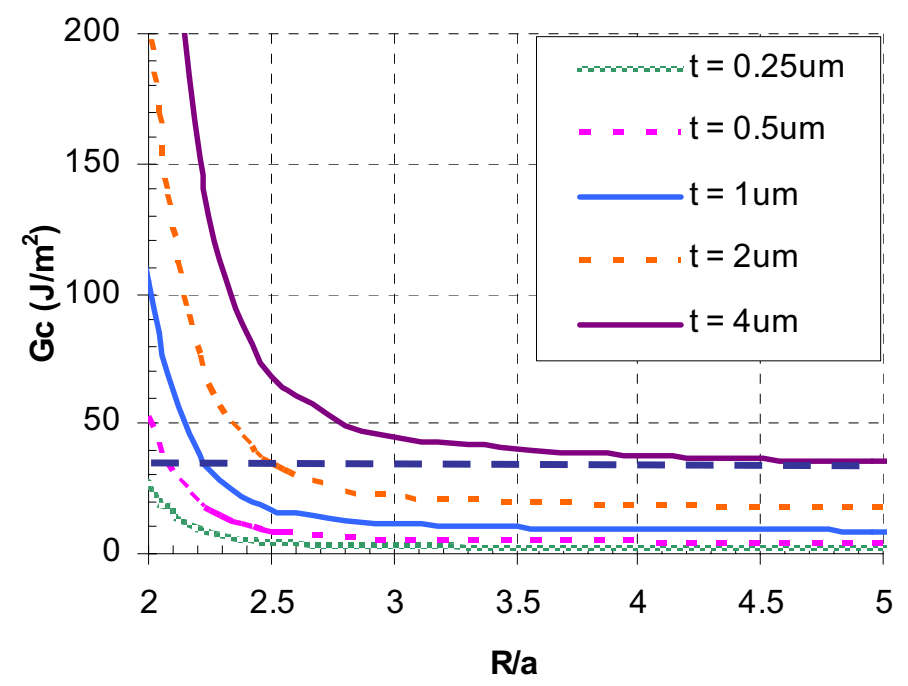

Figure 6 Simulation Results for a Large Substrate at a Load of $60 \mathrm{~kg}$ under Frictionless Conditions

The plot shows $G_{c}$ values which are large in the region close to the indent and trail off to constant values in the region far away from the indenter. The constant values of $\mathrm{G}_{\mathrm{c}}$ away from the indenter correspond to the $\mathrm{G}$ due to residual strains only. Thus, for a given oxide thickness, spontaneous spallation occurs when the critical energy release rate reaches the minimum of the curve which corresponds to the energy release rate due to residual strains in the scale.

\section{Indentation Test Experimental Results}

\section{SAG Exposed Specimens}

As described in the earlier section, mechanical loading via indentation of the test specimen exposed to an SAG environment resulted in peeling of an intact chromia scale. The critical energy release rate associated with this type of debonding can be quantified by measuring the radial extent of the debond. Figure 7 shows an SEM image of the 26Cr ferritic alloy exposed to SAG for $264 \mathrm{hrs}$. The white region represents the debonded area and the dashed circle gives a rough estimate of the radius of the debond, R.

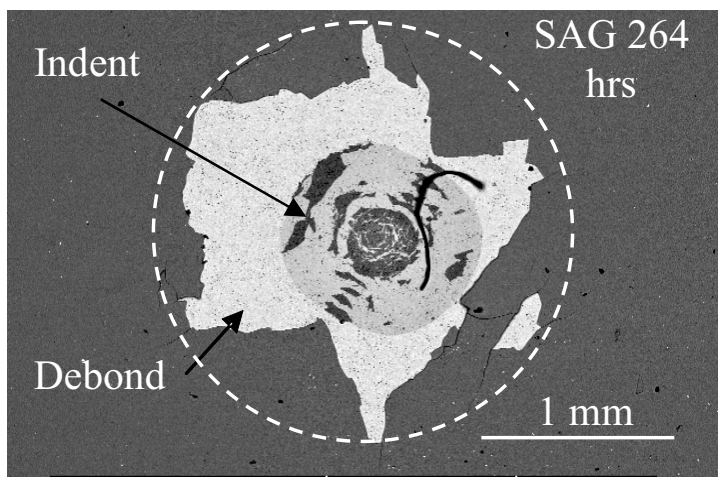

Figure 7 SEM Image of an Indented Specimen Exposed to SAG for $264 \mathrm{hrs}$

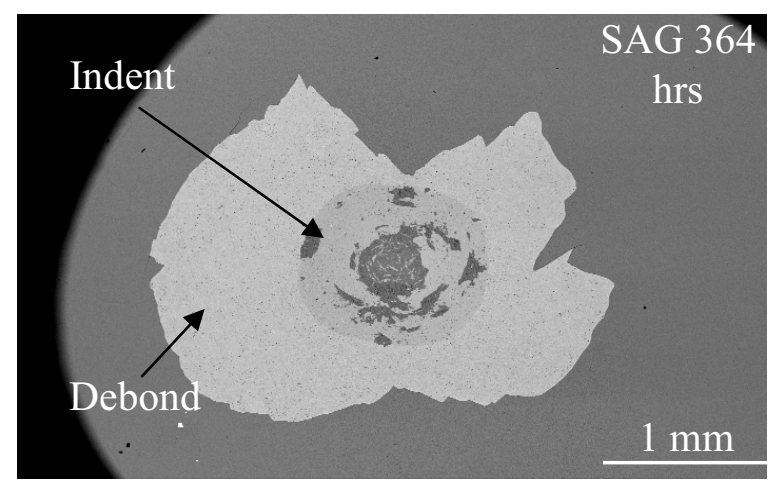

Figure 8 SEM Image of an Indented Specimen Exposed to SAG for $364 \mathrm{hrs}$ 
In analyzing the debonded area, the important parameter is the ratio of the extent of debonding to the indent radius, R/a, which in the case of Figure 7 is approximately 2. Figure 8 shows an image from indentation of the same specimen, but after an exposure time of $364 \mathrm{hrs}$, with an approximate value of $\mathrm{R} / \mathrm{a}=2.5$ (based on the maximum extent of debonding). From a fracture mechanics view point (as suggested by eq (1)) this increase in the extent of debonding could be due to an increase in the residual stress or loss of adhesion or scale thickening. The increasing weight gain exhibited by SAG-exposed specimens (Figure 4) suggests a growth in the oxide scale and thus part of the cause for extended debonding in the case of $364 \mathrm{hrs}$ exposure compared to $264 \mathrm{hrs}$ exposure is a thicker oxide scale.

A key concern associated with this type of visual quantification of the debond extent is that the oxide scale could be barely attached to the substrate but still appear bonded. To investigate this issue, a test specimen exposed to $464 \mathrm{hrs}$ was indented using a $60 \mathrm{~kg}$ load and then tinted by exposing it at $700^{\circ} \mathrm{C}$ for 10 minutes, followed by indentation at a higher load of $150 \mathrm{~kg}$. Even though indentation at a higher load results in more extensive debonding compared to that at a lower load, the non-dimensional ratio of $\mathrm{R} / \mathrm{a}$ remains unchanged. As can be seen from Figure 9, the process of tinting enables verification of the actual extent of debonding caused by the $60 \mathrm{~kg}$ load. The inner light gray region represents the debonded area from the indent load of $60 \mathrm{~kg}$ and the outer darker gray area is the debonded area from the indent load of $150 \mathrm{~kg}$. The inner light gray area from the $60 \mathrm{~kg}$ indent has the same size and shape as what was observed immediately after the $60 \mathrm{~kg}$ indent was made. Because of this, it appears that observed debond sizes correlate well with the actual extent of scale debonding from the substrate.

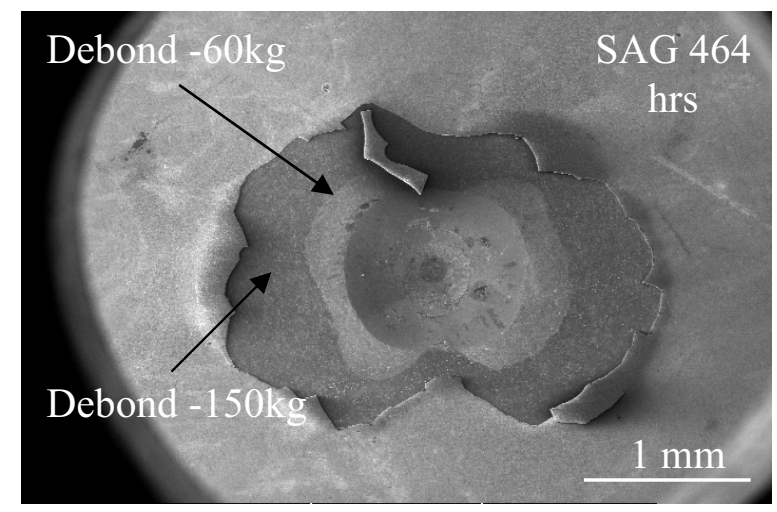

Figure 9 SEM Image Showing Debonding of a Tinted Specimen, with an Inner, Lighter Gray Region from a $60 \mathrm{~kg}$ Load and an Outer, Darker Region from a $150 \mathrm{~kg}$ Load

The combined experimental and simulation results for $\mathrm{G}_{\mathrm{c}}$ can be used to obtain a rough estimate of the exposure time at which spontaneous spallation will occur. In the case of a test specimen exposed for 364 hrs the maximum R/a was approximately 2.5 , with an oxide scale thickness of approximately $2 \mu \mathrm{m}$ (as obtained from cross section SEM thickness measurements). The corresponding critical energy release rate due to stresses induced by indentation and residual stress is found to be $34 \mathrm{~J} / \mathrm{m}^{2}$ as shown by the horizontal dashed line in Figure 6. Therefore, if for a given oxide scale thickness the energy release rate due to residual stress reaches a value of $34 \mathrm{~J} / \mathrm{m}^{2}$, spontaneous spallation would occur. From Figure 6 it can be seen that if the oxide thickness reaches a value of $4 \mu \mathrm{m}$ the energy release rate due to residual stresses only will reach this critical value. Cross section SEM measurements indicate that a $4 \mu \mathrm{m}$ oxide thickness corresponds to an exposure time of $800 \mathrm{hrs,} \mathrm{which} \mathrm{suggests} \mathrm{that} \mathrm{the} \mathrm{time} \mathrm{to} \mathrm{spontaneous}$ spallation is approximately $800 \mathrm{hrs}$. 
To test this prediction, indentation tests were performed on a specimen exposed for $822 \mathrm{hrs}$. As seen in Figure 10, out of the 3 indents, in 2 cases the debonding propagated across the specimen. Cross section images (Figure 11) revealed that the oxide scale was barely attached to the substrate, in which case any slight disturbance could cause the oxide scale to spall off. In fact, the detachment of the scale seen in Figure 11 is likely due to disturbance of the scale by the sectioning operation. Thus, indentation testing conducted at shorter exposure times has provided a good indication as to when to expect residual stressinduced spontaneous spallation.

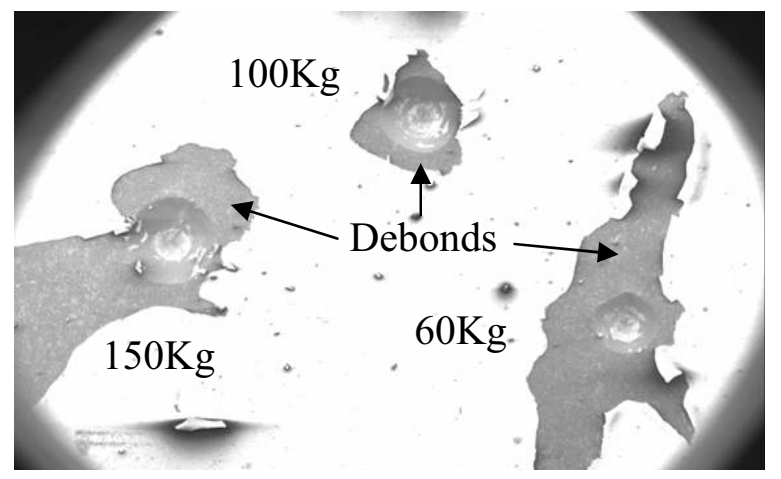

Figure 10 SEM Image of Indentation at Three Different Loads for an SAG Specimen Exposed for 822 hrs at $900^{\circ} \mathrm{C}$

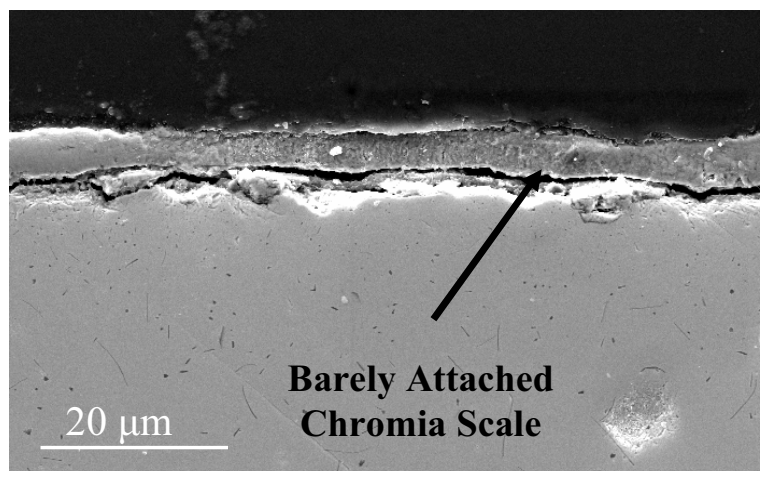

Figure 11 Cross Section SEM Image of SAG Specimen Exposed for $822 \mathrm{hrs}$ at $900^{\circ} \mathrm{C}$

\section{SCG Exposed Specimens}

The non-uniform flaking of the oxide scale caused by the indentation of SCG-exposed specimens complicates the test analysis, as characterizing the adhesion by a single $G_{c}$ value is no longer appropriate. Therefore, a methodology different from the one described for SAG-exposed specimens must be employed. An image analysis was formulated for this purpose, in which the debonded area outside the indent image was decomposed into three to seven concentric rings, with each ring having an average radius $\mathrm{R}$ as shown in Figure 12. A macro written in the image analysis software package SCION was used to obtain a percentage of debonded oxide scale in each ring. The percentage of debonded chromia scale was plotted for each ring against a normalized distance $\mathrm{R} / \mathrm{a}$, where a is the indent radius and $\mathrm{R}$ the average radius of the ring (see Figure 13).

The percentage debond plot suggests that the when R/a is small (close to the indent) the percentage of debonding is large and trails off with an increase in R/a. Also, the curves for $100 \mathrm{hrs}$ and $200 \mathrm{hrs}$ exposures (as indicated by $100 \mathrm{~h}$ and $200 \mathrm{~h}$ in the legend) are not very different, suggesting the attainment of a steady state with regard to susceptibility to debonding. The weight gain measurement plot Figure 4, shows that after approximately $50 \mathrm{hrs}$ the weight gain curve for the SCG-exposed $26 \mathrm{Cr}$ ferritic alloy reaches a more or less constant value. Two mechanisms can cause fracture behavior and specific weight measurements to reach a steady state. First, as the average scale thickness increases with exposure time, thicker or poorly bonded portions of the scale may spall, causing the average scale thickness to reach a steady state. Second, there is evidence to suggest that chromia evaporation, which can also reduce or eliminate scale thickening, can be significant in SCG environments. Fracture tests can yield insight into the role of the spallation mechanism in reaching a steady state. 

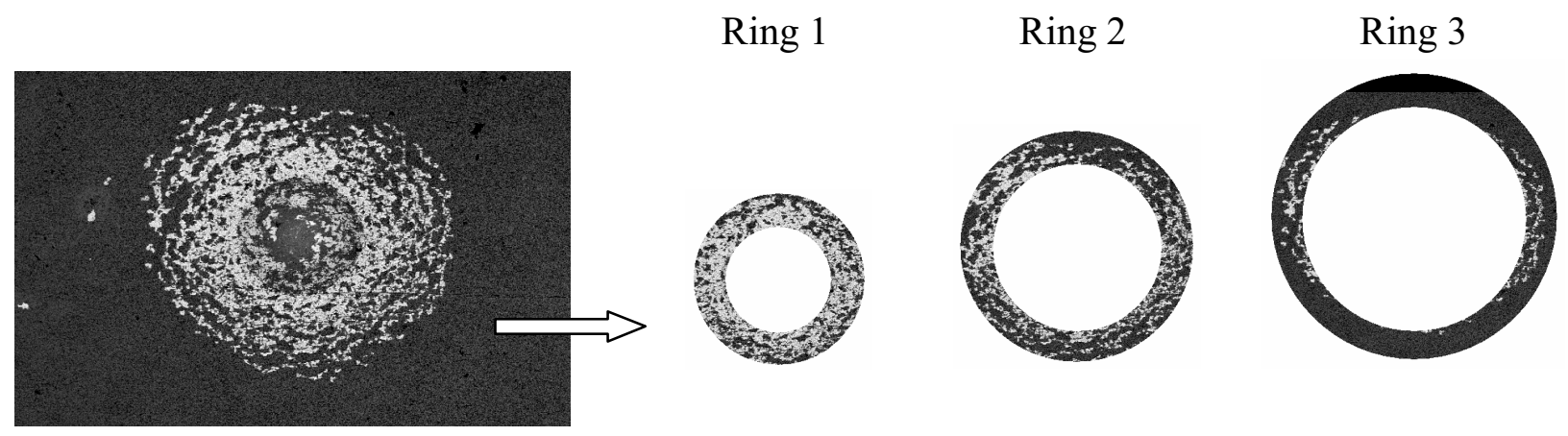

Figure 12100 hr SCG Indent Image Decomposed into 3 Rings

Indentation tests on specimens subjected to a very short exposure time of $10 \mathrm{hrs}$ have revealed initial debonding from compressive stress-induced shear cracks, as seen in Figure 14. Figure 13 shows percentage debond curves for the 10 hour exposure and the amount of debonding is significantly less compared to that at 100 and $200 \mathrm{hrs}$. It is planned to indent specimens exposed to up to $100 \mathrm{hrs}$ to track the transition to steady state conditions.

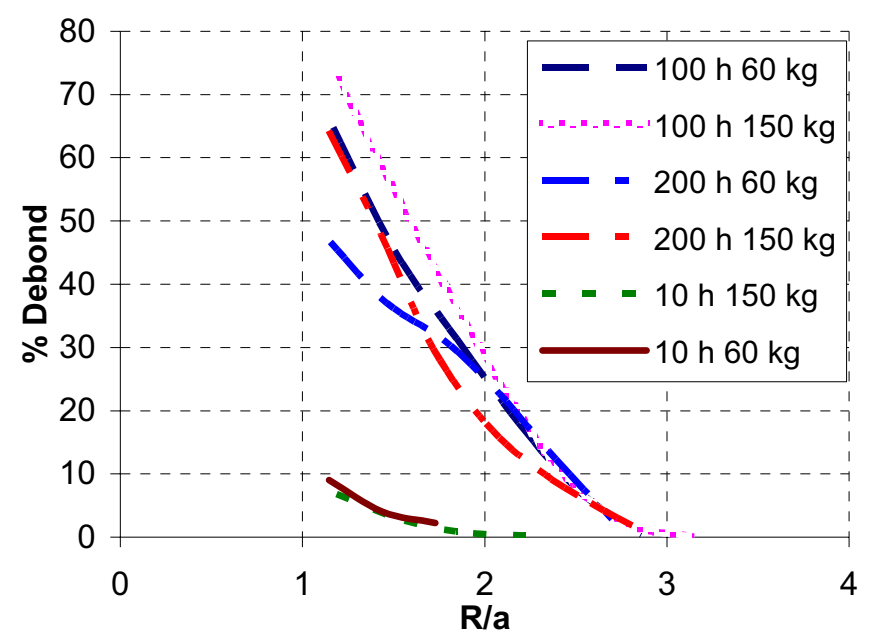

Figure 13 Percent Debond Plot for 10, 100 and 200 hour SCG-Exposed Specimens Indented at $60 \mathrm{~kg}$ and $150 \mathrm{~kg}$

Sensitivity of the image analysis could potentially influence the percentage debond results. In order to ensure that the image analysis would yield sensible results, the SEM image was studied qualitatively using EDS which confirmed that the white region in the image was indeed the debonded area (substrate) and the darker area was the bonded oxide scale. Since the pixel intensity was used to determine if a given pixel was bonded or debonded, as one gets close to the demarcation value, it gets harder to segregate them appropriately. For this purpose a sensitivity analysis was performed, in which a few pixel intensities close to the demarcation value were considered bonded in one case and debonded in the other. It was found that in both cases the percentage of debonding data was almost unaffected. The reason behind this is that the number of pixels with intensity values close to the demarcation value were on the order of 10-15, while the total number of pixels was in the order of thousands. 


\section{0 hrs}

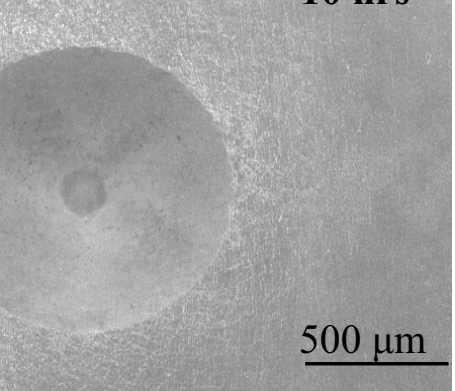

Figure 14 SEM Image of 10 hour SCG-Exposed Specimen

Showing Initial Debonding from Shear Cracks

\section{Summary and Conclusions}

The spallation of the chromia scale on interconnect alloys for planar solid oxide fuel cells has been modeled and analyzed as an interfacial fracture mechanics problem. An accelerated testing protocol employing indentation techniques has been established. Indentation tests performed on $26 \mathrm{Cr}$ ferritic alloy test specimens exposed to short times in SAG and SCG environments at $900^{\circ} \mathrm{C}$ have indicated very different debond mechanics. The SAG-exposed specimens exhibited a peeling type debond of an intact chromia scale, while the SCG-exposed specimens exhibited a non-uniform flaking of the oxide scale. As a result, different techniques were employed to analyze specimens subjected to the two types of exposure environments.

The peeling type debond in SAG-exposed specimens was characterized by the extent of debonding and an estimate of the critical energy release rate associated with the debond was obtained from the numerical simulation results. It was found that for these specimens, although the weight gain measurements showed an increasing trend suggesting that the oxide scale was growing, accelerated testing revealed that mechanical failure was possible much earlier than the weight gain measurements suggested. Also, the mechanical testing gave an estimate of the thickness at which spontaneous spallation could occur. Cross-section SEM images were consistent with the indentation analysis in saying that mechanical failure is possible at an earlier time of just over $800 \mathrm{hrs}$, which was not obvious from the weight gain measurement data available up to $2000 \mathrm{hrs}$. Finally, the quantification of debond size based on a visual estimate of the extent of debonding from the SEM images was validated by employing a tinting technique.

In the case of SCG-exposed specimens, the non-uniform flaking of the oxide scale required a different analysis technique. An image analysis was performed to quantify the percentage of debonded area as a function of non-dimensional distance outside the indent. Results for 100 and $200 \mathrm{hrs}$ exposures suggested that the radial distribution of debonding had reached a steady state, consistent with specific weight gain measurements. Experiments are underway to track the transition to this steady-state condition.

Chromia scale spallation is one of three potential failure mechanisms for fuel cell interconnects, the others being increased resistance from chromia scale growth and chromia evaporation. Changing the alloy system or exposure environment can cause a different mechanism to dominate, such that it is the 
first to reach a critical value as exposure time is increased. The mechanisms are also coupled, where increased chromia scale growth also increases the likelihood of scale spallation, but increased chromia evaporation reduces the scale thickness and the likelihood of spallation. Overall, results from experiments to date suggest that scale spallation can be the dominant failure mechanism.

\section{Acknowledgment}

This research was supported by the US Department of Energy National Energy Technology Laboratory and the SECA program under contract DE-FC26-02NT41578. The authors wish to thank Lane Wilson and Chris Johnson of NETL and Prabhakar Singh at PNNL for their insights into this research and for supplying test specimens to this program. The authors also thank Jim Rakowski of Allegheny Ludlum for providing test specimens and E-BRITE material properties.

\section{References}

1. W. J. Quadakkers, T. Malkow, J. Pirón-Abellán, U. Flesch, V. Shemet, and L. Singheiser, "Suitability of Ferritic Steels for Application as Construction Materials for SOFC Interconnects," Proc. Fourth European Solid Oxide Fuel Cell Forum, A. J. McEvoy, ed., 2000, p. 827.

2. J. Pirón-Abellán, V. Shemet, F. Tietz, L. Singheiser, W. J. Quadakkers, and A. Gil, "Ferritic Steel Interconnect for Reduced Temperature SOFC," Proc. Solid Oxide Fuel Cells VII, H. Yokokawa and S. C. Singhal, eds., The Electrochem. Soc., 2001, p. 811.

3. W. J. Quadakkers, H. Greiner, and W. Köck, "Metals and Alloys for High Temperature SOFC Application," Proc. First European Solid Oxide Fuel Cell Forum, U. Bossel, ed., 1994, p. 525.

4. C. S. Tedmon, "The Effect of Oxide Volatilization on the Oxidation Kinetics of $\mathrm{Cr}$ and $\mathrm{Fe}-\mathrm{Cr}$ Alloys," J. Electrochem. Soc., 113, 1966, p. 766.

5. W. J. Quadakkers, H. Greiner, W. Köck, H. P Buchkremer, K. Hilpert, and D. Stöver, "The Chromium Base Metallic Bipolar plate - Fabrication, Corrosion and Cr Evaporation," Proc. Second European Solid Oxide Fuel Cell Forum, B. Thorstensen, ed., 1996, p. 297.

6. C. Gindorf, L. Singheiser, and K. Hilpert, "Determination of Chromium Vaporisation from Fe, $\mathrm{Cr}$ base Alloys Used as Interconnect in Fuel Cells (SOFC)," Steel Research, 72, 2001, p. 528.

7. M.D. Drory and J.W. Hutchinson, "Measurement of the Adhesion of a Brittle Film on a Ductile Substrate by Indentation," Proc R Soc. London, 452, 1996, p. 2319.

8. Q. Ma, Indentation Methods for Adhesion Measurement in Thermal Barrier Coating Systems, Ph.D. Thesis, Carnegie Mellon University, 2004. 